\title{
1 Observations of an aeolian landscape: from surface to orbit in Gale Crater
}

2 Mackenzie Day $^{1 *}$, Gary Kocurek ${ }^{1}$

$3 \quad{ }^{1} 2275$ Speedway Stop C9000 Department of Geological Sciences, Jackson School of

4 Geosciences, University of Texas at Austin, Austin, TX 78712 USA

$5 \quad *$ Corresponding author: mdday@utexas.edu

Abstract

Landscapes derived solely from aeolian processes are rare on Earth because of the

9 dominance of subaqueous processes. In contrast, aeolian-derived landscapes should typify Mars

10 because of the absence of liquid water, the long exposure times of surfaces, and the presence of

11 wind as the default geomorphic agent. Using the full range of available orbital and Mars Science

12 Laboratory rover Curiosity images, wind-formed features in Gale Crater were cataloged and

13 analyzed in order to characterize the aeolian landscape and to derive the evolution of the crater

14 wind regime over time. Inferred wind directions show a dominance of regional northerly winds

15 over geologic time-scales, but a dominance of topography-driven katabatic winds in modern

16 times. Landscapes in Gale Crater show a preponderance of aeolian features at all spatial scales.

17 Interpreted processes forming these features include first-cycle aeolian abrasion of bedrock,

18 pervasive deflation, organization of available sand into bedforms, abundant cratering, and

19 gravity-driven wasting, all of which occur over a background of slow physical weathering. The

20 observed landscapes are proposed to represent a spectrum of progressive surface denudation

21 from fractured bedrock, to retreating bedrock-capped mesas, to remnant hills capped by bedrock

22 rubble, to desert pavement plains. This model of landscape evolution provides the mechanism by

23 which northerly winds acting over $\sim 3 \mathrm{Ga}$ excavated tens of thousands of cubic kilometers of

24 material from the once sediment-filled crater, thus carving the intra-crater moat and exhuming

(C) 2015. This manuscript version is made available under the Elsevier user license 
25 Mount Sharp (Aeolis Mons). The current crater surface is relatively sand-starved, indicating that

26 potential sediment deflation from the crater is greater than sediment production, and that most

27 exhumation of Mount Sharp occurred in the ancient geologic past.

28 Keywords: Aeolian processes, Mars, surface, cratering

\section{Introduction}

On Earth, landscapes evolve through the interplay between tectonics, and water-

32 dominated erosion and deposition. In contrast, Mars has generally been regarded as the most 33 aeolian-dominated planet in the solar system (e.g., Sagan and Bagnold, 1975; Arvidson et al.,

34 1979; Greely et al., 1999). On Earth, landscapes fashioned solely by wind action are rare. For 35 example, although extensive aeolian dune fields blanket the modern Sahara Desert of North 36 Africa, even a cursory examination of this landscape reveals uplands marked by erosional

37 dendritic fluvial networks, and lowlands marked by mid-Holocene lakes and fluvial systems

38 (e.g., Bouchette et al., 2010). Uniquely aeolian erosional and depositional features such as

39 yardangs and dunes are well known, but sand dunes are nearly universally sourced by

40 contemporaneous or earlier wet period fluvial systems (Kocurek and Lancaster, 1999), and

41 yardangs are typically fashioned from lacustrine deposits (Wang et al., 2011). Similarly,

42 although the Dry Valley of Antarctica displays a rich variety of cold-climate aeolian features

43 (Gillies et al., 2013), the fundamental fabric of the landscape is glacial-dominated. While fluvial-

44 dominated and glacial-dominated processes and their landscapes are well described and modeled,

45 with the paucity of aeolian-dominated Earth landscapes, there is no comparable body of work

46 describing landscapes that evolve where wind is the prime or sole geomorphic agent.

47 Resurfacing by aqueous processes and tectonism on Earth precludes the formation of aeolian 48 landscapes over geologic spans of time. 
On Mars, landscapes and strata formed in fluvial, deltaic and lacustrine environments are

50 well known from the most ancient Martian surfaces. However, beginning with global climatic

51 change at $\sim 3.5 \mathrm{Ga}$ (Bibring et al., 2006), aeolian processes have increasingly dominated. In the

52 absence of liquid water at the surface, wind emerges as the "default" global geomorphic agent,

53 with more localized geomorphic change caused by impacts, ice, and gravity-driven slope retreat,

54 all imprinting over a background of very slow physical weathering. Mars, therefore, may be the

55 best natural laboratory in which to delineate the attributes of an aeolian landscape. In this study

56 we use satellite and surface images to explore the extent to which the landscape of Gale Crater is

57 aeolian-dominated, thus helping to define the attributes of such a system. The collection of

58 aeolian features associated with Gale Crater also serves to reconstruct the history of the wind

59 regime over orders of magnitude of time.

\section{2. Gale Crater study area and data set}

The impact that formed Gale Crater is estimated to have occurred $~ 3.6-3.8$ billion years

62 ago (Thomson et al., 2011; Le Deit et al., 2013). At $155 \mathrm{~km}$ in diameter, Gale Crater sits just

63 south of the dichotomy boundary near Aeolis Mensae (Fig. 1) (Wray, 2013). The interior of Gale

64 is dominated by the central mound Mount Sharp (Aeolis Mons), which stands roughly $5 \mathrm{~km}$

65 high, or three times the depth of the Grand Canyon. The mound and surrounding features have

66 been extensively mapped (e.g., Anderson and Bell, 2010; Hobbs et al., 2010; Thomson et al.,

67 2011) and are similar to other intra-crater mounds found across Mars (Grotzinger and Milliken,

68 2012). 

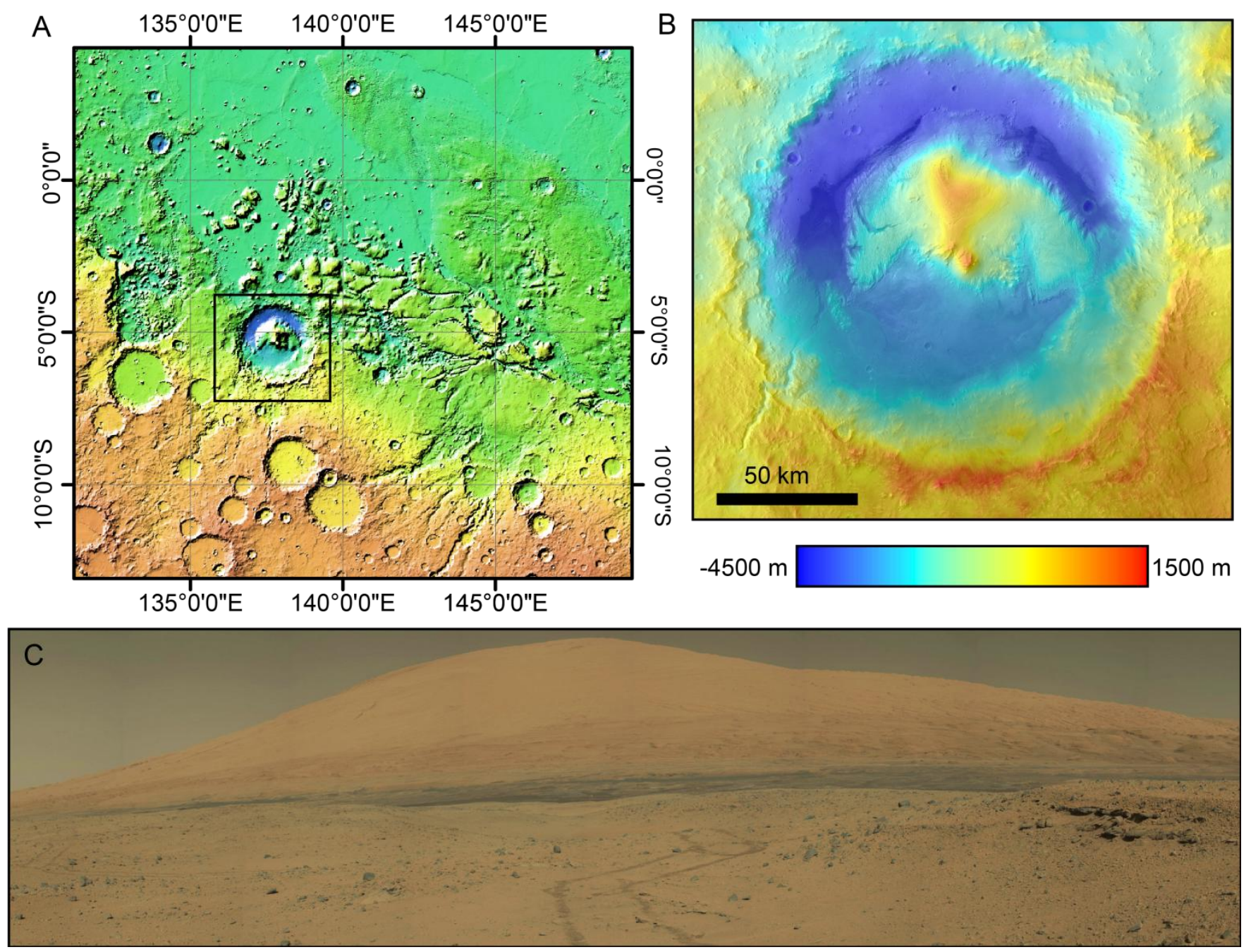

70 Figure 1. Gale Crater context. A. Mars Orbiter Laser Altimeter (MOLA) colorized elevation map

71 showing context of Gale Crater (boxed). Note the change from high elevation in the south to low

72 elevation in the north associated with the global topographic dichotomy. B. Gale Crater shown

73 with HRSC-derived DEM superimposed on HRSC visual basemap. The crater interior is

74 dominated by Mount Sharp (Aeolis Mons). C. Mount Sharp as seen from the surface by Curiosity.

75 Foreground wheel tracks are $30 \mathrm{~cm}$ wide, and the total relief on the mound is $\sim 5 \mathrm{~km}$ (sol 530 ,

76 Mastcam mosaic starting at frame 0530ML0021050000203319E01_DRCX; all MSL data can be

77 accessed through the JPL PDS archive). 
In association with the ongoing Mars Science Laboratory (MSL) mission, an

unprecedented number of images have become available for the study of Gale Crater. To date,

81 the rover Curiosity has spent over 1,000 Martian sols traversing the floor of Gale, taking images

82 at resolutions down to $15 \mu \mathrm{m} / \mathrm{px}$ (Edgett et al., 2012). Using the full range of available scales, for

83 this study features were first mapped in orbital images using a High Resolution Stereo Camera

84 (HRSC) basemap, overlain with higher resolution Context Camera (CTX) and High Resolution

85 Imaging Science Experiment (HiRISE) images. Resolution ranged from $25 \mathrm{~cm} / \mathrm{px}$ in HiRISE

86 coverage, to $\sim 10 \mathrm{~m} / \mathrm{px}$ in HRSC. Surface images were then used to sample aeolian features along

87 the Curiosity rover traverse from Bradbury Landing to Pahrump Hills (sols 1-960). Sampling

88 every 200 to $300 \mathrm{~m}$, Navigation Camera (Navcam) mosaics were used to document aeolian

89 features in the landscape. Mast Camera (Mastcam), and Mars Hand Lens Imager (MAHLI)

90 images were used to support identification and characterization of the aeolian features discussed

91 below.

\section{3. Non-aeolian activity in Gale Crater}

93 Gale Crater is fundamentally an impact crater. Smaller-scale cratering blankets the crater

94 interior (Le Deit et al., 2013), disrupting the morphology of aqueous and aeolian features alike.

95 Subaqueous erosional and depositional processes clearly dominated during the early crater

96 history. Although upper portions of Mount Sharp have been speculated to be aeolian in origin

97 (Anderson and Bell, 2010), basal portions of Mount Sharp thus far investigated are interpreted as

98 subaqueous (lacustrine) in origin (Grotzinger et al., 2014). Moreover, the trek of Curiosity from

99 its landing site to the base of Mount Sharp revealed deposits of conglomerates, sandstones and

100 mudstones of interpreted fluvial, deltaic and lacustrine origins (Williams et al., 2013; Grotzinger

101 et al., 2014). The crater rim is characterized by dendritic channel systems, which give rise to

102 alluvial fans (Anderson and Bell, 2010; Palucis et al., 2014). Similarly, entrenched channels

103 emanating from Mount Sharp evidence subaqueous erosion on Mount Sharp (Thomson et al., 
104 2011). Subaqueous erosion and backwasting of the crater rim and central uplift, in addition to a

105 few drainage networks that breach the crater rim, are thought to have sourced the subaqueous

106 strata within Gale Crater through a series of fluvial-deltaic systems and basinal lacustrine body

107 (Grotzinger et al., in press).

108 The subaqueous history of Gale Crater, however, records an ancient period on Mars with

109 the presence of liquid water and a denser atmosphere. Crater counts suggest that the subaqueous

110 sedimentary strata were emplaced before 3.2-3.3 Ga (Grant et al., 2014; Newsom et al., 2014).

111 For the subsequent $\sim 3 \mathrm{Ga}$, Gale Crater has arguably been under the domain of aeolian processes,

112 gravity-driven slope processes, and cratering. All subaqueous features are in a current state of

113 erosion. For example, channel networks show a high albedo indicating dust mantling, inverted

114 channels have been exhumed through wind deflation, and fan surfaces are heavily cratered

115 (Palucis et al., 2014).

116 4. Exhumation of Mount Sharp

117 Although a depositional origin for Mount Sharp has been suggested (Kite et al., 2013),

118 consistent with observations presented here, most works interpret Mount Sharp as a remnant

119 morphology from the exhumation of a once totally filled crater (e.g., Malin and Edgett, 2000;

120 Grotzinger et al., in press). Gale Crater is one of many craters to host an intra-crater mound 121 separated from the rim by an interpreted erosional moat (Grotzinger and Milliken, 2012). The

122 streamlined morphology of Mount Sharp argues for N-S net transport by wind. The amount of

123 sediment removed by aeolian deflation to yield current Mount Sharp topography can be

124 estimated using the HRSC-derived digital elevation model (DEM). Assuming the crater was

125 once filled to the maximum height of Mount Sharp, the removed volume was calculated as 6.34

$126 \times 10^{4} \mathrm{~km}^{3}$. This does not include the volume of loose sediment in dune fields, sand sheets,

127 transverse aeolian ridges (TARs), and dust. 
129 and the crater rim, consistent with Tirsch et al., (2011) who suggest that intra-crater dune fields

130 are sourced primarily from landscapes within the crater. However, because craters act as

131 temporary depo-centers, the crater has also likely received an unknown quantity of sediment

132 transported into the crater from external sources. Dust would be created with erosion internal to

133 the crater, but the crater must also house dust derived from the global dust budget. In order to

134 estimate the total volume of sediment housed in dune fields, TARs, and sand sheets, major

135 deposits of these were mapped in the crater interior (Fig. 2). The total mapped surface area was

136 multiplied by an assumed average depth (Table 1) and, neglecting porosity, yielded a volume on

137 the order of $10 \mathrm{~km}^{3}$. This volume is dominated by dune sediment, so assumptions of equivalent

138 sand depth are not trivial. The largest and smallest barchan dunes and linear dunes in the

139 Bagnold Dune Field were used to bracket estimates of equivalent sand thickness in the dunes.

140 Lee slopes in this field were measured as $\sim 30^{\circ}$ (Atwood-Stone and McEwen, 2013; Silvestro et

141 al., 2013) and assuming $10^{\circ}$ stoss slopes, equivalent sand depths ranged from 3-17 m. Dune

142 spacing is variable and exposed bedrock in interdune areas is estimated to account for $\sim 10 \%$ of

143 the mapped area. Taking the average estimated sand depth of $10 \mathrm{~m}$ and subtracting the $10 \%$

144 interdune area, the total sand volume is estimated as $6.44 \mathrm{~km}^{3}$. Similar considerations were

145 applied to TARs $\left(5.31 \times 10^{-2} \mathrm{~km}^{3}\right)$ and sand sheets $\left(1.85 \times 10^{-2} \mathrm{~km}^{3}\right)$. Varying estimates of depth

146 and total coverage can alter the total estimate by a scaling factor, but the order of magnitude of

147 the sand volume is estimated to remain the same. In any estimate, the amount of potentially

148 mobile sand housed in Gale Crater is relatively minor, and the crater represents an overall sand-

149 starved system. 


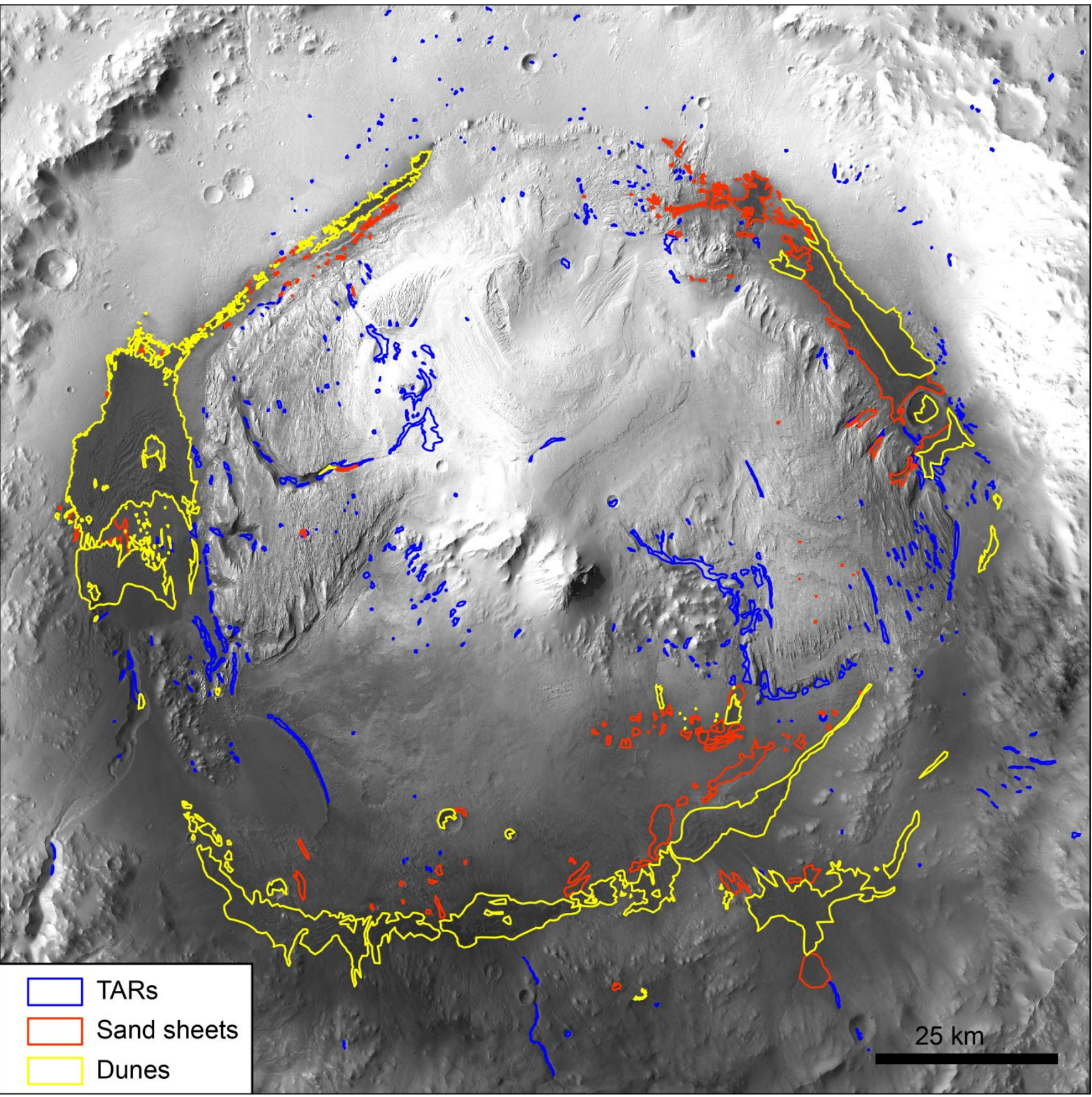

151 Figure 2. Mapped areas of dunes, sand sheets and TARS used to estimate the volume of sediment

152 in Gale Crater. Total volume is of order $10 \mathrm{~km}^{3}$. See Table 1 for assumed average depths and

153 surface areas. North-up oriented background HRSC mosaic of Gale Crater is also used in

154 subsequent figures (h1916_0000, h1927_0000, h4235_0001). 
157 can be made assuming a $1 \mathrm{~mm}$ thick mantling of dust across the entire surface area approximated

158 by $\pi r^{2}$. This simple calculation yields a volume of $7.6 \times 10^{-2} \mathrm{~km}^{3}$, but does not take into account

159 any surface roughness. Here roughness contributions come at a range of scales from the

160 topography of Mount Sharp, to individual grain coatings. The total contribution of dust in Gale

161 could be orders of magnitude higher than this simple calculation, which is given here as a

162 conservative lower bound to the dust mantle volume.

164 Table 1: Gale Crater interior loose sediment volume estimates and assumptions

\begin{tabular}{|l|l|l|l|}
\hline $\begin{array}{l}\text { Sediment } \\
\text { Type }\end{array}$ & $\begin{array}{l}\text { Measured surface } \\
\text { area }\left(\mathbf{k m}^{\mathbf{2}}\right)\end{array}$ & $\begin{array}{l}\text { Assumed average thickness } \\
(\mathbf{m})\end{array}$ & $\begin{array}{l}\text { Total volume } \\
\left(\mathbf{k m}^{\mathbf{3}}\right)\end{array}$ \\
\hline Dunes & 715 & 9 & 6.44 \\
\hline TARs & 106 & 0.5 & $5.31 \times 10^{-2}$ \\
\hline Sand sheets & 185 & 0.1 & $1.85 \times 10^{-2}$ \\
\hline
\end{tabular}

Assuming a horizontal crater floor (DTM-derived slope is $<1^{\circ}$ ), the gross volume of

167 Mount Sharp is estimated as $1.25 \times 10^{4} \mathrm{~km}^{3}$. Volume occupied by a central uplift peak created

168 during impact is unknown and here included in the Mount Sharp volume. This estimate yields a

169 total crater interior volume of $\sim 7.59 \times 10^{4} \mathrm{~km}^{3}$, with Mount Sharp occupying $16 \%$ of the interior

170 volume, and the remaining $84 \%$ removed. The time over which the postulated exhumation of

171 Mount Sharp occurred is unknown, and erosion rates are expected to have varied, with

172 significantly greater rates early in crater history (Warner et al., 2010; Grotzinger et al., in press)

173 and very low rates currently (Golombek et al., 2010; Farley et al., 2014). An assumption of 3 Ga

174 of excavation yields an average annual flux of $2 \times 10^{4} \mathrm{~m}^{3} / \mathrm{yr}$, whereas assuming 1 Ga yields $6 \mathrm{x}$

$17510^{4} \mathrm{~m}^{3} / \mathrm{yr}$. The Namib Sand Sea on the west coast of southern Africa houses roughly $1.02 \times 10^{3}$

$176 \mathrm{~km}^{3}$ of sand, with modern sand influx rates of approximately $4 \times 10^{5} \mathrm{~m}^{3} / \mathrm{yr}$ (Lancaster, 1989a).

177 Over the past $3 \mathrm{Ga}$ on Mars, 60 Namib Sand Seas worth of sediment have been excavated from 
178 Gale Crater, at average rates of excavation an order of magnitude lower than modern sediment

179 influx rates seen on Earth.

$180 \quad$ 5. Orbital observations

181 Ripples, dunes, TARs, yardangs, and crater wind streaks can all be observed from orbit in

182 Gale Crater. These features exhibit morphologies characteristic of their formative wind regimes, 183 and cover a wide range of temporal and spatial scales. Considered together, these aeolian

184 features can be used to explore the history of sand-transporting winds spanning a significant

185 period of the geologic past of Gale Crater. Although absolute time scales of formation are

186 unknown, relative time scales can be inferred from superposition of these features (Fig. 3).

187 Ripples orient to a particular wind quickly and can be seen on dune stoss and lee slopes

188 (Howard, 1977). Dunes, in turn, are seen migrating over TARs, which commonly form between

189 yardangs. Finally, yardang morphology is influenced by channel topography, requiring that the

190 channels formed first. Small crater wind streaks also serve to indicate wind direction, but were

191 not observed in superposition with any other features. Each feature is here discussed in turn, and 192 analyzed for a record of formative wind direction. 


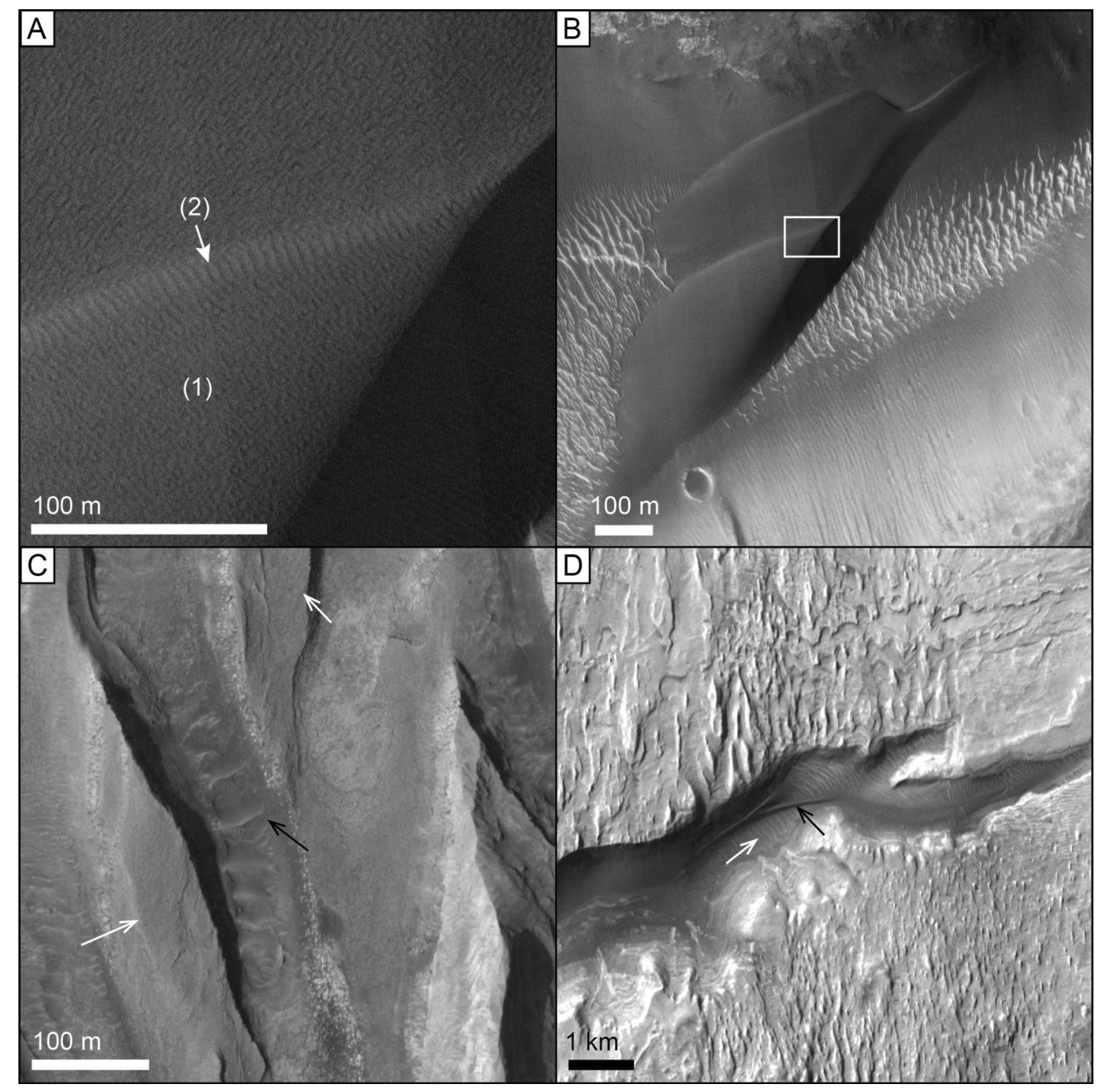

194 Figure 3. Superposition of aeolian features. A. Ripples superimposed upon the stoss (1) and lee

195 (2) surfaces of a dune. B. The same dark dune migrating over light toned granule ripples or small

196 TARs. White box indicates position of A. HiRISE image PSP_006143_1745. C. TARs (black

197 arrow) positioned between yardangs (white arrows), transverse to the yardang-formative north-

198 south wind direction. HiRISE image EPS_019698_1750. D. Yardang field formed across a

199 channel valley. Yardang scale and spacing changes dramatically from north to south sides of 
valley, suggesting that flow disturbance associated with valley topography affected yardang

201 formation. The valley topography, therefore, necessarily predates the associated yardangs. Note

202 also the intra-valley linear dune (black arrow) covering light toned intra-valley TARs (white

203 arrow). HiRISE images ESP_012195_1750 and PSP_008147_1750. A and B have been contrast-

204 stretched to increase feature definition. Locations are indicated in Figure 5, and north is up in all 205 images.

\subsection{Crater wind streaks}

Gale Crater exhibits a low albedo wind streak that extends from the southern rim of the

209 crater onto the surrounding plains and into Lasswitz crater (Fig. 4). This wind streak is $\sim 150 \mathrm{~km}$

210 wide and $\sim 370 \mathrm{~km}$ long, and is interpreted to have formed from dune sands excavated from the

211 crater interior by northerly winds (Edgett and Malin, 2000; Wray, 2013). Its low albedo contrasts

212 with the bright surfaces seen in the surrounding area (Christensen, 1986), and is interpreted as an

213 absence of dust mantling and an indication of active transport processes (Veverka, 1975).

214 Bedforms (i.e., ripples or dunes) are not visible on the wind streak, arguing that sediment on

215 wind streak represents a veneer too thin to be organized into bedforms visible at CTX resolution.

216 In addition, wind speeds needed to overcome the topography of the rim and transport sand out of

217 large craters likely occurs only during rare high-speed wind events. Given the size of the wind

218 streak, therefore, wind streak construction must have occurred over significant time.

219 A separate population of much smaller wind streaks emanate from small craters $(\mathrm{d}<0.5$

$220 \mathrm{~km}$ ) on the southern rim of Gale Crater (Fig. 5). These bright albedo wind streaks contrast with

221 dark dune sands from the Southern Dunes, and are thought to form by the collection of air-fall

222 dust in the sheltered lee of craters (Fig. 6) (Sagan et al., 1972). Similar wind streaks, observed

223 near the Mars Exploration Rover (MER) Opportunity landing site in Meridiani Planum, reversed

224 direction before and after a dust storm, suggesting constructive time scales of weeks to months 
225 (Sullivan et al., 2005). On the north, west and east Gale Crater rim, where no streaks are

226 observed, rim deposits are homogenous in their light tone, thus preventing definition of any dust-

227 mantle wind streaks. On the south rim, measurements of 180 high albedo wind streaks yielded an

228 average orientation of $351^{\circ}$ interpreted to form from southerly $\left(171^{\circ}\right)$ winds (Fig. 6B, Table 2).

229 The southerly winds recorded by these features are counter to the dominance of northerly winds

230 observed elsewhere, but match observations in the Southern Dunes discussed below.

231

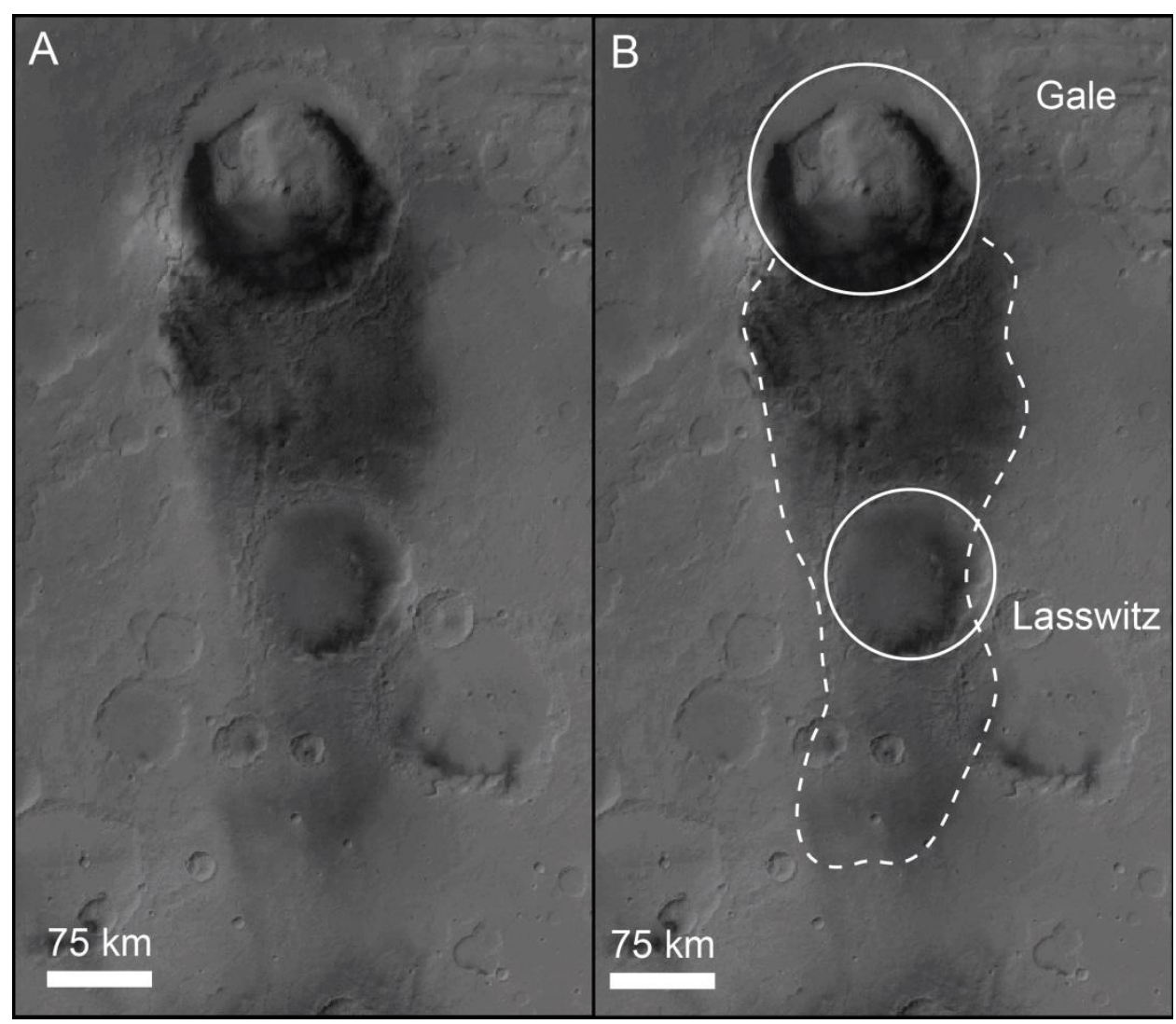

233 Figure 4. Gale Crater wind streak A. Gale Crater with its low albedo wind streak extending into

234 Lasswitz Crater to the south. B. Same image as A, but with extent of the wind streak and craters

235 shown by dashed and solid lines. North-up oriented Mars Orbiter Camera (MOC) wide angle 236 mosaic from Aeolis (MC-23) quadrangle. 


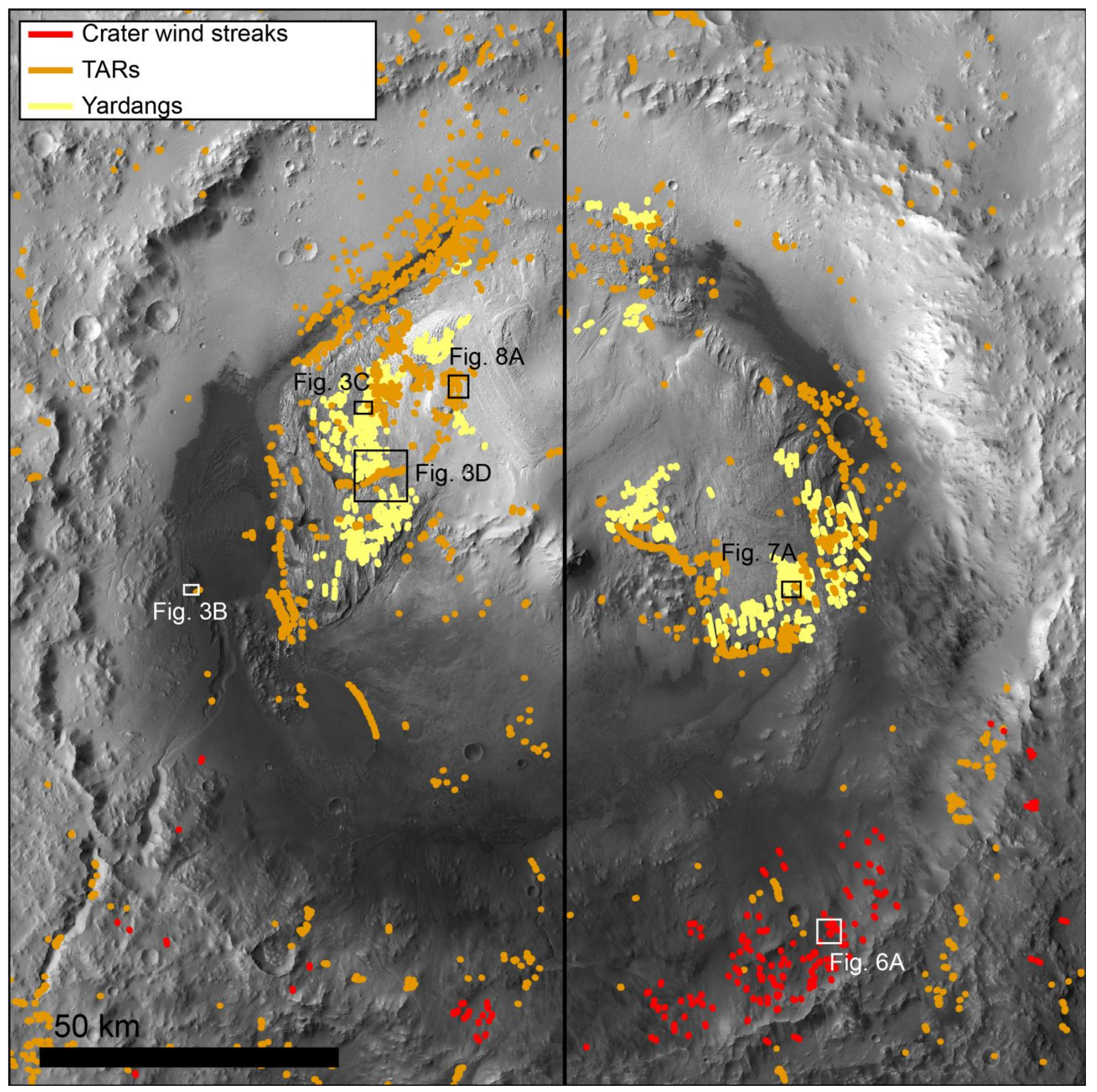

238 Figure 5. Distribution of mapped yardangs, TARs, and crater wind streaks in Gale Crater.

239 Yardangs are found only on Mount Sharp, and crater wind streaks are seen only on the southern

240 crater rim. Black axial line denotes where yardangs orientations (Fig. 7) were divided between the

241 two halves of the mound. Boxes over HRSC background denote the locations of panels in other

242 figures as indicated. See Table 2 for detailed statistics and sample sizes of each dataset. 
245 Table 2: Wind indicator sample statistics

246

\begin{tabular}{|c|c|c|c|c|c|c|c|}
\hline 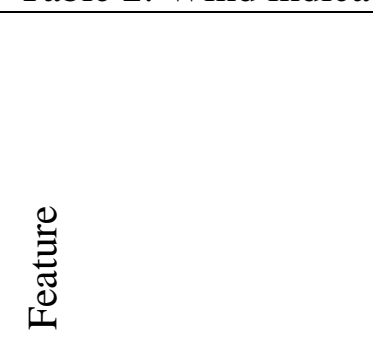 & 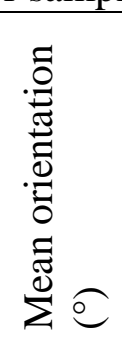 & 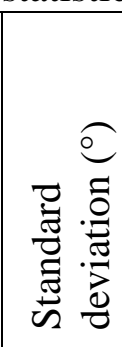 & 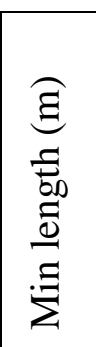 & 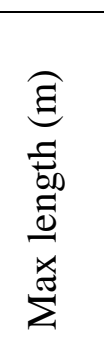 & 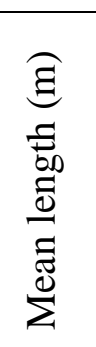 & 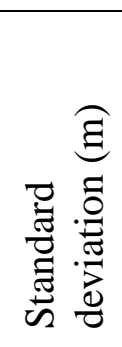 & 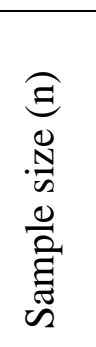 \\
\hline Crater wind streaks & 351 & 33 & 66 & 962 & 206 & 141 & 180 \\
\hline Yardangs - east & 347 & 24 & 60 & 4340 & 530 & 508 & 329 \\
\hline Yardangs - west & 359 & 13 & 33 & 1320 & 349 & 240 & 440 \\
\hline TARs total & 88 & 47 & 9 & 876 & 124 & 103 & 3222 \\
\hline TARs major & 71 & 24 & 9 & 721 & 125 & 106 & 2047 \\
\hline TARS minor & 337 & 22 & 10 & 650 & 93 & 89 & 1175 \\
\hline Sand shadows & 189 & 0.5 & 0.12 & 3.74 & 0.59 & 0.34 & 69 \\
\hline
\end{tabular}
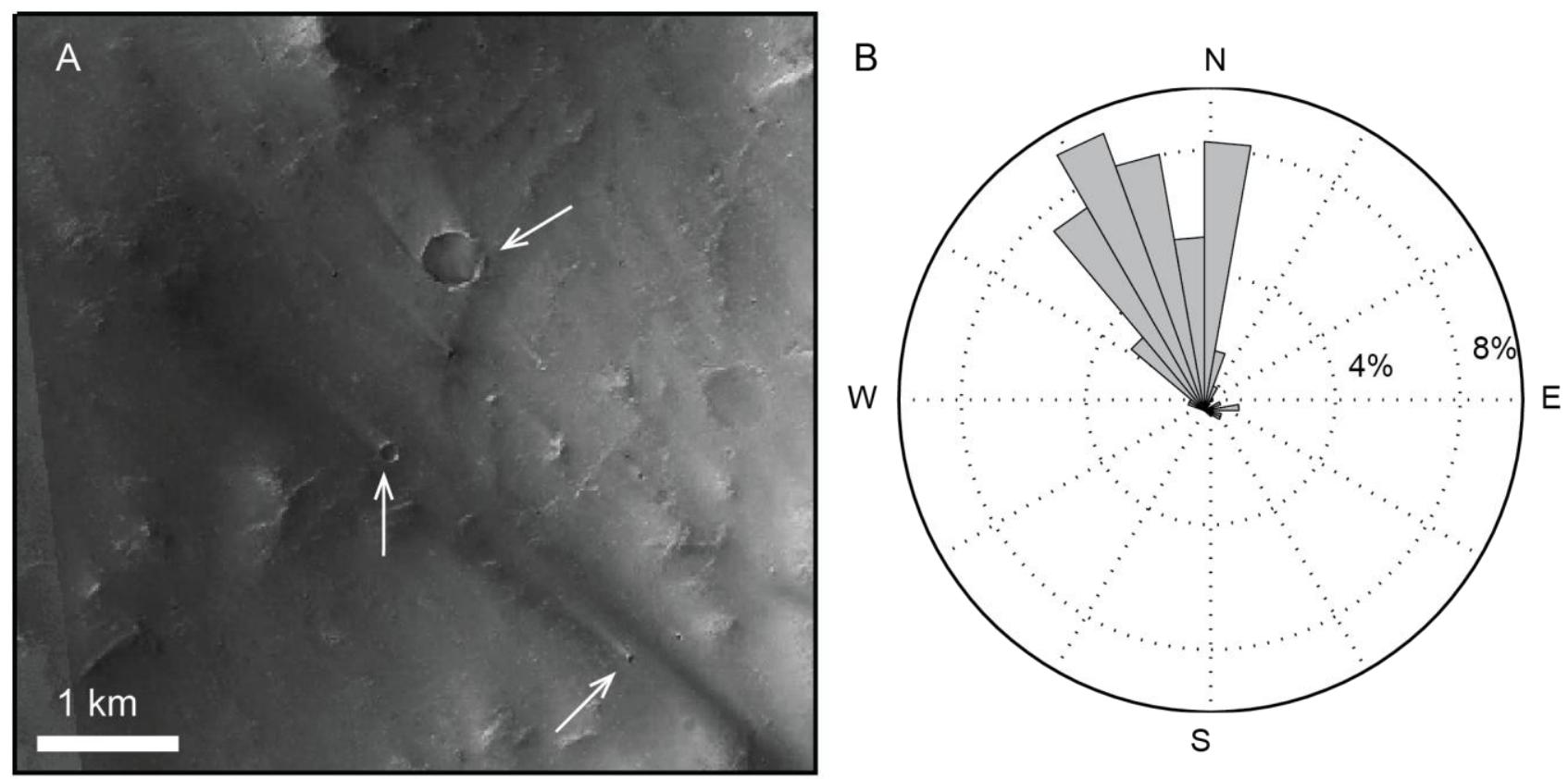

248 Figure 6. Southern rim wind streaks. A. Small crater wind streaks on the southern Gale Crater

249 rim. Arrows indicate just a few of the craters with NW trending streaks in this scene. Image is

250 contrast-stretched to make streaks more visible (CTX image P01_001554_1745_XI_05S221W,

251 north-up oriented). B. Histogram of orientations of mapped crater wind streaks. Mean orientation

$252\left(351^{\circ}\right)$ is interpreted to form from southerly $\left(171^{\circ}\right)$ winds. 


\subsection{Yardangs}

Yardangs form from persistent aeolian erosion by abrasion, causing elongate flow-

256 parallel features to be carved out of the bedrock (Hedin, 1903). Typically occurring as fields,

257 yardangs form slightly asymmetric morphologies, with the upwind end of the feature blunted

258 into an inverted boat-hull shape. Because some fluvial and mass wasting processes can generate

259 morphologies similar to yardangs (Ward, 1979), features associated with sinuous channels, or

260 headward eroding canyons were not included in this study. Positive relief on both sides of the

261 feature was also required to prevent misidentification of linear textures in layered terrain as

262 yardangs. A perfect yardang would indicate an absolute wind azimuth with its blunted upwind

263 hull, but the yardangs observed on Mars commonly do not exhibit this classical asymmetry (Fig.

264 7). This study, therefore, considers yardangs to be $180^{\circ}$ ambiguous indicators of wind direction.
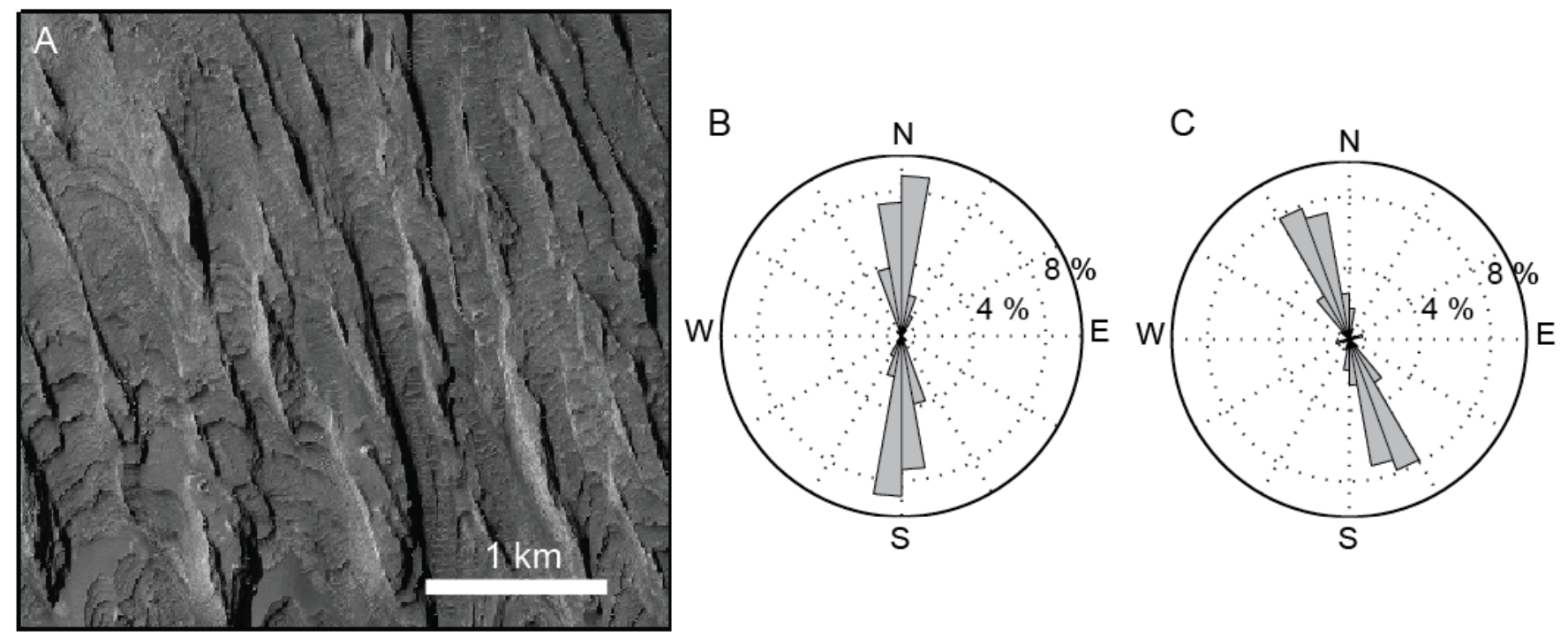

266 Figure 7. Yardangs. A. Yardangs in Gale Crater. These elongated erosional forms have tapered

267 ends and typically form in groups (Ward, 1979). HiRISE image ESP_018643_1745 is oriented

268 north up. B and C. Yardang orientations measured on the west (B) and east (C) sides of Mount

269 Sharp (Fig. 5). Orientations are shown symmetric to account for $180^{\circ}$ ambiguity in formative

270 wind direction. The two sides are statistically distinct and the $12^{\circ}$ difference in mean orientation is

271 interpreted to result from flow divergence around Mount Sharp topography. 
273 well with independent mapping of Mount Sharp (Anderson and Bell, 2010; Thomson et al.,

274 2011). The presence of yardangs on Mount Sharp and the general absence of well-defined

275 yardangs elsewhere imply that the strata of Mount Sharp are fine-grained and not strongly

276 cemented. Ranging from $33 \mathrm{~m}$ to $4.3 \mathrm{~km}$ in length, yardangs are elongated N-S with a mean

277 orientation of $354^{\circ}$. Dividing yardangs between the east and west sides of Mount Sharp (Fig. 5)

278 yields two statistically distinct populations of yardangs with means differing by $12^{\circ}$ (Fig. 7,

279 Table 2, t-test, $\alpha<0.01$ ). This variation could be explained by large-scale flow divergence of

280 northerly winds around Mount Sharp.

2815.3 Transverse aeolian ridges

The term "transverse aeolian ridge" (TAR) describes Martian bedforms with size and

283 morphology intermediate between ripples and dunes (Fig. 8) (Wilson and Zimbelman, 2004).

284 Most commonly found in Martian equatorial regions, TARs form symmetric linear ridges with

285 wavelengths between 20 and $60 \mathrm{~m}$ (Wilson and Zimbelman, 2004; Zimbelman, 2010). TARs are

286 distinguished from dunes by high albedo, linear crests, lack of activity, and symmetric cross-

287 sectional profiles (Shockey and Zimbelman, 2013). TARs are distinguished from sand shadows

288 by scale and lack of an upwind obstacle, and from ripples by scale, context, and albedo. TARs

289 are commonly found in topographic lows, and are thought to align normal to their formative

290 wind direction (Balme et al., 2008). The formation mechanism of TARs is still debated, with

291 hypothesized terrestrial analogs including granule ripples, reversing transverse dunes

292 (Zimbelman and Scheidt, 2014), anti-dunes (Geissler, 2014), and megaripples (de Silva et al.,

293 2013; Sullivan et al., 2014). To date, lateral migration of TARs has not been observed. Recent

294 work on armored granule ripples in South America has suggested that TARs may be aggrading

295 through the capture and infiltration of dust (de Silva et al., 2013; Bridges et al., 2015). Gravels

296 armoring terrestrial "megaripples" are too large to be transported off the bedform by wind, but 
can still trap passing finer material. These fines are kinetically sieved downward as gravels

298 vibrate during wind events, raising the bedform surface. This process is suggested as an analog 299 for TAR aggradation on Mars.

300
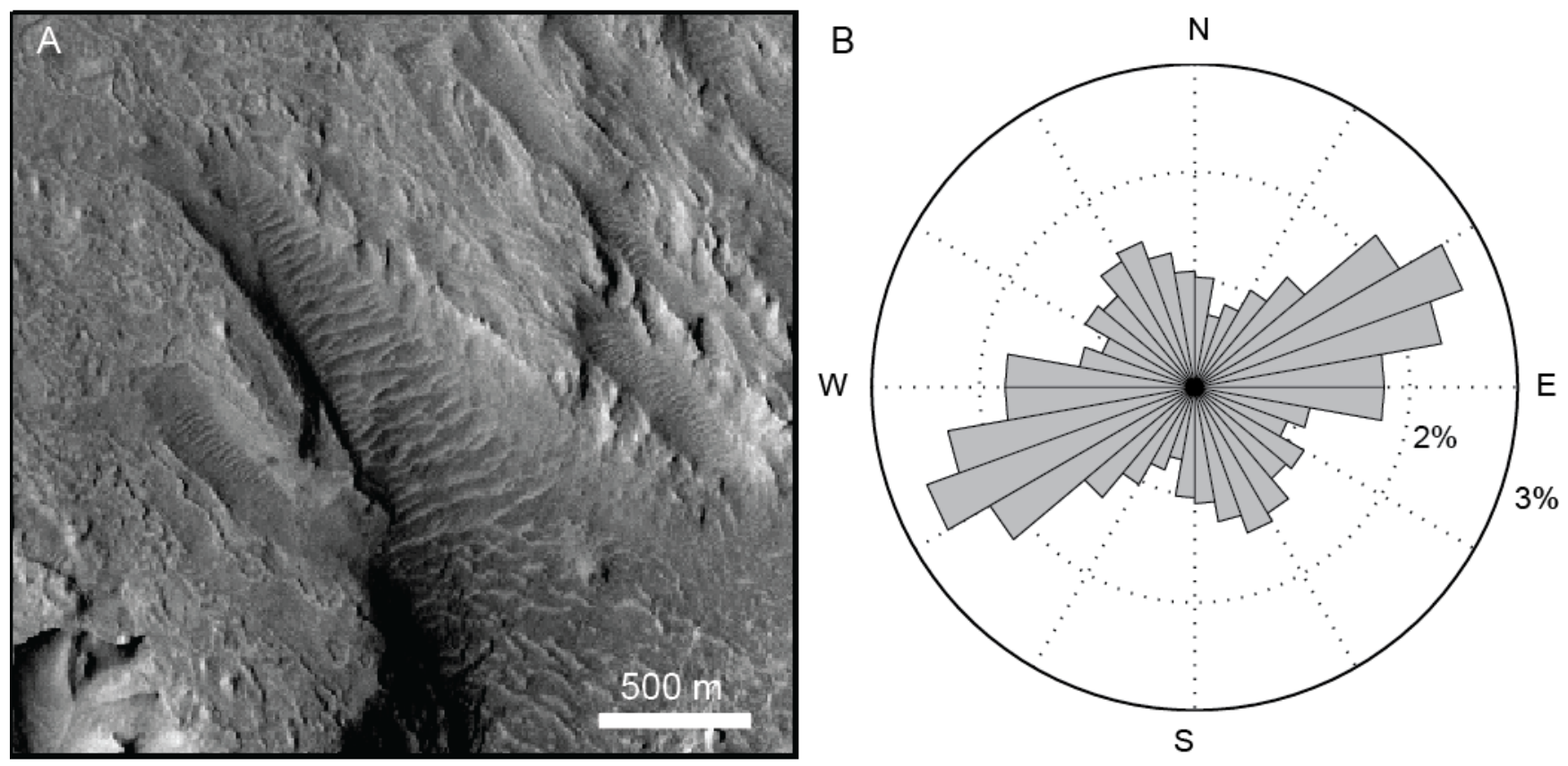

302 Figure 8. Transverse aeolian ridges. A. TARs confined to a valley on Mount Sharp, and oriented

303 normal to valley walls. TAR orientation is clearly dependent on local topography, making TARs

304 poor indicators of regional-scale winds. These TARs show simple linear and forked morphologies. HiRISE image ESP_031948_1750 is oriented north up. B. Orientations of all

306 TARs mapped in Gale Crater, symmetric to account for $180^{\circ}$ formative wind ambiguity. Two

307 overlapping populations of TAR orientations were modeled to have mean NE $\left(71^{\circ}\right)$ and NW

$308\left(337^{\circ}\right)$ trends. These are interpreted to form from dominant northwesterly $\left(341^{\circ}\right)$ and subordinate

309 northeasterly $\left(67^{\circ}\right)$ winds similar to winds interpreted in the Bagnold Dune Field.

Mapping of TARs in Gale Crater (Fig. 5, Table 2) found that they most commonly form

312 in local topographic lows (e.g., in channels, between yardangs, and in small craters) where flow 
313 is directed by topography. TAR morphologies were dominantly simple (linear) and forked

314 (Balme et al., 2008), but networked morphologies, marked by a plaid pattern of crossing ridges,

315 were seen in HiRISE at the northern base of Mount Sharp. The observed TARs were

316 predominantly confined, enclosed on all sides by topography, or controlled, forming in

317 association with less than circumferential topography (Balme et al., 2008). Some TARs formed

318 on the crater floor and smooth reaches of Mount Sharp, independent of local topography.

319 Ranging from 9 to 876 m long, TARs cover approximately $1 \%$ of the Gale Crater interior

320 surface, and are oriented in all directions. To prevent a premature genetic interpretation, TARs

321 are here considered $180^{\circ}$ ambiguous indicators of formative wind direction. The mean

322 orientation of all bedforms is $88^{\circ}$, but the set of sampled TARs can be modeled as two

323 overlapping normally-distributed populations, with mean orientations of $71^{\circ}$ and $337^{\circ}$ for major

324 and minor signals, respectively (Fig. 8, Table 2). These are interpreted to correspond with

325 primary northwesterly and subordinate northeasterly winds.

$326 \quad 5.4$ Dunes and ripples

\section{5.4.1 Approach}

328 Dune fields in Gale Crater occur within the moat between Mount Sharp and the crater

329 rim. These dune fields have been extensively characterized by Hobbs et al. (2010). Here we more

330 broadly identify four morphologically distinct regions (Fig. 9), and independently map the

331 orientations of dunes and dune brinklines in order to further reconstruct the wind regime in the

332 crater interior. The most detailed analysis is for Bagnold Dune Field because of extensive

333 HiRISE coverage (Silvestro et al., 2013). Analysis for the other regions is necessarily less

334 comprehensive because of the incomplete HiRISE coverage of these fields. 


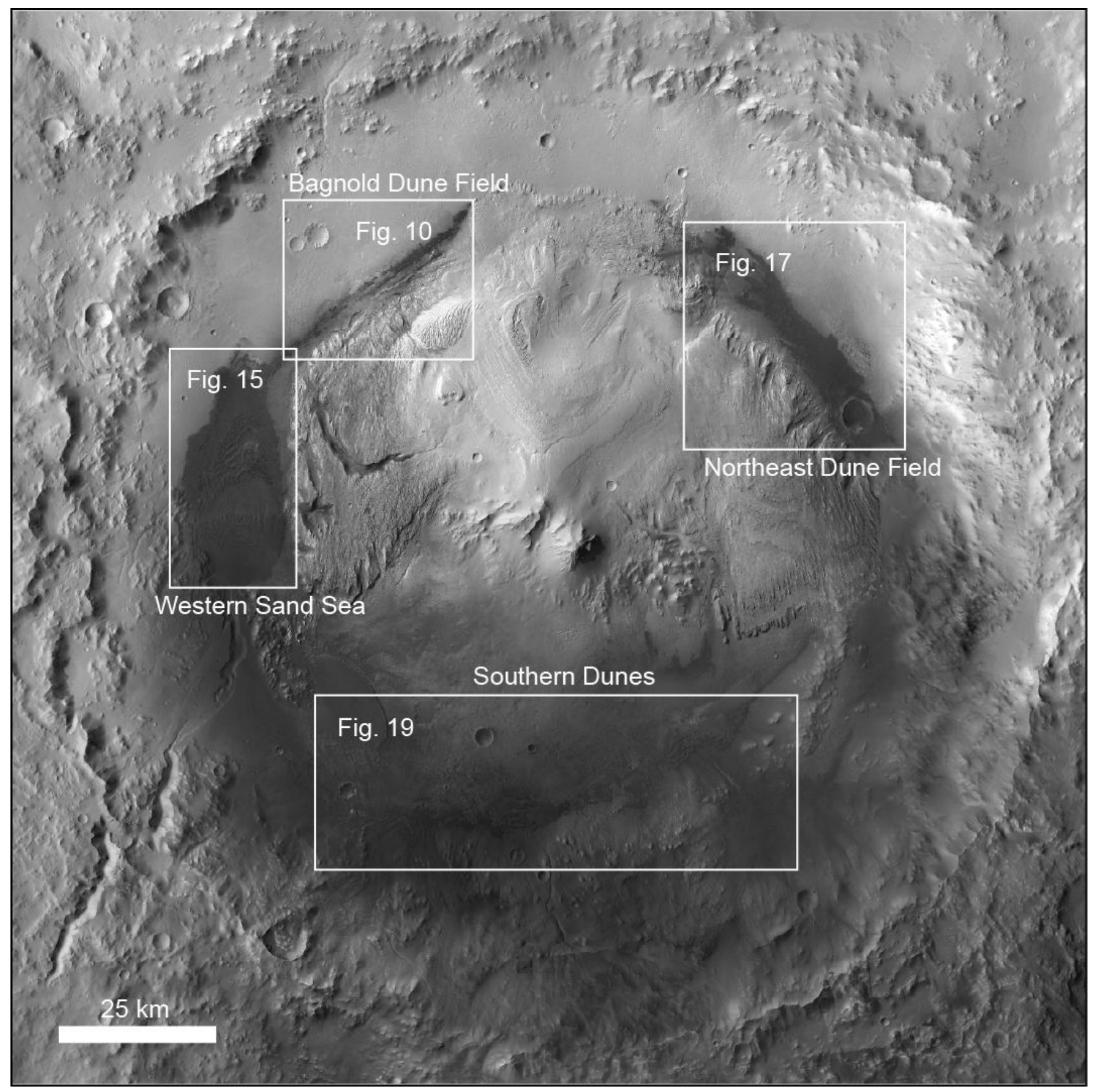

336 Figure 9. Morphologically distinct dune field regions discussed in section 5.4. White boxes

337 indicate the named dune fields and extent of corresponding context images. Note that the fields

338 are all circumferential to Mount Sharp and associated with steep slopes of either Mount Sharp or

339 the southern crater rim. Background HRSC mosaic. 
342 winds dominated Gale Crater and that these winds are strongly channeled by crater topography.

343 Because dunes and ripples form from mobile sand, their morphology and orientation are thought

344 to reflect the current wind regime in Gale Crater, in contrast to features such as yardangs that

345 require orders of magnitude more time to form. Where sand availability is not restricted and dune

346 reconstitution time is longer than cycles in the wind regime, dune crestlines are oriented to be as

347 perpendicular as possible to all components of the wind regime, the gross bedform-normal

348 orientation of Rubin and Hunter (1987). Where sand availability is restricted, as is commonly the

349 case on Mars, dunes elongate in the mean transport direction from a local sand source (du Pont et

350 al., 2014). In either case, dune crestline trend reflects the total wind regime and net dune

351 migration direction, and not a specific wind direction except where the wind regime is essentially

352 unimodal. Wind ripples, because of their small size and shorter reconstitution times, are more apt

353 to show the last significant wind event, but their orientation is also strongly affected by dune

354 topography (Howard, 1977).

355 5.4.2 Bagnold Dune Field

356 The Bagnold Dune Field is situated along the upcoming Curiosity traverse, and will be

357 the location of the first surface observations of active Martian dunes. Orbital measurements

358 yielded ripple and dune migration rates in this field of $0.66 \mathrm{~m} / \mathrm{yr}$ and $0.4 \mathrm{~m} / \mathrm{yr}$, respectively

359 (Silvestro et al., 2013). This long and thin field runs $30 \mathrm{~km}$ along the northwest basal margin of

360 Mount Sharp, and averages $1 \mathrm{~km}$ wide. Following the field from NE to SW, the dune field

361 features a $16 \mathrm{~km}$ long main section of well-defined duneforms, followed by a $9 \mathrm{~km}$ stretch of

362 bypass where dunes are mostly absent, finally ending in a $5 \mathrm{~km}$ long set of re-formed barchan

363 dunes (Fig. 10A). 


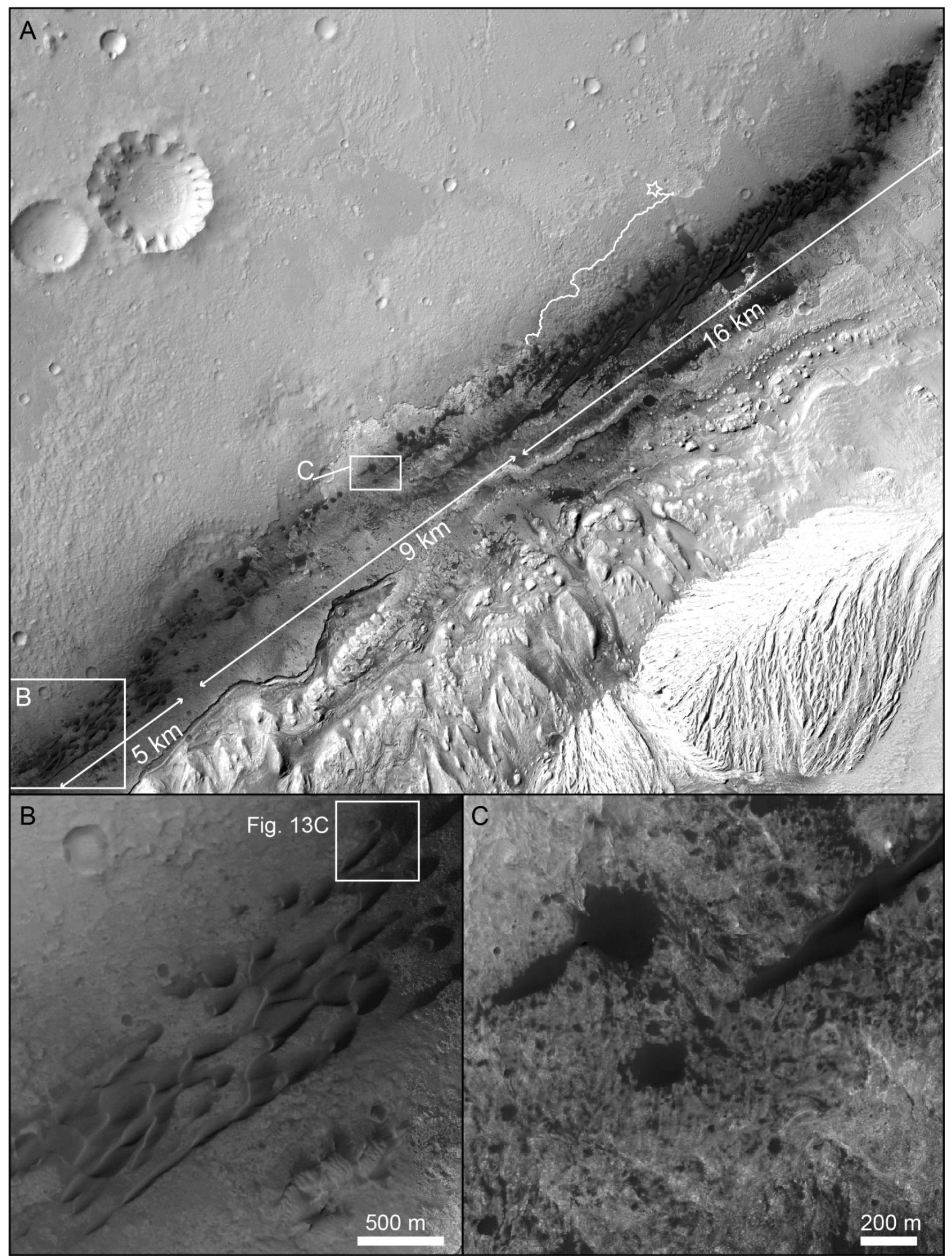


365 Figure 10. Bagnold Dune Field. A. HiRISE mosaic of the Bagnold Dune Field showing three

366 regions discussed in section 5.4.2. The main area is $16 \mathrm{~km}$ long and houses the majority of the

367 dunes. The middle $9 \mathrm{~km}$ region is sediment-starved, featuring only sparse bedforms and sand

368 sheets that fill topographic lows. The final $5 \mathrm{~km}$ is dominated by asymmetric barchans interpreted

369 to have reformed from sediment sourced from the main field. White boxes show the locations of

370 B and C. The Curiosity landing site and traverse through sol 960 are given by the star and white

371 line, respectively. B. Southwest end of the Bagnold Dune Field where SW-facing (Population 2)

372 slipfaces dominate and SE-facing slipfaces (Population 1) are mostly absent. White box shows the

373 location of Figure 13C (HiRISE images ESP_025790_1750 and ESP_012841_1750). C. Sand-

374 starved duneforms in the middle region of sediment bypass. This contrast-stretched image shows

375 the tail end of a linear dune (right) and a tear-drop dune (left) dying out as they migrate to the

376 southwest. Circular dark patches in the image are sand sheets filling small craters (HiRISE image

377 ESP_028823_1755). North is up in all panels. 


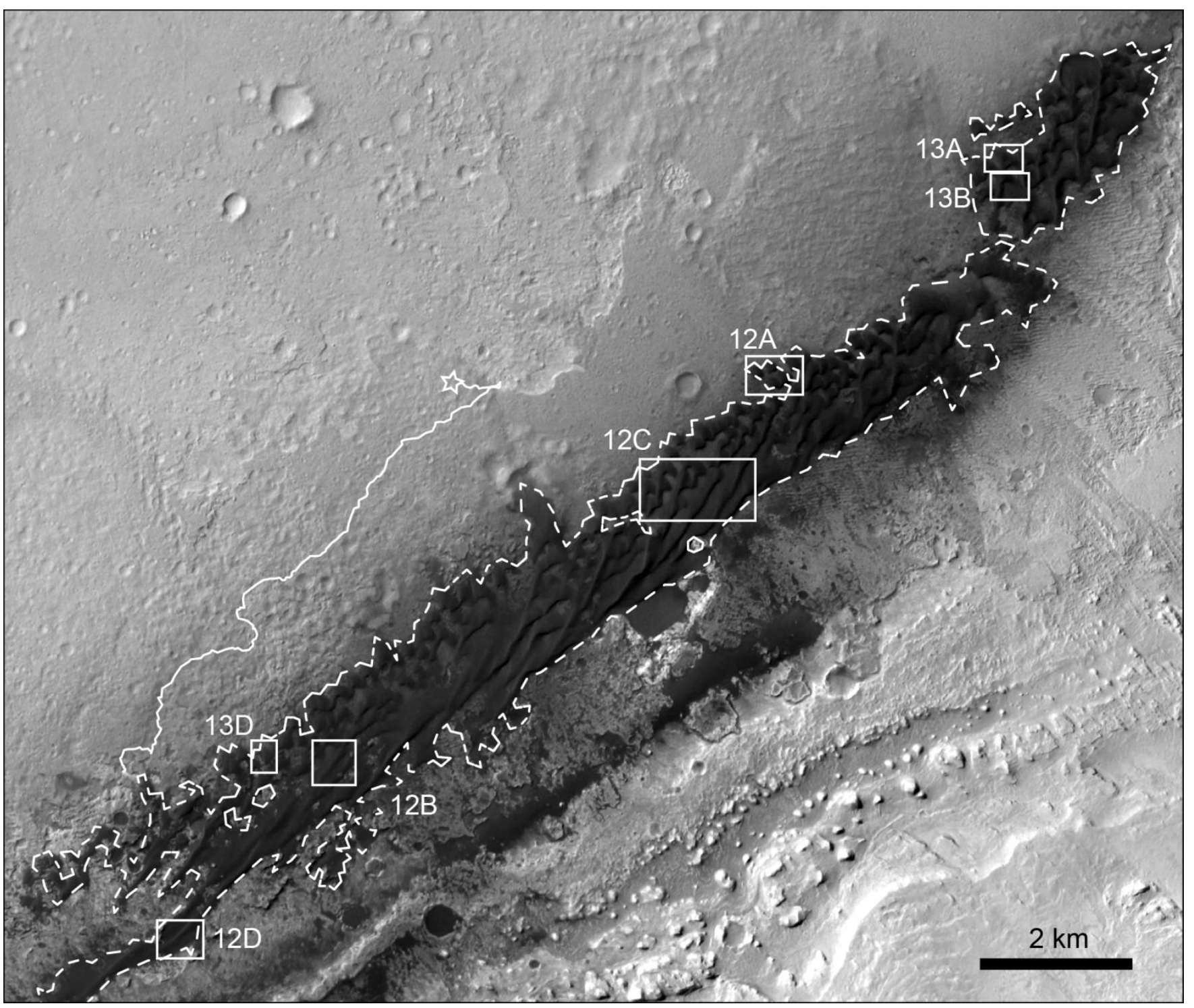

379 Figure 11. North-up oriented HiRISE mosaic of the main section of the Bagnold Dune Field with

380 locations of panels in Figures 12 and 13. White star and line indicate the Curiosity landing site

381 and traverse. Dashed line corresponds to the dashed line in Figure 14 and marks the dune-

382 dominated surface used in this region to estimate loose sediment volume (Table 1). 

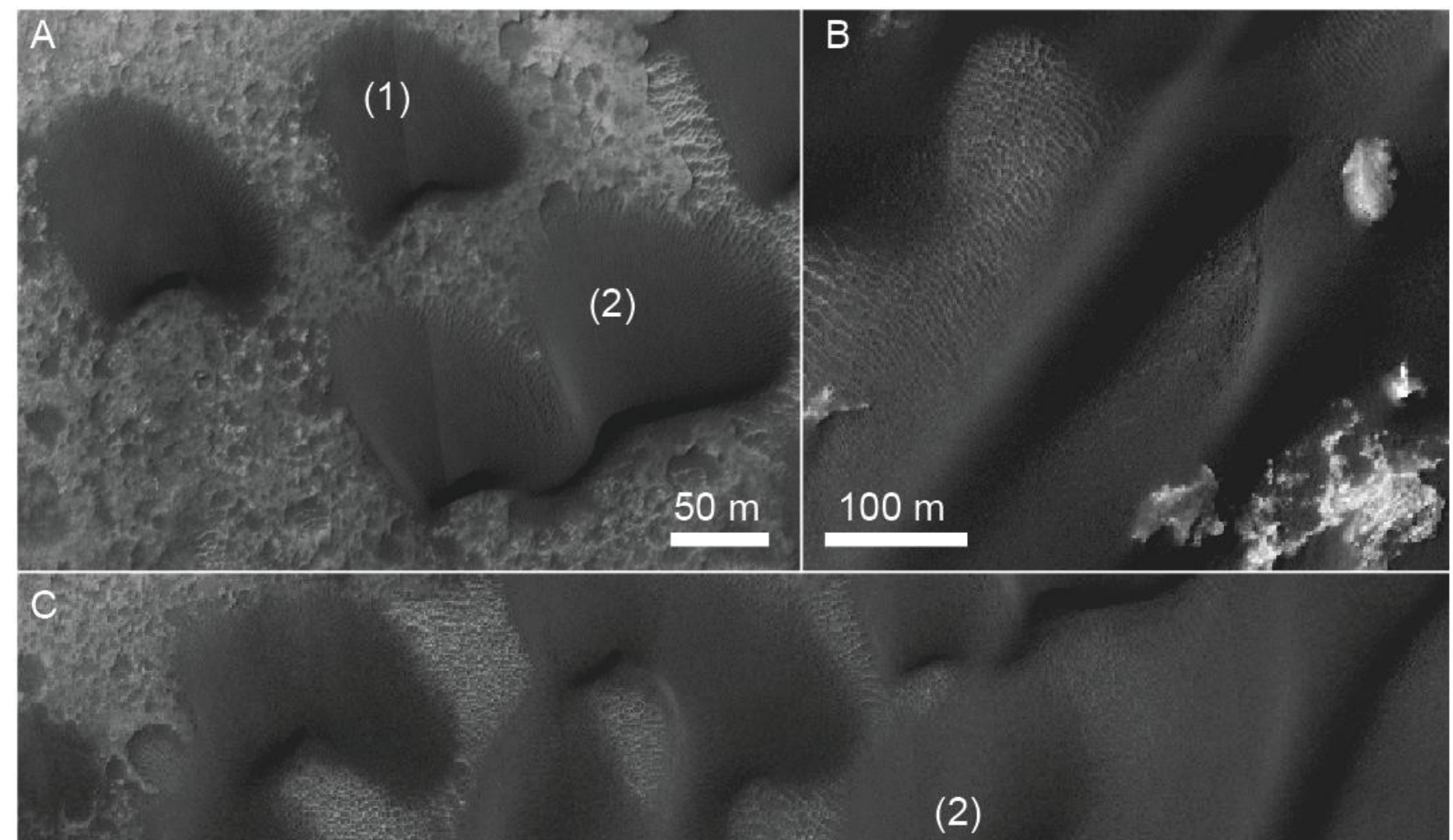

(1)

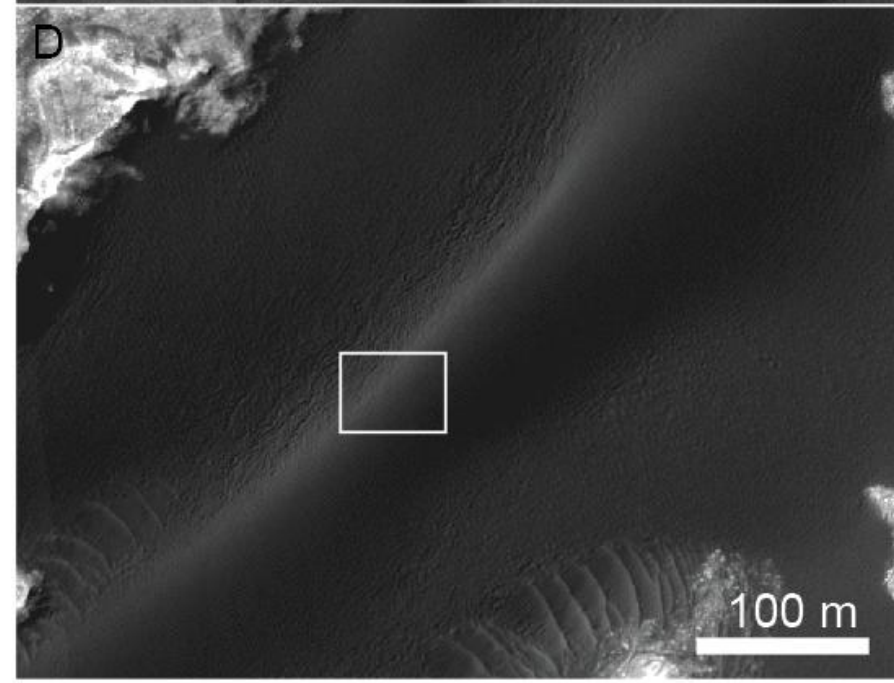

E 
384 Figure 12. Dune morphologies in the Bagnold Dune Field. A. Symmetric barchans (1) migrate

385 and link to become asymmetric barchans (2). B. Symmetric linear dune from the middle of the

386 main section with equally defined slopes to each side of the crestline. C. Progression of dune

387 morphology from west to east in the dune field. Barchans link defect arms downwind to form

388 chains of elongations to the south and southwest (1). Chains become linear dunes, here

389 asymmetric with SE-facing steeper slopes (2). Note how the linear dunes become detached from

390 formative barchans. D. Reversal on linear dune in the SW of the field to have a sharper NW-

391 facing slope. White box shows the location of E. E. Ripples on the linear ridge aligning parallel

392 to ridge direction. Images have been contrast stretched to bring out albedo variation, and north is

393 oriented up in all panels. HiRISE images ESP_024023_1755 (A and C), ESP_033649_1750 (B,

394 D and E).

395

Dune morphologies in the Bagnold Dune Field range from barchans along the NW

397 margin to linear dunes in the interior (Fig. 11). Small symmetric barchans (100-150 m wide),

398 seen in isolation at the NE end of the field, laterally link with other barchans as they migrate

399 downwind, forming asymmetric dunes as one arm elongates to the SW (Fig. 12A). These

400 elongate arms extend and connect with other defect arms downwind to form chains that coalesce

401 into the SW-NE trending linear dunes (Fig. 12C). Near the beginning of the field these linear

402 dunes (0.5-1.5 km long) are asymmetric, with steep SE-facing slopes (Fig. 12C). To the SW,

403 morphologies grade into symmetric linear dunes (Fig. 12B), and even reverse to have sharper

404 NW-facing slopes (Fig. 12D), arguing for formation by barchan arm elongation in bimodal

405 winds (Bourke, 2010). Rippled sand sheets make up the interdune areas between linear dunes,

406 and ripples observed on linear dunes crests are parallel to the dune ridge (Fig. 12E). 


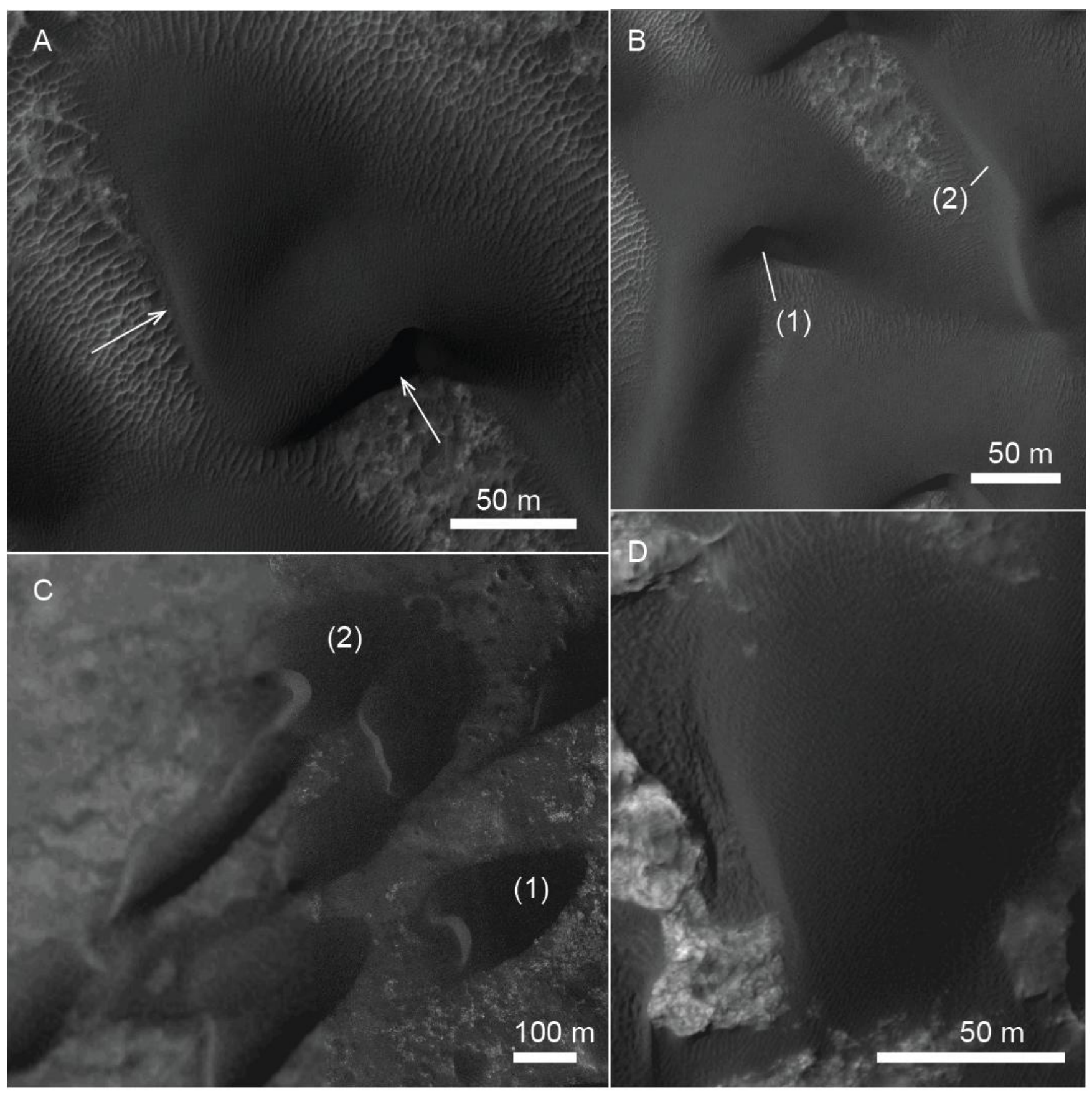

409 Figure 13. Slipfaces on Bagnold Dunes. A. Tear-drop dune with two steep slipfaces (arrows)

410 bisected by an elongating arm. Note the exposed bedrock and light toned granule ripples in the

411 interdune areas. B. Primary (1) and secondary (2) slipfaces in the NE end of the dune field (Fig.

412 11). Note the sharp brinkline in the primary face and the subdued brinkline on the secondary face.

413 Crest and ripple orientations are mapped on this image in Figure 14A. A and B taken from

414 HiRISE image PSP_009861_1755. C. SW-migrating barchans in the SW end of the dune field. 
415 Note the symmetric (1) and asymmetric (2) morphologies and the SW-elongating arm that

416 indicates the presence of a northeasterly wind. (See Fig. 10 for location) D. Barchan dune from

417 the middle of the field (Fig. 11) with no observed primary slipface, and secondary slipface similar

418 to the morphology observed in B. HiRISE image ESP_033649_1750. All images are contrast-

419 stretched to bring out the variation in these dark features, and north is up in all panels.

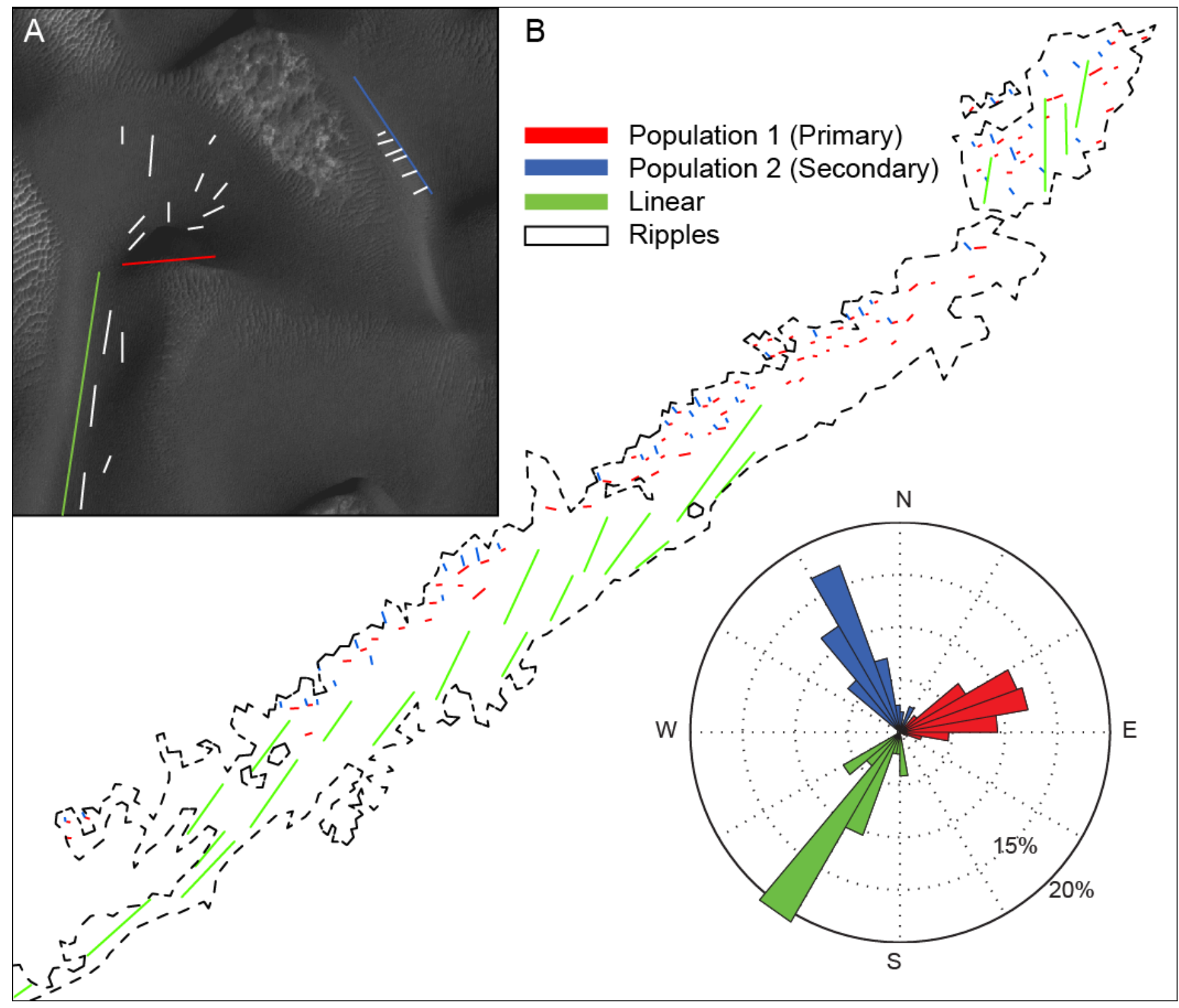

421 Figure 14. Bedform mapping in the Bagnold Dune Field. A. Example mapping superimposed on

422 the same image seen in Figure 13B. Primary brinkline trend is defined by the sharp south-facing

423 slipface (red). Secondary trend is defined by steep lee slopes, reworked by ripples (blue). Linear

424 dune trend is shown stemming from an elongating barchan (green). Ripple trends are shown for 
schematic representation of the variation in orientation with position on the dune. B. Bedforms

426 mapped in the main section of the Bagnold Dune Field with the same lateral coverage shown in

427 Figure 11. Asymmetric barchans were also mapped in the extreme southwest, but were relatively

428 few and are not shown here. Populations of orientations are shown in the rose diagram. Note that

429 the primary and secondary orientations are interpreted to form transverse to winds with upwind

430 azimuths of $\sim 344^{\circ}$ and $\sim 67^{\circ}$, respectively.

Focusing on the barchan dunes, in all regions the interdune areas between barchans are

433 dominated by exposed bedrock and light-toned granule ripples (Fig. 13A). The isolated

434 symmetric barchans near the beginning of the field exhibit a single sharp brinkline and SE-facing

435 slipface. If the reconstitution time of the barchan dunes is longer than the wind alternation time,

436 multiple slipface orientations could be preserved on a single barchan form. The "tear drop"

437 morphology, where two slipfaces are bisected by an elongating arm, has been modeled to form in

438 bimodal wind regimes with a divergence angle of at least $100^{\circ}$ (Parteli et al., 2009), and is seen

439 in abundance on Mars (Hayward et al., 2014). In the Bagnold Dune Field, tear-drop dunes form

440 downwind of symmetric barchans in the main section of the field with SE- and SW-facing

441 slipfaces (Fig. 13A). SE-facing slipfaces (Population 1) have sharp brinklines and smooth (non-

442 rippled) lee surfaces interpreted as grainflow deposits and are hereafter designated the primary

443 slipface population (Fig. 13B). The grainflows seen on these slipfaces indicate formation

444 transverse to flow $\left( \pm 20^{\circ}\right)$ (Eastwood et al., 2012). Ripple orientations on dune stoss slopes align

445 roughly parallel near the dune crest with these sharp slipfaces (Fig. 14A). The SW-facing

446 slipfaces (Population 2) are distinctly different. Hereafter referred to as the secondary slipface

447 population, these slopes exhibit superimposed ripples migrating across and reworking the steep

448 deposit (Fig. 13B). Sharp brinklines are absent on secondary lee faces, and no grainflow deposits

449 were observed. 
451 slipfaces are the most prominent in the NE of the field, and the secondary slipfaces become

452 dominant as one follows the field to the SW (Figs. 13D, 13C). Rather than a sharpening of the

453 secondary lee faces, this transition occurs as a gradual disappearance of the primary lee faces,

454 which become more subdued to the SW (Fig. 13D). The decay of primary slipfaces roughly

455 corresponds with a reversal of the dominant slope on the linear dunes described above. At the

456 very SW end of the dune field, the final group of barchans is clearly dominated by the secondary

457 slipface population. Here, SE-facing lee slopes are all but absent, and the teardrop morphology is

458 no longer observed. Small symmetric barchans are seen migrating to the SW, and a new

459 morphology of asymmetric barchans dominates. The southern defect arm of SW-migrating

460 crescentic barchans elongates in the transport direction to the SW creating an asymmetric

461 barchan with a short northern and long southern defect arm (Fig. 13C). The morphology of these

462 elongated arms requires that the originally dominant northwesterly wind be still present, but now

463 this wind is clearly subordinate to the northeasterly wind (Tsoar et al., 2004).

464 The orientations of the two populations of slipfaces and of the linear dunes were mapped

465 across the Bagnold Dune Field (Fig. 14, Table 3). The average orientation of the linear dunes

466 roughly bisects the average upwind azimuth inferred from the two slipface populations. In

467 bimodal winds, barchan arms tend to elongate in the direction of the resultant wind vector

468 (Tsoar, 1989). Assuming the two slipface orientations are approximate indicators of wind

469 direction $\left( \pm 20^{\circ}\right)$, an inversion of the theory of gross bedform normal (Fenton et al., 2014; Rubin

470 and Hunter, 1987), yielded a ratio of the two wind directions of $\sim 1.3$. The dominant wind

471 direction is therefore interpreted to be from the NW $\left(337^{\circ}\right)$, and the subordinate direction from

472 the NE $\left(74^{\circ}\right)$. This interpreted bimodality is consistent with recent modeling results of barchan

473 morphologies formed in bimodal winds (Parteli et al., 2014), and with the populations of mapped

474 ripples and dunes in the Bagnold Dune Field (Hobbs et al., 2010; Silvestro et al., 2013). This 
simplification considers only the mapped brinkline orientations and not the observed

476 morphological shift that suggests a change in wind dominance from one end of the field to the

477 other.

The Bagnold Dune Field is clearly an availability-limited system (Kocurek and

479 Lancaster, 1999). The asymmetric morphologies are consistent with bedform formation in the

480 sand-starved "fingering mode" identified by du Pont et al. (2014). Barchan and linear dunes have

481 low equivalent sand thicknesses relative to other dune types (Lee and Thomas, 1995), and

482 barchan dunes characterize areas of limited sand supply. The $9 \mathrm{~km}$ break in the dune field further

483 reflects the limited sand supply in this system (Fig. 10C). In this zone, the dunes lose definition,

484 shrink to small domes, and decay into sand sheets. Although the dunes evidence a clear history

485 of sand transport, on the whole sands are being transported through this region and into the

486 Western Dune Field, making the Bagnold Dune Field a bypass dune field rather than an ultimate

487 sand sink.

488 Table 3: Summary of brinkline and linear dune measurements

\begin{tabular}{|c|c|c|c|c|}
\hline Dune Field & 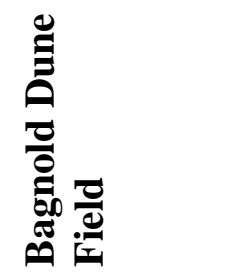 & 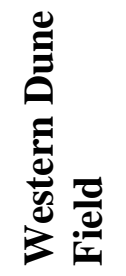 & 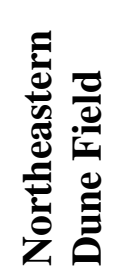 & 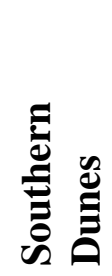 \\
\hline $\begin{array}{l}\text { Population } 1-\text { Mean brinkline } \\
\text { orientation }\left({ }^{\circ}\right)\end{array}$ & 67 - primary & 35 & 18 & 339 \\
\hline Standard deviation $\left(^{\circ}\right)$ & 15 & 27 & 33 & 28 \\
\hline Number of samples & 97 & 553 & 38 & 120 \\
\hline $\begin{array}{l}\text { Population } 2-\text { Mean brinkline } \\
\text { orientation }\left({ }^{\circ}\right)\end{array}$ & $\begin{array}{l}344- \\
\text { secondary }\end{array}$ & 336 & 324 & 49 \\
\hline Standard deviation $\left({ }^{\circ}\right)$ & 17 & 29 & 23 & 14 \\
\hline Number of samples & 77 & 246 & 46 & 122 \\
\hline $\begin{array}{l}\text { Population } 3 \text { - Mean brinkline } \\
\text { orientation }\left(^{\circ}\right)\end{array}$ & - & 88 & 50 & 55 \\
\hline Standard deviation $\left(^{\circ}\right)$ & - & 22 & 14 & 20 \\
\hline Number of samples & - & 105 & 9 & 25 \\
\hline Mean linear dune orientation $\left({ }^{\circ}\right)$ & 32 & 4 & 327 & 5 \\
\hline Standard deviation $\left({ }^{\circ}\right)$ & 15 & 32 & 16 & 32 \\
\hline Number of samples & 24 & 76 & 14 & 17 \\
\hline
\end{tabular}


491 The Western Dune Field extends along the western margin of Mount Sharp, and is the 492 largest body of sand in Gale Crater (Fig. 15) (Hobbs et al., 2010). This dune field is $\sim 34 \mathrm{~km}$ long 493 and is $15 \mathrm{~km}$ at its widest. As indicated on Figure 15B, the northern region of the dune field (20 $494 \mathrm{~km}$ long) is separated from the southern region ( $10 \mathrm{~km}$ long) by a $4 \mathrm{~km}$ region of bypass 495 spanning the width of the field. Dunes funnel in and around antecedent topography associated 496 with nearly $700 \mathrm{~m}$ of elevation rise across the field (north to south). A mound of exposed 497 layered bedrock can be seen in the middle of the northern section just north of a $1.8 \mathrm{~km}$ diameter 498 crater, currently filled with dune sands (Fig. 15B). A dissected ridge marks the boundary 499 between the southern area and the region of bypass, and is associated with a slope break in the 500 local elevation (Hobbs et al., 2010, fig. 5). Clearly deriving sands from the Bagnold Dune Field 501 (Fig. 9), northern reaches of the Western Dune Field align with a retreating scarp (Fig. 16B), 502 possibly laterally equivalent to the "Cratered Surface" terrain unit encountered by Curiosity 503 (Anderson and Bell, 2010; Grotzinger et al., 2014). Initiation of the dune field at this scarp may 504 reflect flow deceleration associated with the negative topography, but erosion of this strata may 505 be an additional sediment source for the Western Dune Field. Dune morphologies observed in the Western Dune Field are more diverse than those in

507 the Bagnold Dune Field. Starting in the north, the field is defined by a rampart of peripheral 508 barchans that coalesce to form crescentic and linear dunes with apparent migration toward the 509 center of the dune field (Fig. 16B). Barchans on the western edge of the dune field (Fig. 16A) 510 have well-defined SE-facing slipfaces, whereas barchans on the eastern edge (Fig. 16E) have 511 SW-facing slipfaces. Both sets of slipfaces face the field interior, and elongating barchan arms 512 are always on the north side. Barchans on the western edge coalesce into crescentic dunes (Fig. 513 16A), but lose definition as they migrate inward toward a zone of markedly smooth topography 
514 that forms a halo around the dune field interior (Fig. 15B). Barchans on the eastern edge also

515 coalesce and develop extended arms (Fig. 16E), but this pattern yields to subdued linear dunes in

516 the interior on the eastern side of the filled crater (Figs. 15B). The central interior of the northern

517 region shows a complex dune pattern. Large primary linear dunes trend northeast, but

518 superimposed bedforms similar to terrestrial zibars (Nielson and Kocurek, 1986) occur in the

519 interdune areas and intersect the primary linear dunes at a high angle (Figs. 15B, 16C). This

520 complex pattern is reminiscent of star dunes formed in converging flows (e.g., Lancaster, 1989b;

521 Zhang et al., 2012).

522 The middle bypass region (Fig. 15B) is devoid of bedforms, except for scattered barchans

523 that range from 80-260 $\mathrm{m}$ in width (Fig. 16D). First observed at the dissected ridge, these

524 symmetric barchans are oriented to migrate north across the exposed plain, and rejoin sands in

525 the northern region of the field. 


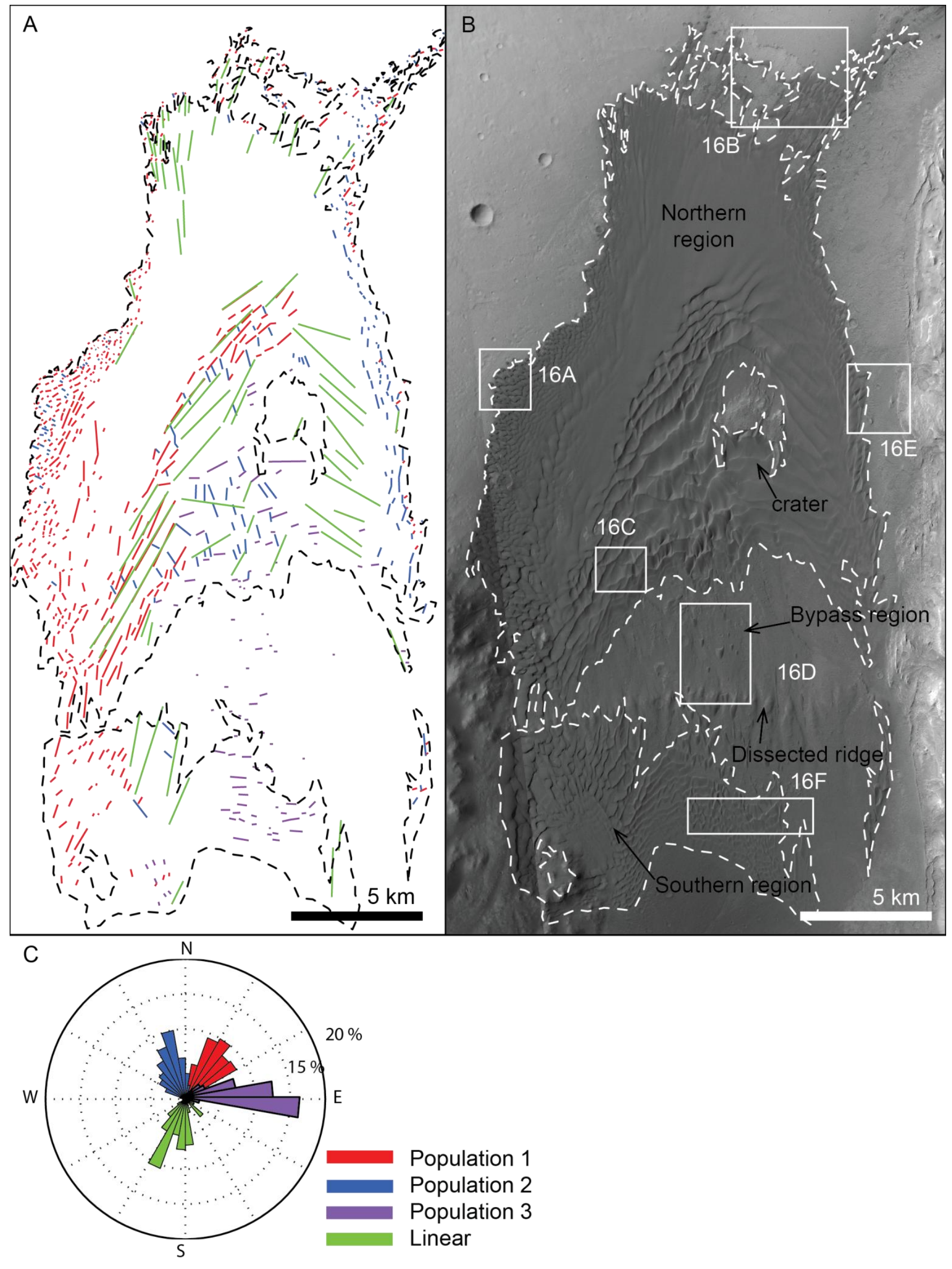


527 Figure 15. Western Dune Field. A. Bedform mapping in the Western Dune Field. Three

528 populations of slipface orientations were mapped in addition to trends of linear dunes. B. Western

529 Dune Field at the base of just visible light toned Mount Sharp strata to the east. Dashed white line

530 marks the edge of dune-dominated surfaces used in this area to estimate the volume of loose

531 sediment. The three regions discussed in section 5.4.4 and the filled crater are indicated (black

532 arrows). White boxes and annotations indicate the location of panels in Figure 16. CTX image

533 P13_006143_1745_XN_05S223W is oriented north-up. C. Rose diagram of populations of

534 slipfaces and linear dunes corresponding to measurements in A. Populations 1 and 2 are shown by

535 convention in the northern hemisphere, but Population 3 is shown together to prevent splitting of

536 the population.

537 


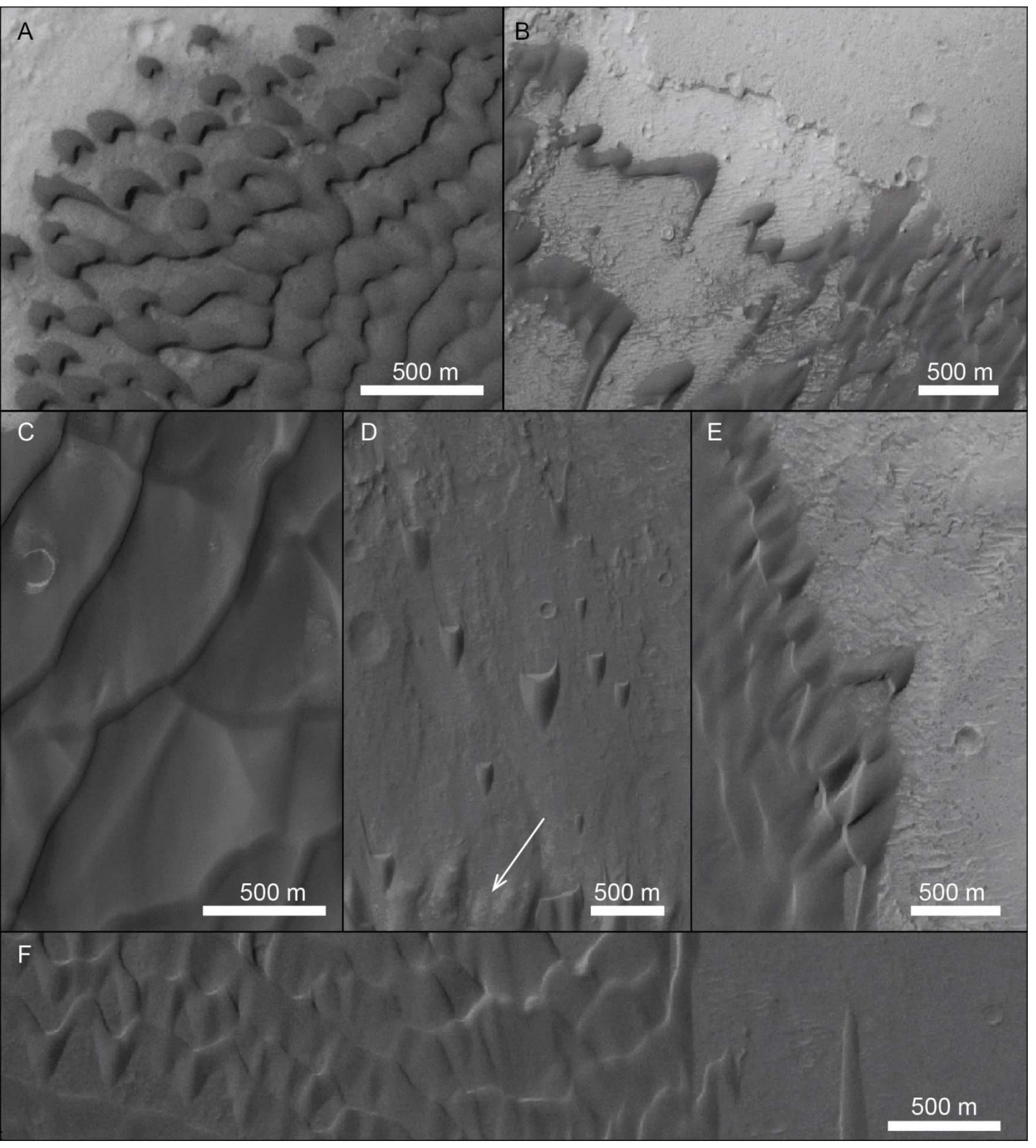

539 Figure 16. Dune morphologies in the Western Dune Field. A. Peripheral symmetric barchans on

540 the west edge of the Western Dune Field. Barchan dunes link with other barchans as they migrate

541 to the SE, becoming increasingly asymmetric and forming crescentic ridges. Slipfaces on these

542 dunes form Population 1 (Fig. 15A). B. Asymmetric barchan dunes at the northern edge of the 
543 dune field form just downwind of a scarp, hypothesized to source some of the dune sands. C. NE-

544 trending linear dunes with superimposed NW-trending crestlines, forming morphologies similar

545 to star dunes. This morphology argues for convergent flows in this region. D. North-migrating

546 symmetric barchans crossing the sand-starved bypass region. Slipfaces are oriented east-west

547 (Population 3) and interpreted to form from southerly winds. Note the dissected ridge (arrow). E.

548 Asymmetric barchans on the eastern margin of the dune field, opposite barchans in A. SW-facing

549 slipfaces from Population 2 are sharpest in this area. F. Barchans and crescentic dunes in the

550 southern region terminate in bedrock plains to the east. The elongated barchan arm (just left of the

551 scale bar) ends before becoming a linear dune. All images have been contrast stretched to bring

552 out variation in the scene, and north is up (CTX image P13_006143_1745_XN_05S223W).

In the southern region (Fig. 15B), barchan dunes link and coalesce to form a

555 morphological continuum between barchan and crescentic dunes (Fig. 16F). Dunes in this region

556 exhibit north-facing slipfaces (Fig. 16F), matching those of the symmetric barchans in the middle

557 bypass region. Slipfaces on crescentic and barchan dunes become less defined toward the eastern

558 edge of this region where dunes abruptly yield to a sand-free plain (Fig. 16F). Elongating defect

559 arms along this eastern edge terminate before forming symmetric linear dunes.

Slipface orientations of the barchan and crescentic dunes and the trends of linear dunes

561 were mapped in the Western Dune Field (Fig. 15A, Table 3), yielding three populations of

562 barchans/crescentic dunes and a population of linear dunes (Fig. 15C). Population 1 largely

563 consists of the dunes on the western side of the dune field, where their brinklines trend $\mathrm{NE}\left(35^{\circ}\right)$

564 and dune orientation shows migration toward $\left(125^{\circ}\right)$ the dune-field interior. Population 2 largely

565 consists of the dunes on the eastern side of the dune field, where their brinklines trend NNW

$566\left(336^{\circ}\right)$ and also show migration toward $\left(246^{\circ}\right)$ the dune-field interior. Population 3 characterizes

567 dunes in the southern and bypass regions, where brinklines trend $\mathrm{E}-\mathrm{W}\left(88^{\circ}\right)$ and dunes are 
oriented to migrate north toward $\left(358^{\circ}\right)$ the dune-field interior. The entire population of linear

569 dunes trends N-S $\left(04^{\circ}\right)$, but those in the western interior trend NE, parallel to Population 1,

570 whereas the more subdued linear dunes in the east and superimposed in the west trend NW,

571 parallel to Population 2.

572 The dune morphologies, their orientations, and the spatial abundance of sand all indicate

573 that wind patterns create a convergence toward the interior dune field in the northern region.

574 Peripheral areas of the dune field show dunes largely resting upon exhumed bedrock (Figs. 16A-

575 E), but in the central interior, dunes are their largest and interdune areas are sand-covered (Fig.

576 16C). The flow convergence toward the central interior is further manifested by the complex

577 superimposed dune trends.

$578 \quad$ 5.4.4 Northeastern Dune Field

579 The northeast quadrant of Gale Crater hosts a dark streak indicative of actively

580 transported aeolian sand that stretches $37 \mathrm{~km}$ along the northeast basal margin of Mount Sharp

581 and averages $\sim 5 \mathrm{~km}$ wide (Fig. 17). High resolution coverage in this dune field is particularly

582 limited, but the area appears to be a mix of dunes, and sand sheets. Following the field from NW

583 to SE, the beginning of the field is marked by symmetric barchans with well-defined east-facing

584 slipfaces. These dunes grade into asymmetric dunes with southern arms elongating to the SE,

585 roughly parallel to the dune field trend (Fig. 18A). Continuing to the south, barchans on the

586 western edge lose definition and grade into apparent sand sheets, such that only about half of the

$587 \sim 5 \mathrm{~km}$ width of the dark streak appears to house enough sand to give rise to visible dunes (Fig.

588 17B). Linear streaks within the sand sheets are oriented parallel to the dune field trend. Further

589 south, bedforms make up increasingly more of the low albedo width. Asymmetric barchans form

590 a rampart margin on the eastern edge of the dune field (Fig. 18B), but their slipfaces are subdued

591 in comparison to the dunes in the north. Where resolvable, these dunes have brinklines trending

592 NW with steep slipfaces toward the interior. Apparent linear dunes also occur within the main 
dune field, but their symmetry is difficult to determine with the limited resolution available.

594 About $27 \mathrm{~km}$ from its northern margin, the dune field is interrupted by a $4.8 \mathrm{~km}$ diameter crater

595 (Fig. 17B). Dune sands fill the crater with a crescentic "bullseye" morphology commonly

596 observed in Martian craters (Hayward et al., 2014). Dark sands are also seen streaming around

597 the exterior of the uplifted crater rim. Finally, at the SE end of the dune field, sands coalesce into

598 several large crescentic dunes with steep SE-facing slopes (Fig. 18C). Ripple orientations on

599 these dunes strongly follow the ridgeline orientation, with interference patterning near the crest

600 attributed to changes in bedform slope (Fig. 18D).
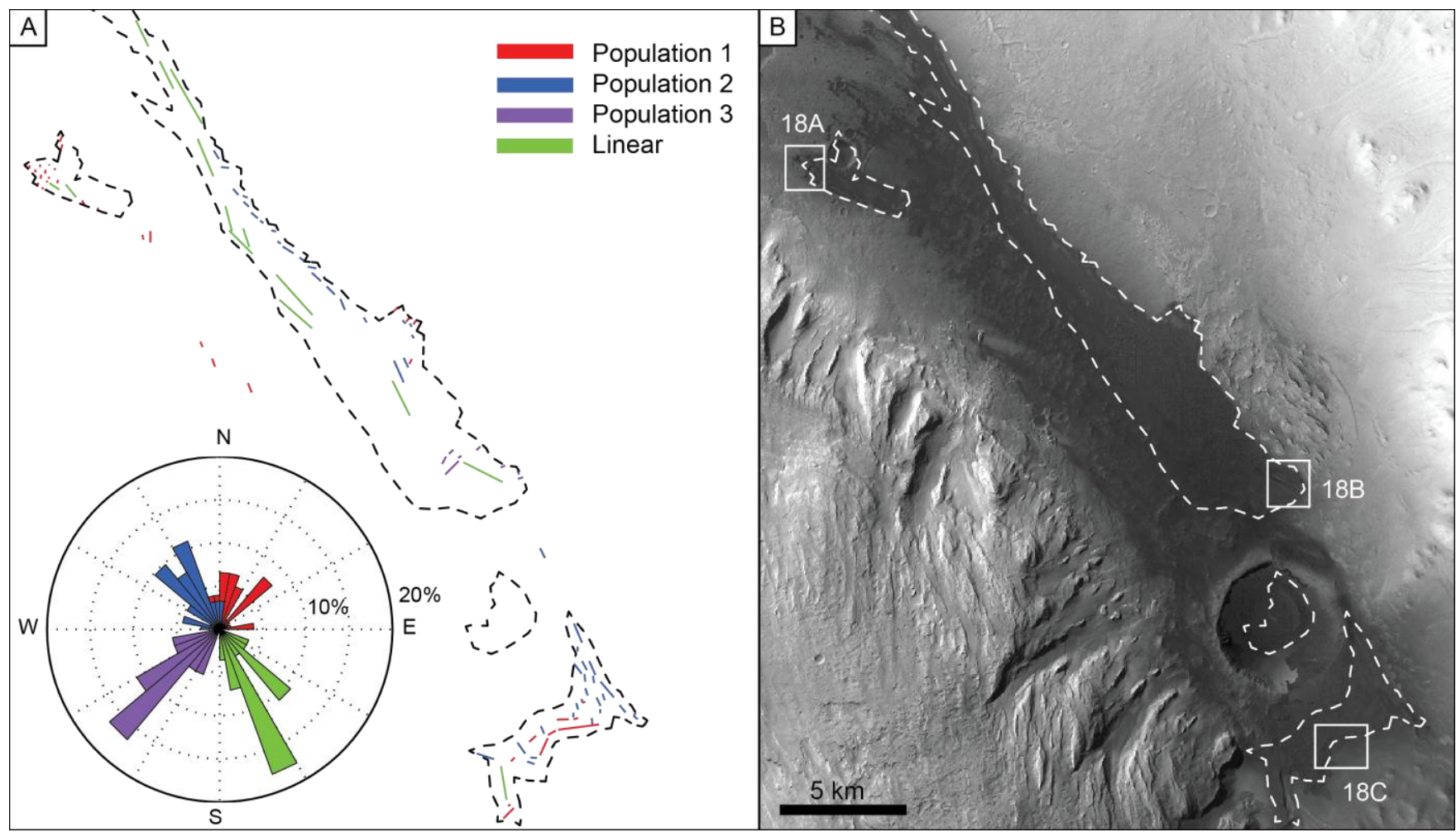

602 Figure 17. Northeastern Dune Field. A. Bedform mapping in the Northeastern Dune Field. Three

603 populations of slipface orientations were mapped in addition to the linear dune orientations. Rose

604 diagram shows histogram of the measured orientations. Population 3 is shown in the southern

605 hemisphere to limit overlap. B. Northeastern Dune Field at the base of dissected Mount Sharp strata to the SW. Dashed line corresponds with dashed line in A and was used to estimate the 
607 volume of dune sand in this region. White boxes show the locations of panels in Figure 18. North-

608 up oriented CTX image G23_027069_1748_XN_05S221W.

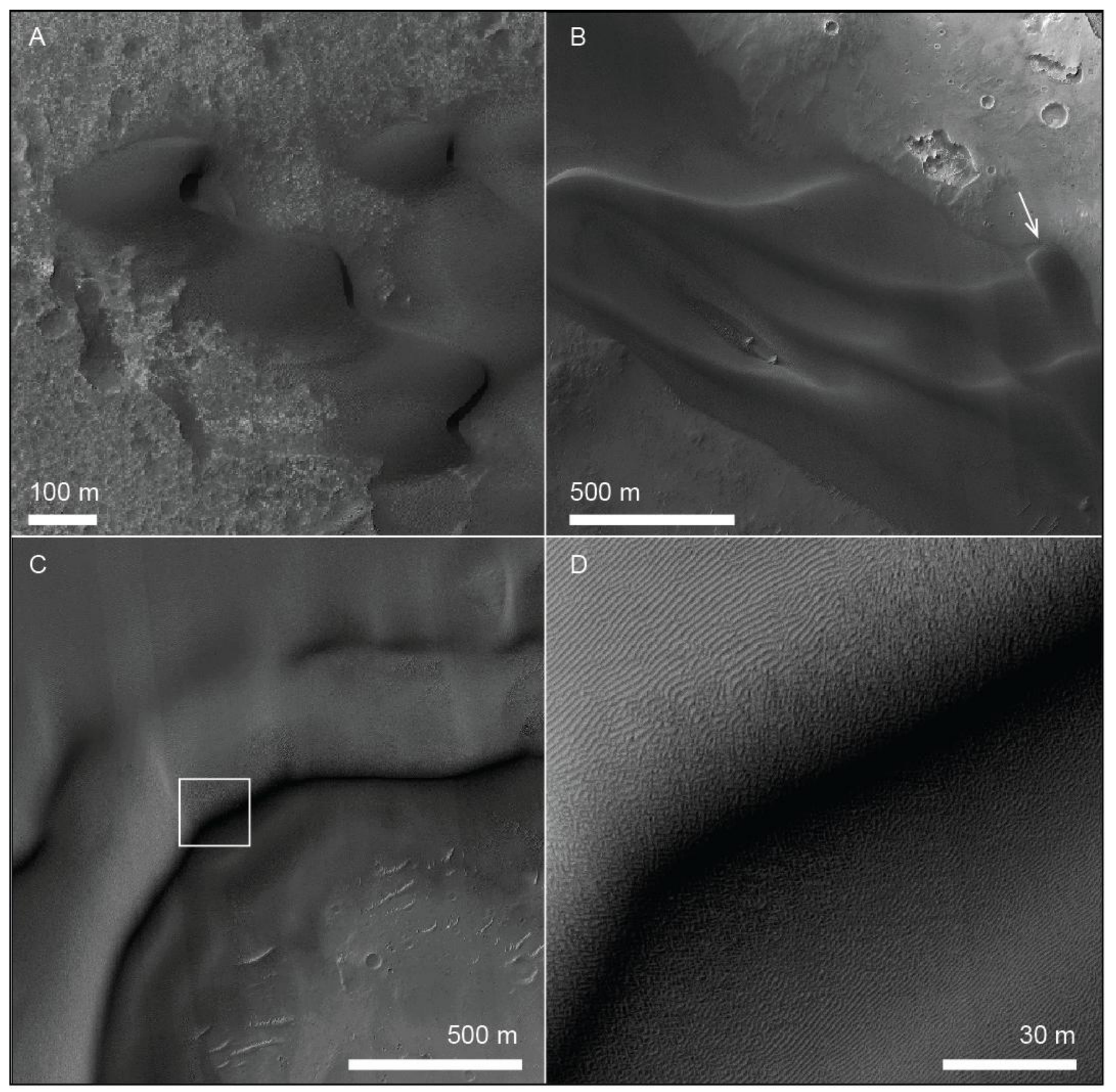

610 Figure 18. Dune morphologies in the Northeastern Dune Field. A. Barchans becoming

611 increasingly asymmetric and linking to form chains of defect arms elongating to the SE. Note the

612 sharp brinklines defining the slipface Population 1. HiRISE image ESP_026291_1750. B. NW-

613 trending asymmetric linear dunes with steep north-facing slopes. Note the degraded teardrop 
614 barchan (arrow) and its two slipfaces. C. Crescentic dune with steep SE-facing slope forming

615 south of the $4.8 \mathrm{~km}$ diameter crater. White box shows the location of D. D. Ripples on crescentic

616 dune surface are parallel to the crest on both the NW stoss and at the base of the steep lee face to

617 the SE. Note the interference patterning near the brinkline. All images have been contrast

618 stretched and are oriented north-up. HiRISE image ESP_026502_1750 covers B, C, and D.

Mapped brinkline orientations north of the $4.8 \mathrm{~km}$ crater define three barchans/crescentic

621 dune populations that, as with the Western Dune Field, suggest that the dune field formed by

622 flow convergence (Fig. 17A, Table 3). Population 1 brinklines, characterizing the dunes in the

623 NW (Fig. 18A), trend NNE $\left(18^{\circ}\right)$ with dune migration toward $\left(108^{\circ}\right)$ the interior. Population 2

624 brinklines, characterizing the eastern periphery dunes, trend NW $\left(324^{\circ}\right)$ with dune migration

625 again toward $\left(234^{\circ}\right)$ the interior. Population 3 brinklines characterize only dunes in the southern

626 reaches of the field, and these trend $\mathrm{NE}\left(50^{\circ}\right)$ with dune migration toward $\left(340^{\circ}\right)$ the interior.

627 Linear streaks in the sand sheets and linear dunes in the main dune field trend $327^{\circ}$, roughly

628 parallel to the dune field and potentially define the mean transport direction that gives rise to the

629 migration directions for dunes in Population 1-3, as expected within a sand-limited system (du

630 Pont et al., 2014).

$631 \quad$ 5.4.5 Southern Dunes

632 The southern floor of Gale Crater hosts a swath of bedforms $\sim 100 \mathrm{~km}$ long and $5 \mathrm{~km}$

633 wide (Fig. 19). Unlike the other fields, which form at the base of Mount Sharp, these dunes form

634 far from the mound and instead are associated with steep rim topography. Morphologies in this

635 region are again dominated by a continuum between barchan, crescentic, and linear dunes (Lee

636 and Thomas, 1995). Barchans dunes seen across the field form tear-drop morphologies that

637 elongate into linear dunes (Fig. 20D) or coalesce into crescentic dunes (Fig. 20B). Topography

638 from raised ridges and small hills clearly disrupts bedform morphology in southern Gale Crater 
639 (Figs. 20A, 20C). This region also appears sediment-starved. Bedrock plains can be seen in most

640 interdune areas, and dunes grade into sand sheets to the north and laterally (Fig. 20C).

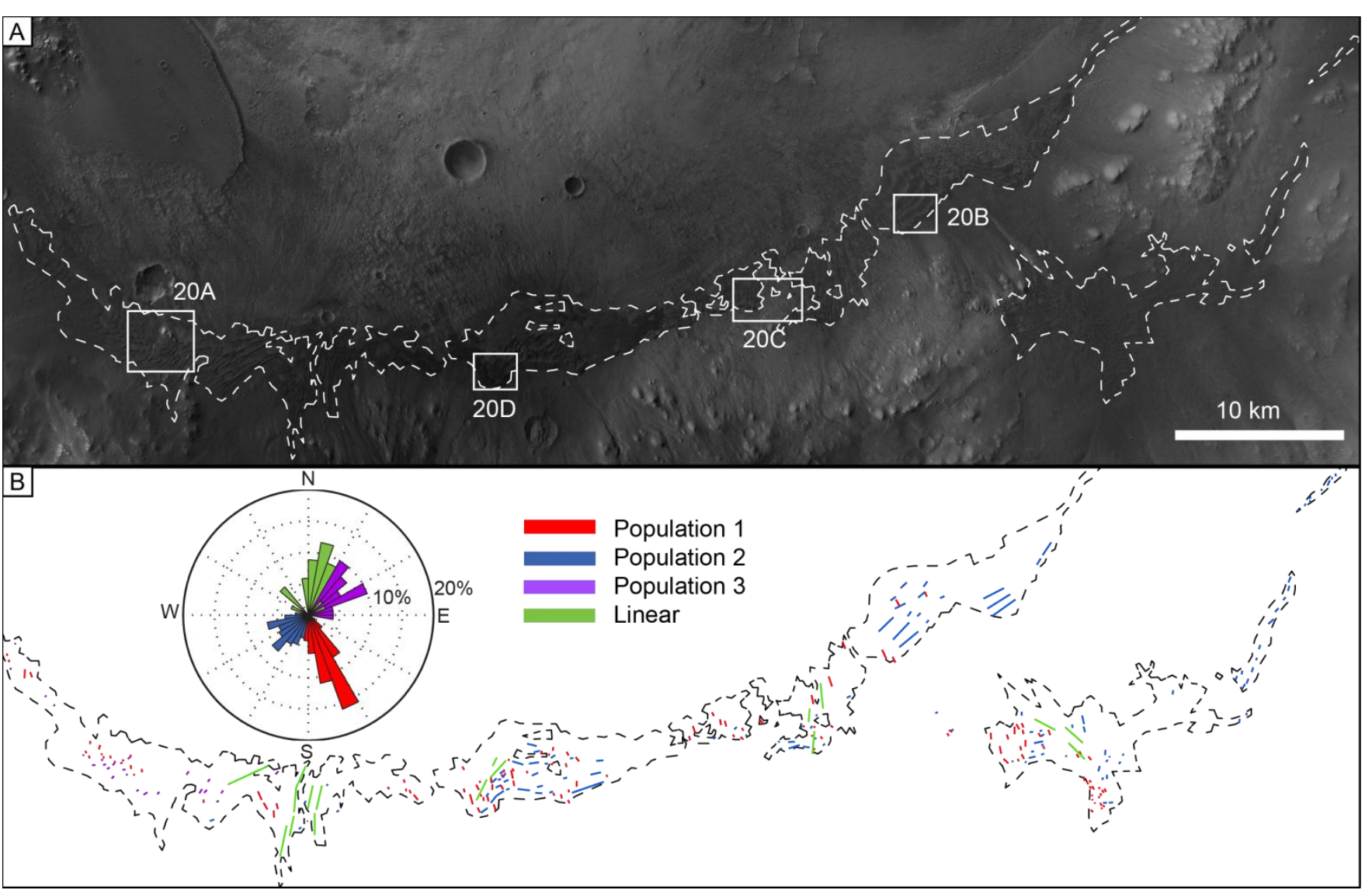

642 Figure 19. Southern Dunes A. Southern Dunes distributed across the floor of Gale Crater over

643 north-up oriented CTX mosaic. Dashed line corresponds with the dashed line in B and was used

644 to estimate the volume of dune sand in this region. Dunes are spread along the base of the crater

645 rim and absent close to the base of Mount Sharp. White boxes show the locations of panels in

646 Figure 20. B. Mapping of the Southern Dunes. Three populations of slipface orientation were

647 mapped in addition to the linear dunes. Populations are shown in the rose diagram in both the

648 north and south hemispheres to prevent overlap, and highlight the difference between north-facing

649 Populations 1 and 2 in this region and south-facing Populations 1 and 2 in the other dune fields.

650 Note the variation in linear dune trend from west to east that roughly follows normal to crater rim

651 curvature. 
653 Gale Crater (Fig. 19, Table 3). Three populations of brinkline orientations emerged, in addition

654 to the linear dune trends. In the west, the sharpest and most abundant brinklines (Population 1)

655 trend $\mathrm{NW}\left(339^{\circ}\right)$ with lee faces oriented toward the NE $\left(69^{\circ}\right)$. In the east, however, the sharpest

656 brinklines (Population 2) trend NE $\left(49^{\circ}\right)$ with lee faces oriented toward the NW $\left(319^{\circ}\right)$. The trend

657 of the linear dunes varies from west to east as well. Trending on average N-S $\left(05^{\circ}\right)$, the linear

658 dunes form perpendicular to the strike of the rim, swinging from a NE-SW trend in the west to a

659 NW-SE trend in the east. The radial pattern in the orientations of both the linear and barchan

660 dunes suggests that the formative winds for these southern dunes is associated with flow down

661 rim topography and toward the crater interior (Hobbs et al., 2010).

662 A third population of brinklines, trending NE $\left(55^{\circ}\right)$ but with SE-facing $\left(145^{\circ}\right)$ lee faces,

663 was observed only in the western end of the area (Fig. 19). Figure 20A shows where these

664 Population 3 slipfaces interact with Population 1 slipfaces, capturing the transition from

665 dominantly north winds in the Western Dune Field to south winds in the Southern Dunes region. 


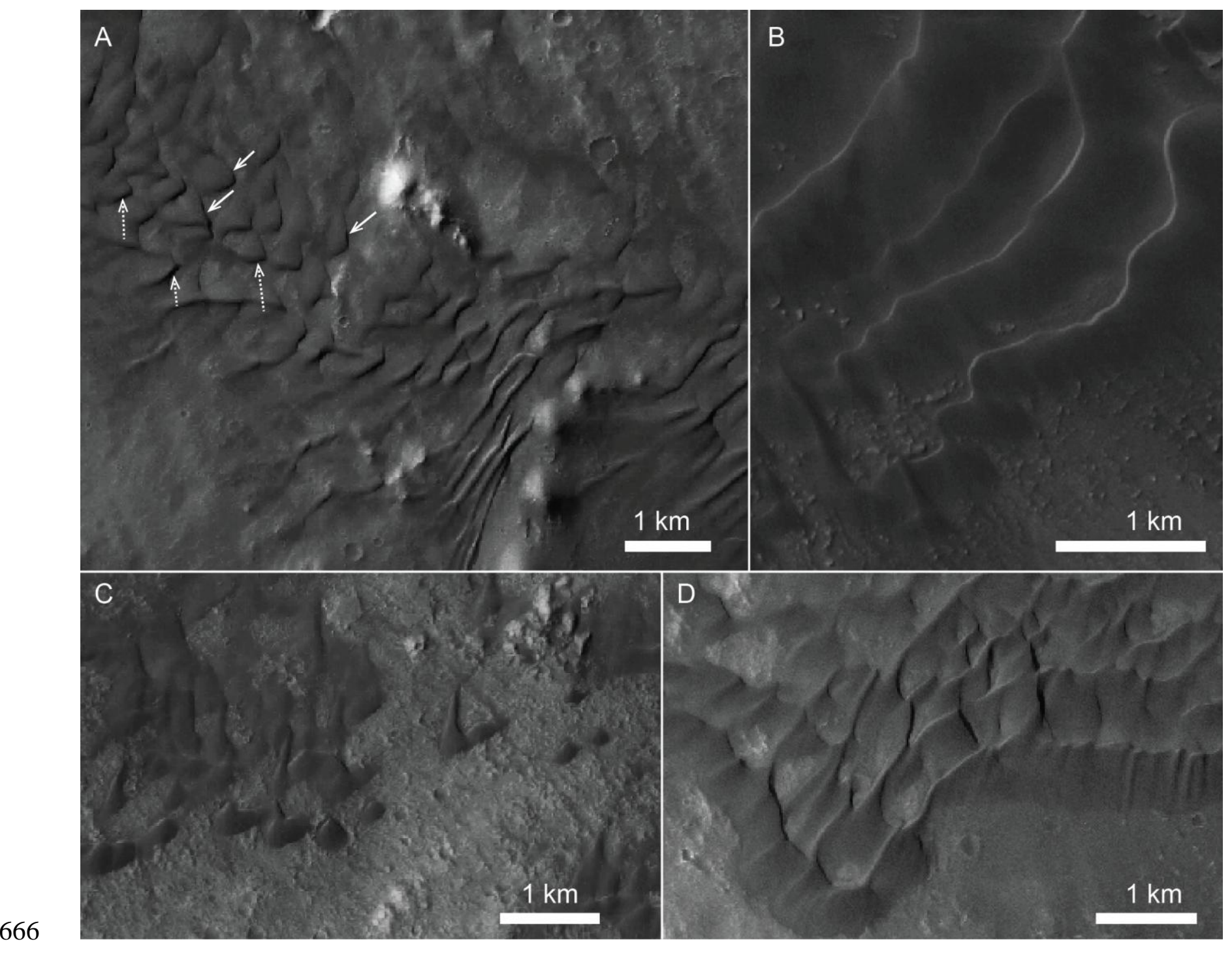

667 Figure 20. Dune morphologies in southern Gale Crater. A. Teardrop barchan dunes with slipfaces

668 from Populations 1 (solid arrows) and 3 (dotted arrows) depicting the transition from dominantly

669 north to southerly winds. Note divergence around hill topography and gradation into linear dunes

670 streaming toward the crater center (NNE). CTX image P15_006855_1746_XN_05S222W. B.

671 Crescentic ridges with steep NW-facing lee slopes form along from the opposite end of this

672 region from A. Note that the orientation has swung around such that inferred wind direction is

673 still normal to the crater rim. CTX image P01_001554_1754_XI_05S221W. C. Asymmetric

674 barchans elongating to the north and evidencing two populations of slipfaces (Populations 1 and

675 2). Note the bare interdune areas and gradation to sand sheets to the north. CTX image 
676 P01_001620_1749_XI_05S222W. D. Sinuous crescentic ridge splitting into tear-drop dunes as

677 defects elongate to the north. Note the two populations of slipfaces also observed in C. CTX

678 image P14_006644_1747_XI_05S222W. All images have been contrast stretched and are

679 oriented north-up.

680

$681 \quad$ 6. Surface observations

682 The traverse of Curiosity from its landing site at Bradbury Landing to the base of Mount

683 Sharp at Pahrump Hills allowed for field observations of landscapes that can otherwise only be

684 viewed from orbit. Toward the goal of characterizing this interpreted aeolian landscape, terrain

685 along the first 960 sols of the traverse was surveyed using Navcam mosaics to determine

686 landscape morphologies typical of this area of Gale Crater (Fig. 21). The observed landscapes

687 can be grouped into four broad categories: rocky plains, undercut bedrock, capped mesas, and 688 remnant hills (Fig. 22).

689 As of sol 960, Curiosity had traveled $8.3 \mathrm{~km}$ across the floor of Gale Crater, moving 690 generally up-section for a total elevation gain of $\sim 70 \mathrm{~m}$. The traverse aimed to capture the

691 diversity of landforms and chemistry observed from orbit, targeting several named waypoints to

692 characterize distinct units in the stratigraphy (Fig. 21). The four landscapes discussed in this

693 section are not unique to any one terrain or stratigraphic unit (Anderson and Bell, 2010;

694 Grotzinger et al., 2014), but rather are broadly representative of processes repeatedly seen

695 shaping the crater interior. In addition, some of the features observed in these landscapes indicate

696 a formative wind direction, thus adding to the body of wind directions inferred from orbital

697 observations. 


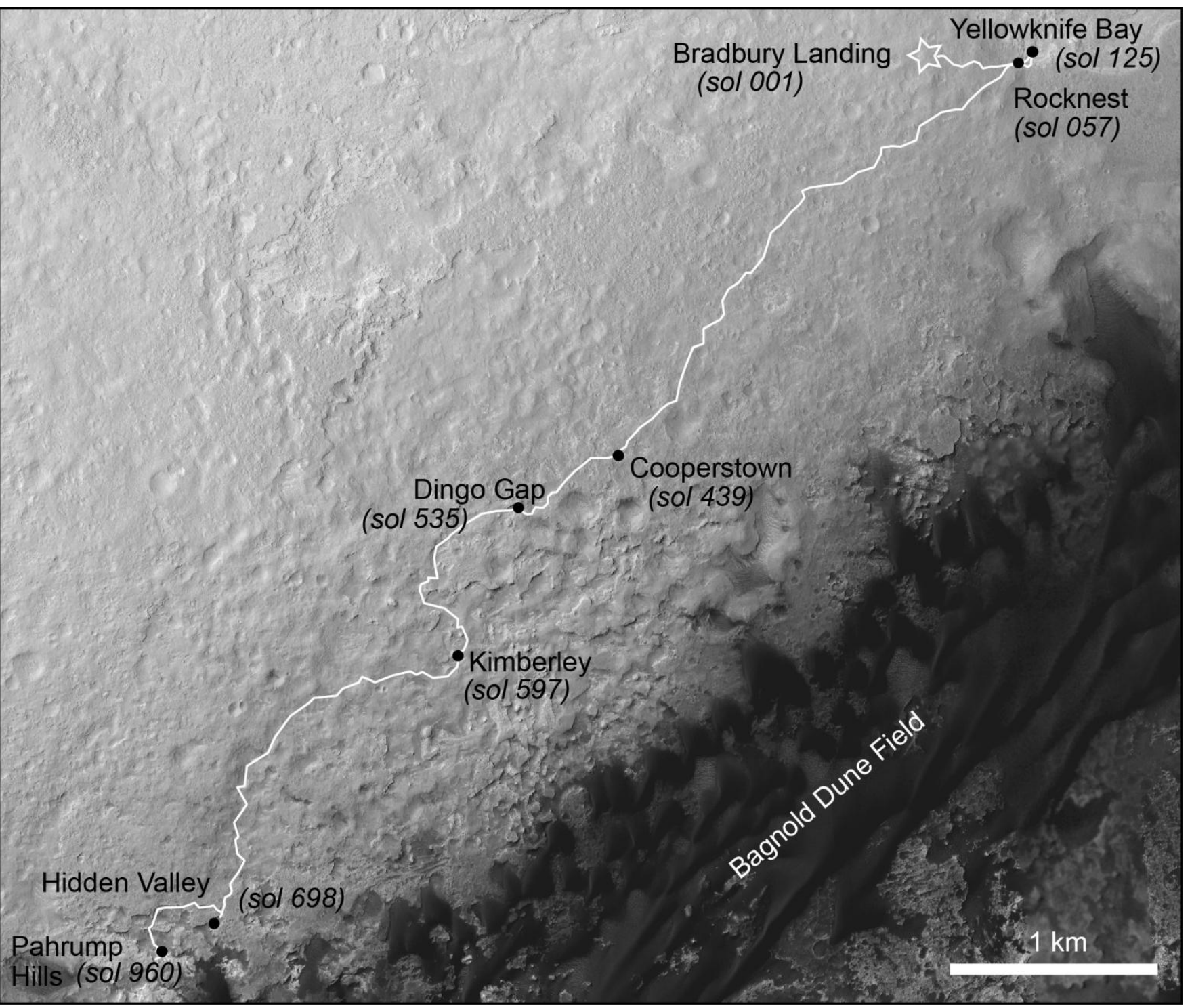

699 Figure 21. Curiosity rover traverse from sols 1-960 covering Bradbury Landing to Pahrump Hills

700 over HiRISE mosaic. Waypoints discussed in section 6, and approximate sol when they were first

701 reached, are indicated by the black dots. This image also covers barchan and linear dunes in the

702 main region of the Bagnold Dune Field. North is up. 


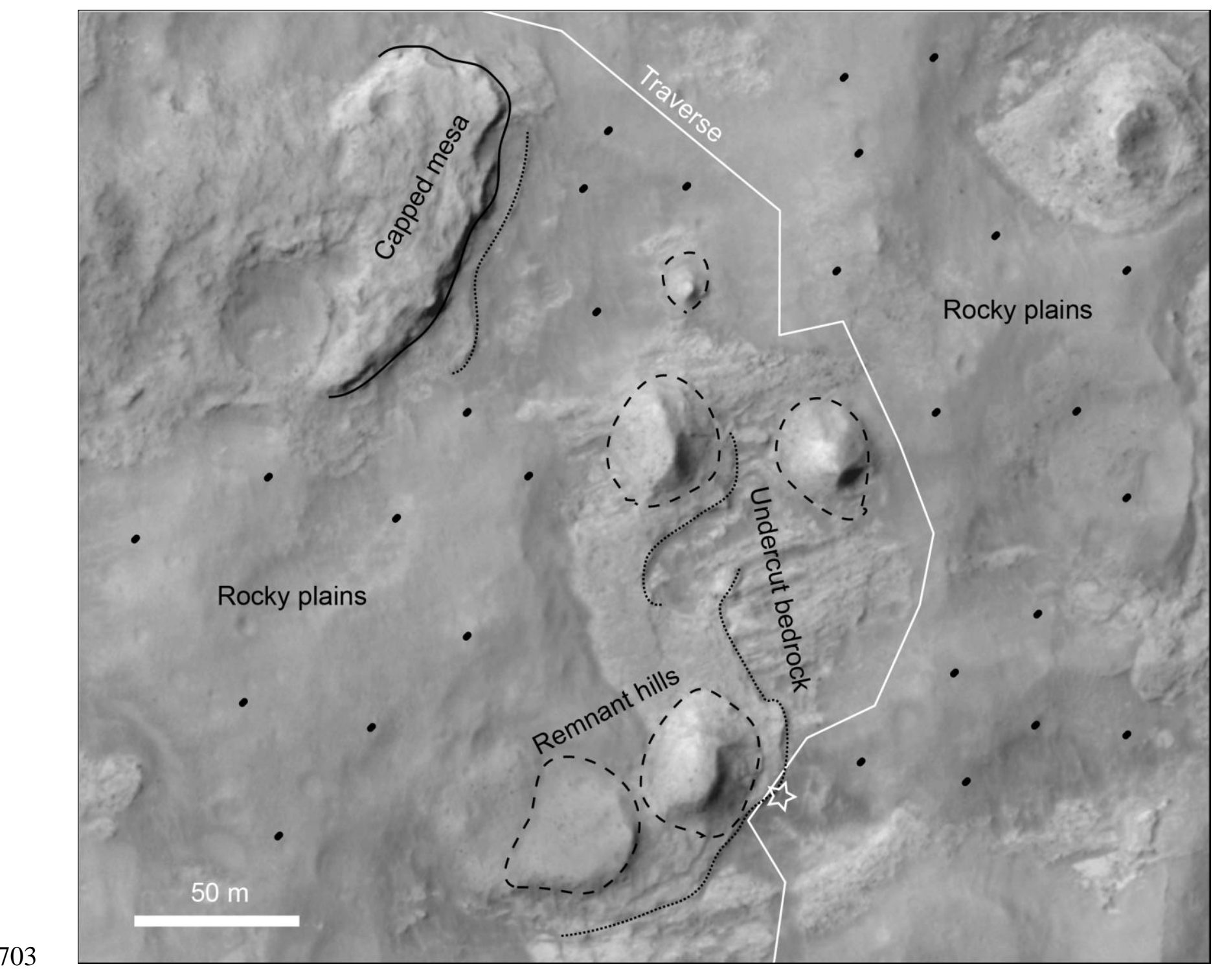

704 Figure 22. Orbital view of the four landscapes classified in section 6 interacting near the

705 Kimberley waypoint. This view shows all four stages of the erosional process. Capped mesas

706 (solid line) once overlaid the Kimberly (star), but have retreated to the northwest, leaving behind

707 remnant hills (dashed lines) and rocky plains (dotted area). At the eastern base of the remnant

708 hills we see where plains have eroded down to a new bedrock level, already forming low scarps

709 (dotted line) that will eventually become the capped mesas. White line shows the approximate

710 rover traverse, and the star indicates the rover position when Mastcam mosaic in Figure 29 was

711 taken. North-up oriented HiRISE image ESP_036128_1755. 
The most common landscape observed along the traverse can be characterized as a flat

715 plain with a varying amounts of scattered rock sitting atop a hard, dusty surface (Fig. 23A).

716 Rocky plains are captured in nearly all scenes from the first 500 sols, after which they are less

717 dominant, but still ubiquitously observed. The "Rugged" and "Hummocky Plains" terrain units,

718 mapped in Grotzinger et al. (2014), are overwhelmingly dominated by this landscape. The

719 distribution of rock across the surface appears pseudo-random with no clustering or preferential

720 alignment between rocks. Unassociated with outcrop, these rocks come from no obvious near-

721 field source and range in size from pebbles to decimeter-sized cobbles. Transport by wind of a

$722 \sim 3 \mathrm{~cm}$ clast was observed by the Viking 1 lander after a substantial storm (Arvidson et al., 1983),

723 but many cobbles on these plains are too large to have been transported by winds. Rather, rocks

724 on these plains are most similar to terrestrial desert pavements. Formed when fine material is

725 deflated away from a surface faster than rock is weathered and eroded, desert pavements armor

726 planar surfaces with tightly packed rock, slowing and ultimately halting aeolian deflation of the

727 surface (Cooke, 1970). In some cases, desert pavement can even be aggrading, raising surface

728 stones with kinetic sieving as trapped fines are vibrated to below the armored surface (McFadden

729 et al., 1987), similar to the hypothesized TAR formation mechanism (Bridges et al., 2015). The

730 Gale Crater surface rock armor is typically less closely-packed than some interlocking

731 pavements observed on Earth (e.g., Death Valley, CA; Haff, 2001), but the spatial density of

732 clasts on the surface (Fig. 23C) is sufficient to raise the aerodynamic surface roughness to

733 preclude most deflation, making these surfaces stable. 


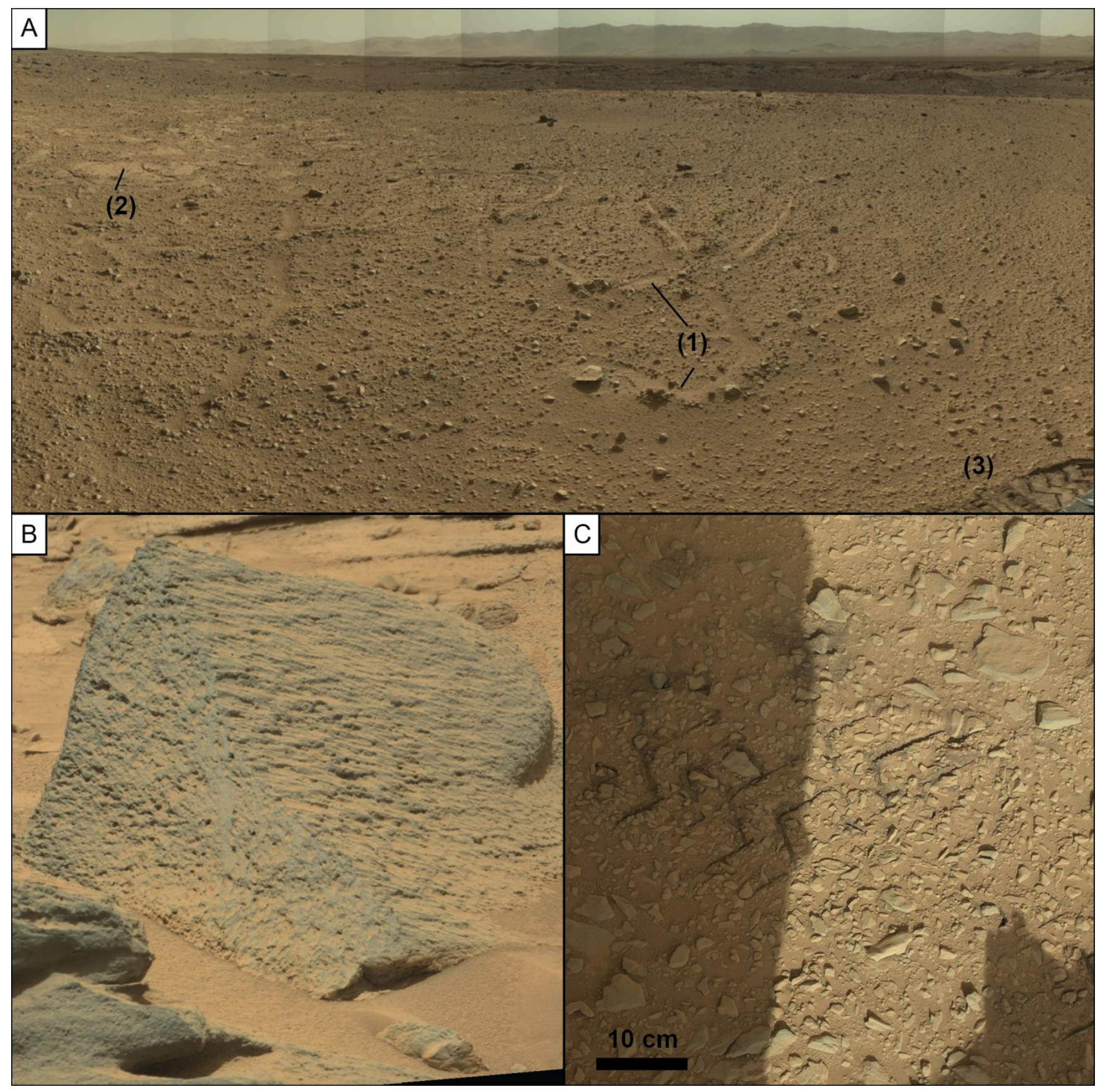

735 Figure 23. Rocky plains landscape. A. Mastcam mosaic of flat cobbled plains taken on sol 541

736 (mcam02134). Plains show dust-filled fractures from underlying bedrock (1) and exposures of

737 light toned bedrock (2). Foreground wheel track (3) is $30 \mathrm{~cm}$ wide (Mastcam mosaic starting at

738 0541ML0021340010203723E01_DRCX). B. Ventifact observed on sol 694. Note the elongated

739 pits and fluting on the right hand face as compared with the blunted (upwind) left face. Image is

$740 \sim 40 \mathrm{~cm}$ wide (Mastcam image 0694MR0029330020402220E01_DRCX). C. Light toned dust 
741 mantling rocky cobble surface is disturbed by wheel tracks that cut into the surface and reveal

742 dark-toned regolith (Mastcam mosaic from sol 456 starting at

743 0456ML0018370000201931E01_DRCX).

Pebbles and cobbles littering the rocky plains commonly exhibit fluting, lineations and

746 the distinctive polish characteristic of ventifacts formed from persistent aeolian abrasion (Fig.

747 23B), reflecting the long exposure of these stones on the surface (Laity and Bridges, 2009).

748 Indicators of wind direction, measured in ventifacts along the first 100 sols of Curiosity's

749 traverse, recorded a relatively wide NW-SW range of winds (Bridges et al., 2014). Comparison

750 between ChemCam observations of the rock called Jake Matijevic, a well-defined ventifact near

751 the Rocknest outcrop in Yellowknife Bay, and less abraded bedrock indicated that the high

752 lithium rind seen on the bedrock outcrop is absent on highly ventifacted surfaces (Bridges et al.,

753 2014). This argues that abrasion has removed the coating, or is resurfacing the rock faster than

754 the rind can form, confirming the dominance of physical weathering over chemical. Heavily

755 ventifacted rocks have also been observed in similar landscapes of rocky plains seen at the

756 Pathfinder (Greeley et al., 1999), Viking 1 (Arvidson et al., 1983), and Mars Exploration Rover

757 (MER) Spirit (Sullivan et al., 2008, fig. 50) landing sites.

758 In Gale Crater, rocky plains landscapes are typically devoid of bedforms, consistent with

759 the interpretation that these surfaces are highly deflated, and show a paucity of transport-

760 available sand at the surface. Unlike the abundant ripples observed on rocky plains by Spirit

761 (Sullivan et al., 2008, fig. 28), only occasional sand shadows were encountered along Curiosity's

762 traverse across the rocky plains (Fig. 24A). Sand shadows are linear accumulations of sand that

763 are deposited in the lee of obstacles even on sand-starved surfaces (Hesp, 1981), thus making

764 them reliable indicators of the last significant wind direction. Measurement of the orientation of

76569 sand shadows, from Yellowknife Bay to Pahrump Hills, generated a mean orientation of $09^{\circ}$ 
766 with standard deviation of $0.5^{\circ}$ (Fig. 24B, Table 2), thereby indicating a narrowly constrained

767 north formative wind. Ranging from $12 \mathrm{~cm}$ to $3.74 \mathrm{~m}$ long, these accumulations are similar to

768 those observed at the Pathfinder landing site (Greeley et al., 1999, fig. 2). Despite an abundance

769 of available obstacles, sand shadows and other bedforms were absent from the plains from sols

$770 \quad 361-369,429-439$, and 634-644.

771 The Rocknest sand shadow, observed in Yellowknife Bay from sol 57 to 100, is the most

772 studied sand shadow to date in conjunction with the first scooping activities by Curiosity (e.g.,

773 Blake et al., 2013). Also interpreted to have formed by northerly winds, this sand shadow

774 exhibits a 2-3 mm thick armored surface formed by 1-2 $\mathrm{mm}$ rounded, dust-rimmed grains, which

775 formed cohesive rafts during the excavations (Minitti et al., 2013). In contrast to the armored

776 surface, the sand shadow interior consists of fine sediment largely below the resolution of

777 MAHLI $(\sim 150 \mu \mathrm{m})$. This contrast between the coarse armored surface and the fine dusty interior

778 suggests that the sand shadow may have originated as a coarse-grained feature that subsequently

779 grew by the infiltration of dust and fine sand into the interior, similar to the dynamics of TARs

780 described above. 


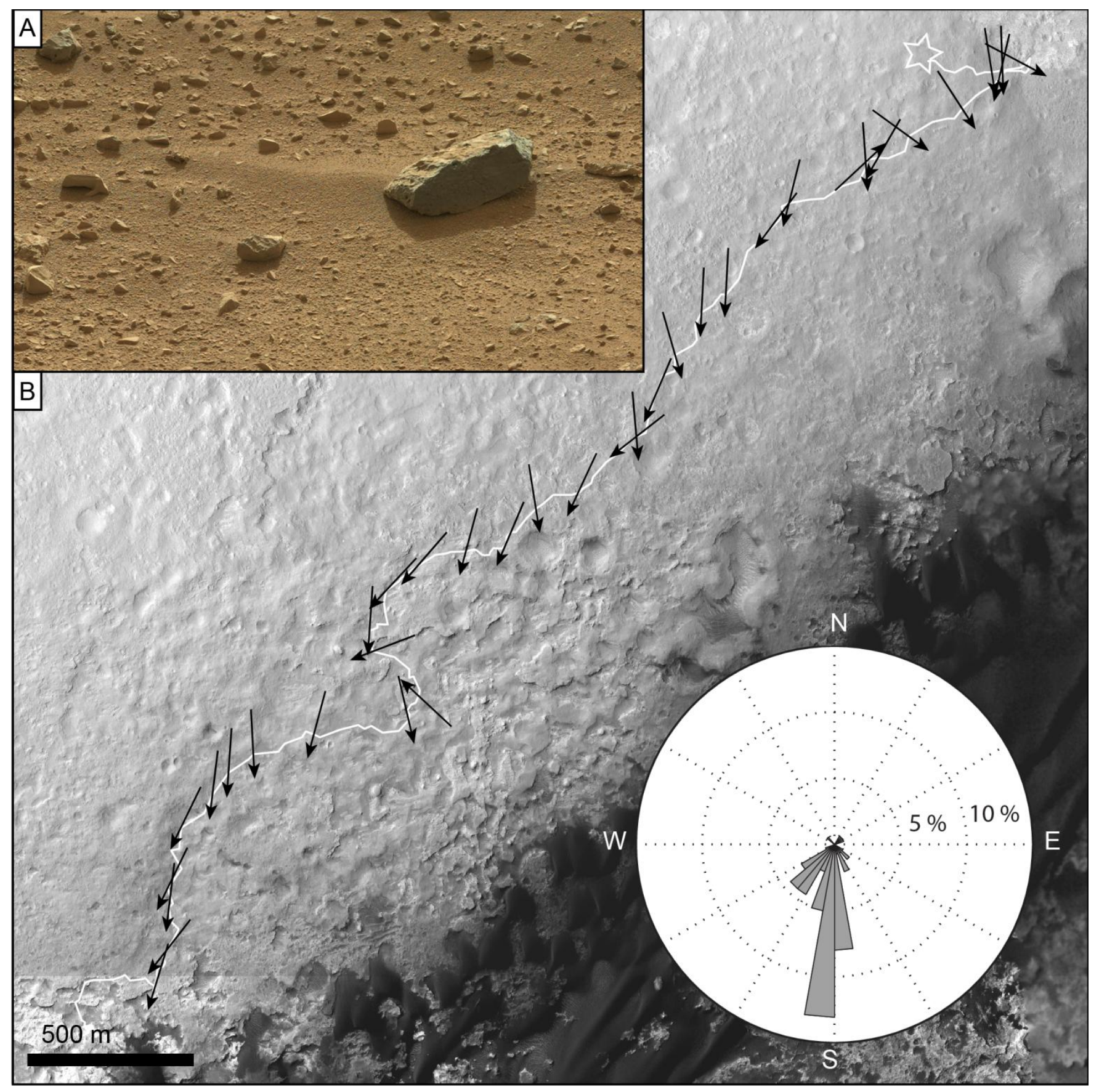

782 Figure 24. Sand shadow surface observations. A. Sand shadow (50 cm long) accumulating behind

783 a float rock obstacle in rocky plains (sol 333 Mastcam image

784 0333ML0013490070107979E01_DRCX). B. HiRISE map of the Curiosity traverse with

785 measured sand shadow orientation superimposed on location of observation. Where multiple sand

786 shadows were observed in a single mosaic, the average orientation is shown. Rose diagram shows

787 the orientation and inferred upwind azimuth of all 69 measured sand shadows. 
Bedrock outcrops are seen consistently every few hundred meters for the length of the

790 traverse. Exposures are typically heavily fractured, with fractures forming local sediment traps

791 filled with dust or sand (Fig. 25). Similarly fractured outcrops were observed near Home Plate by

792 Spirit (Sullivan et al., 2008, fig. 43), and at the Burns formation by Opportunity (Grotzinger et

793 al., 2005, fig. 4). Exposures of bedrock are commonly undercut, forming small scarps, and

794 decimeter-scale relief shelters N-S trending sand shadows (Fig. 25). Float rocks can be seen on

795 top of some exposed bedrock, and in clusters at the base of small scarps, tending to decrease in

796 size away from the outcrop. Outcropping bedrock is typically surrounded by rocky plains, and

797 scalloping and polish of bedrock surfaces evidence long exposure to aeolian abrasion.

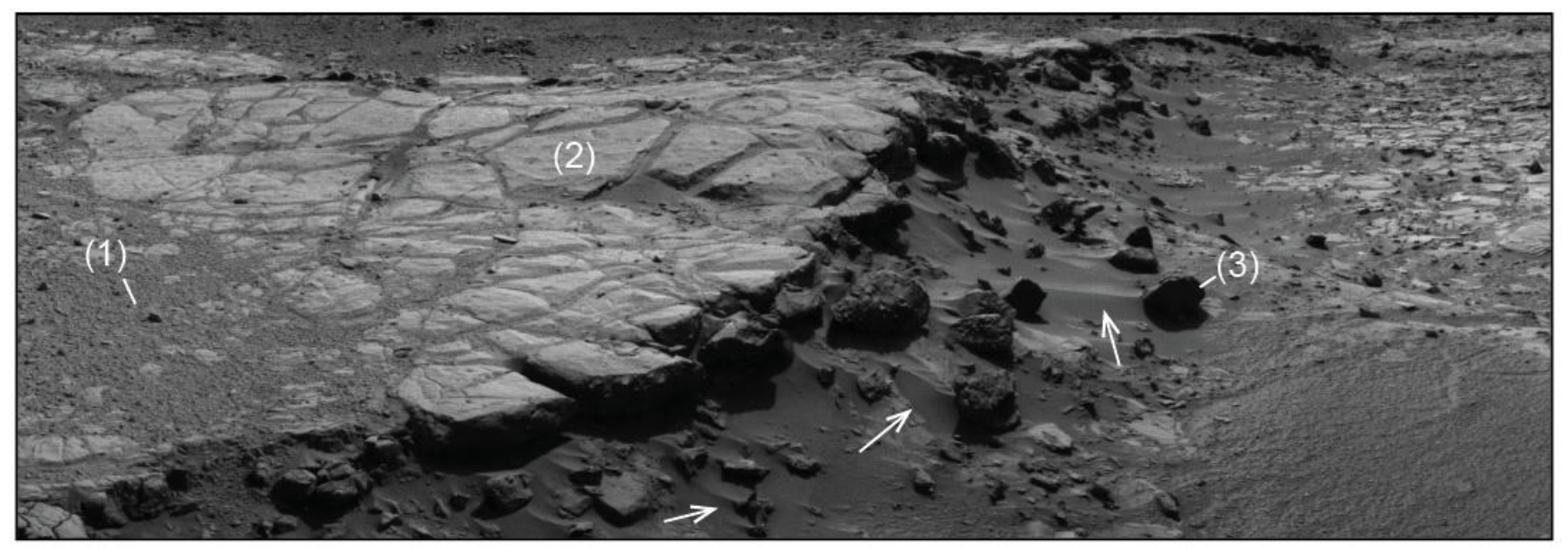

799 Figure 25. Undercut bedrock outcrop at Cooperstown (sol 440 Navcam mosaic centered on image

800 NLB_436560260EDR_F0220000NCAM00259M). Float rock is visible atop bedrock exposure

801 (1). Exposed surface is heavily fractured with sand and dust filling most fractures (2). Arrows

802 indicate small sand shadows forming in the lee of scarp float boulders, including the $40 \mathrm{~cm}$

803 boulder indicate by (3).

804

Close examination of exposed bedrock in Yellowknife Bay revealed streamlined nodules in the bedrock surface. Similar to concretions observed by Opportunity in the Burns formation 
807 (Grotzinger et al., 2005), these diagenetic features range from 1-3 $\mathrm{mm}$ in diameter. Nodules in

808 the Sheepbed mudstone (Grotzinger et al., 2014) appear partially exhumed with one blunted edge

809 and opposing tail of bedrock all aligned locally in the same direction $\left(345^{\circ}\right)$ (Fig. 26). These

810 features are interpreted as caused by direct wind abrasion of bedrock from NW winds (Stack et

811 al., 2014). A surface exposure age of $78 \pm 30$ Ma was measured on the Sheepbed mudstone at the

812 Cumberland drill target (Farley et al., 2014). Cumberland is located $\sim 1 \mathrm{~m}$ from an overlying

813 scarp of Gillespie Lake unit, implying a relatively slow modern erosion rate of $\sim 1 \mathrm{~m}$ of scarp

814 retreat per $100 \mathrm{Ma}$.

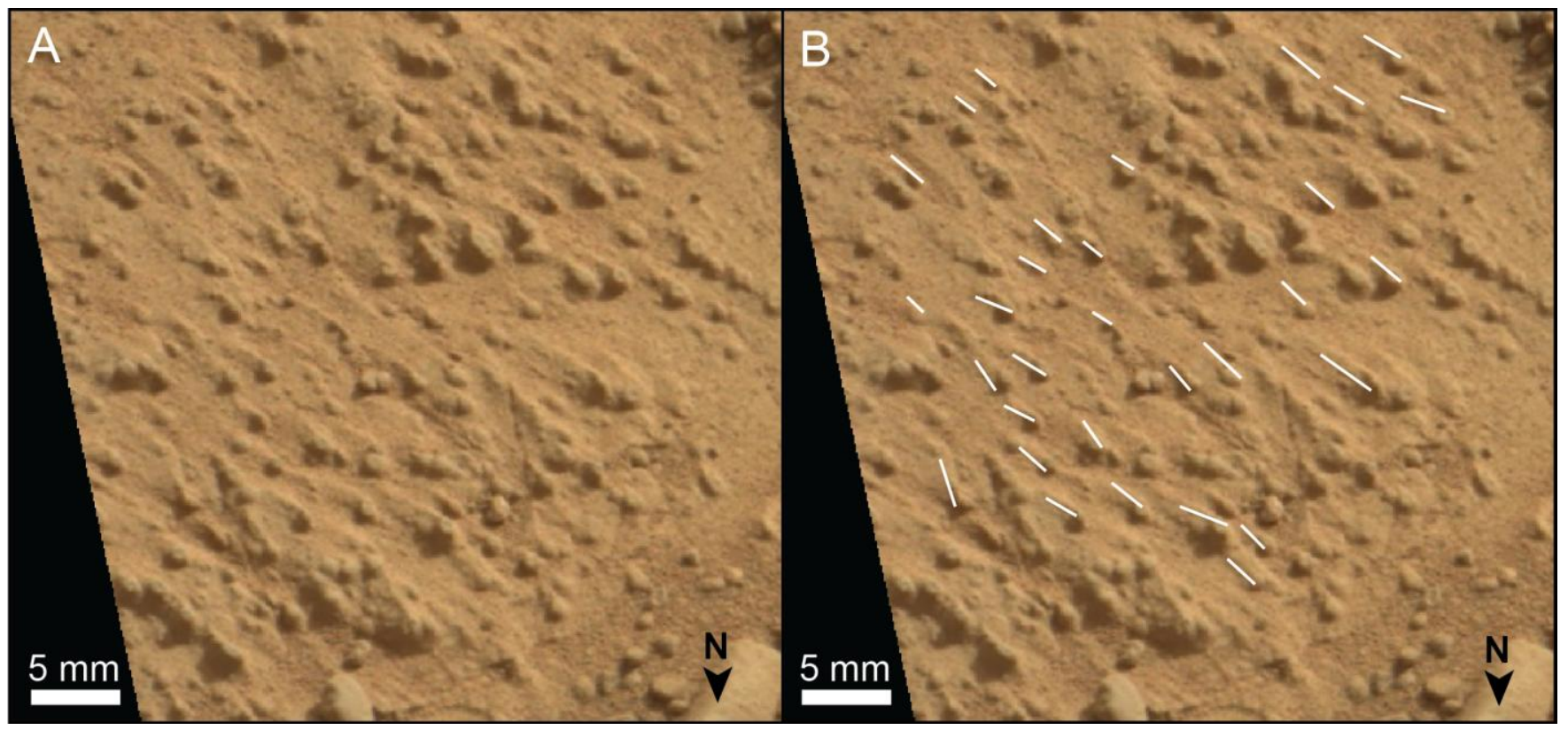

816 Figure 26. Streamlined nodules in the Sheepbed mudstone found at Yellowknife Bay. A. In-place

817 nodules being exhumed from bedrock (sol 298 Mastcam mosaic starting at

818 0298MR0012480590203737E01_DRCX). B. Same image as A but with orientations of

819 streamlines superimposed on leeward tails. Average orientation is $345^{\circ}$ with inferred wind from

820 the NE. 
Capped mesas become increasingly common along the traverse (Fig. 27). First observed

826 on either side of Dingo Gap, mesas commonly form along the edges of the "Cratered Surface"

827 terrain unit (Grotzinger et al., 2014), and on opposing sides of valleys (e.g., Hidden Valley,

828 Dingo Gap). These flat-topped landforms are defined by 2-4 $\mathrm{m}$ high hills capped by scarps of

829 retreating competent rock typically $\sim 1 \mathrm{~m}$ thick. Below the scarps, decimeter- to meter-sized

830 boulders, apparently sourced from the caprock, armor dusty slopes. Similar observations of

831 eroded float rock are seen coming from capping layers in the Burns Formation along the

832 Opportunity traverse (Grotzinger et al., 2005). In Gale Crater, ventifacting was observed on float

833 rock near the base of slopes, but fluting and polish textures could not be resolved nearer to the

834 hilltops. Sand shadows were commonly observed in association with basal slope boulders, and in

835 some cases the topography sheltered fields of ripples (Fig. 27).

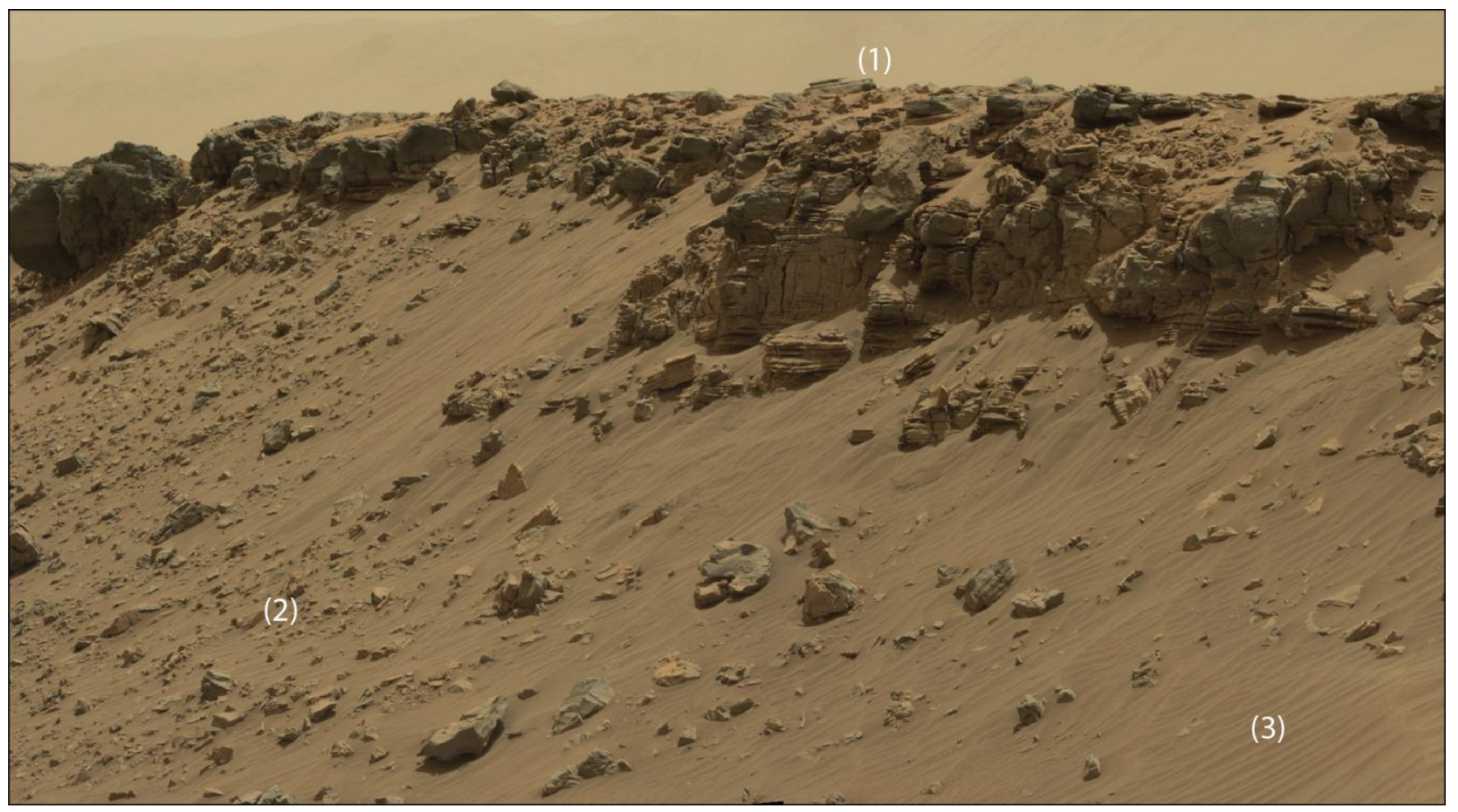

837 Figure 27. Retreating scarps cap the northwest wall of Hidden Valley, forming a flat-topped mesa

838 (1). Boulders on the lower slopes (2) are partially covered by ripples (3) and appear to be sourced 
839 from the resistant caprock. Vertical relief in this image is $\sim 4 \mathrm{~m}$ (sol 707 Masctam images

840 0707ML0030050030304604E01_DRCX and 0707ML0030050020304603E01_DRCX).

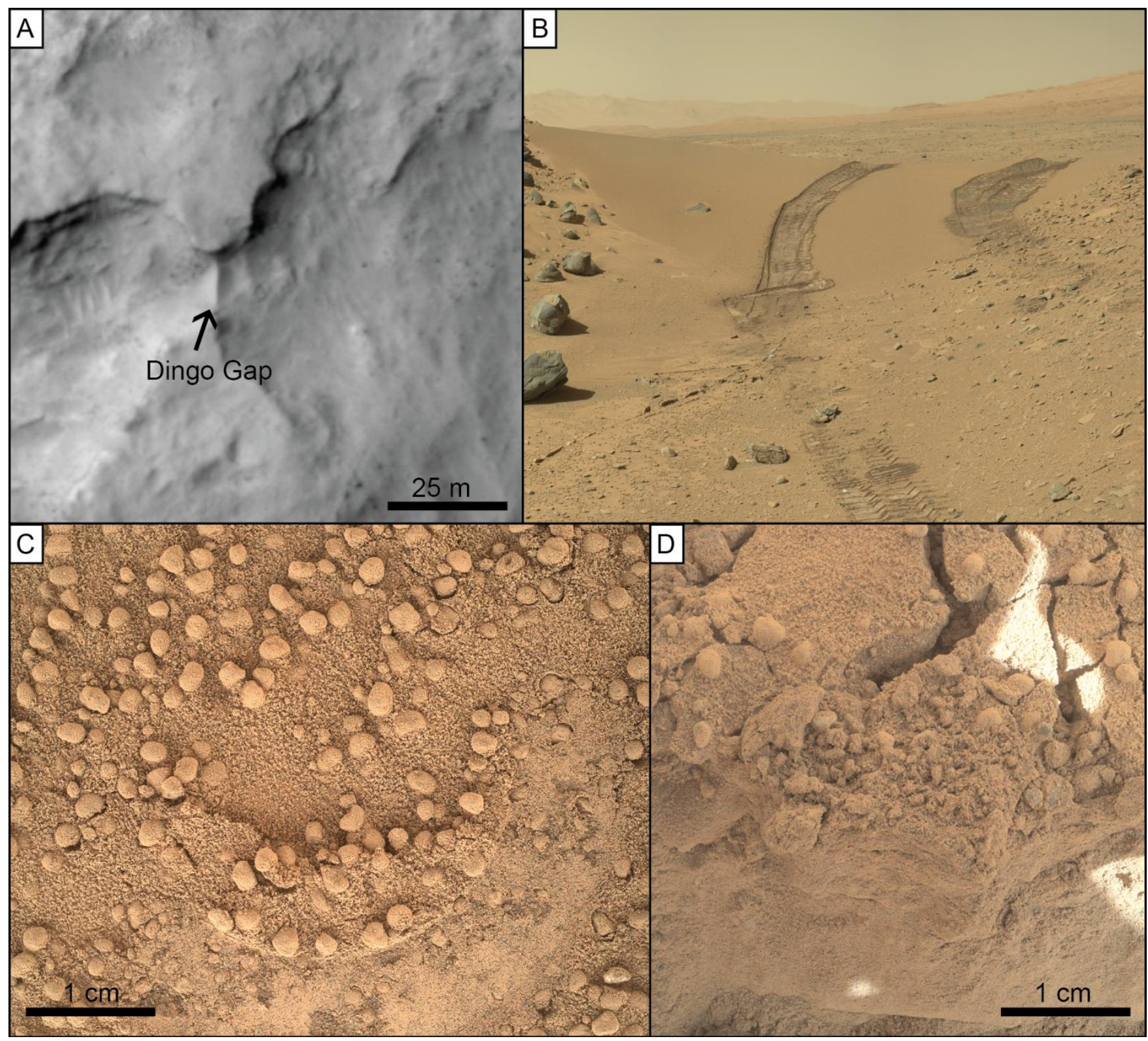

842 Figure 28. Dingo Gap TAR. A. Valley-spanning TAR at Dingo Gap as observed from orbit

843 (HiRISE image ESP_036128_1755). B. East-facing Mastcam mosaic of Curiosity tracks across

844 Dingo Gap TAR. Tracks are $\sim 30 \mathrm{~cm}$ wide (sol 538, starting image

845 0538ML0021240000203532E01_DRCX). C. MAHLI image of Dingo Gap surface. Rounded

846 grains cover $\sim 20 \%$ of the TAR surface in contrast to more tightly packed armoring seen on the

847 Rocknest sand shadow. Note the thin coating of dust on all grains. Crescent impression on the 
surface is from Curiosity's Alpha Particle X-ray Spectrometer (APXS) on target Barker (sol 531,

850 shows subsurface to be dominated by dust-sized fines, rafting at the dusty surface implies some 851 cohesion of dust (sol 531, 0531MH0003470010201183C00).

On sol 535 of its traverse, Curiosity crossed the TAR named Dingo Gap, spanning 12

$854 \quad 1-2 \mathrm{~mm}$ grains covering $20 \%$ of the surface, similar to the Rocknest sand shadow but not as

855 tightly packed (Fig. 28). These armoring grains are similarly coated in dust that fell away after

856 contact with rover hardware. Imaging of the wheel tracks revealed the interior of the TAR to be

857 dominated by the fine dust particles, with some rounded grains supported in a dust matrix.

858 Surface armoring was also observed by Spirit on the El Dorado ripple field, but surface grains

859 were only 300 microns, and much more closely packed (Sullivan et al., 2008). Despite their

860 differences, bedforms such as the Rocknest sand shadow, the Dingo Gap TAR, and the El

861 Dorado ripples appear to represent a common class of Martian bedforms sharing coarse-grained

862 armored surfaces and fine interiors. The well-rounded grain surfaces indicate that these sands are

863 not freshly eroded from bedrock, but rather have been transported sufficiently to generate near-

864 spherical rounding. As described above, these bedforms may also share a dynamic of surface

865 stabilization with continued vertical growth by dust infiltration.

$866 \quad 6.4$ Remnant hills

Small hills, not capped by erosionally resistant rock layers, increase in frequency along

868 the traverse in conjunction with the increasing frequency of the capped mesas. Characterized by

869 rounded tops, slopes on remnant hills in Gale Crater are typically shallower than slopes below

870 capped mesas, but total relief is similar (1-3 m). These hills exhibit the same armoring of

871 decimeter- to meter-scale boulders seen below capped mesas (Fig. 29). Float rock was measured

872 in a $\sim 50 \mathrm{~m}$ transect from the top of a hill just beyond Dingo Gap, down the slope, and across the 
873 plains until float rock size became uniform with the surrounding area (Fig. 30). Choosing the

874 largest float rocks in the scene, rocks identified in the high resolution Mastcam mosaic were

875 measured using stereo Navcam mosaic. Distance from the rover was used as an approximation

876 for distance along the transect, and is differenced to be relative to the hilltop in Figure 30.

877 Measured diameters decreased in size away from the hilltop, following roughly an exponential

878 decay. Though resolution in this area was not high enough to resolve ventifact textures,

879 ventifacts were observed at the base of remnant hills later in the traverse (e.g., at the Kimberley).

880 No observations of larger hill-boulders were captured in enough resolution to see fluting or pits.

881 Small accumulations of sand in the form of ripples or sand shadows were again found against

882 these hills, but remnant hill TARs have not yet been observed. Spirit observations of McMurdo

883 capture rock-covered hillslopes with similar morphology (Greeley et al., 2008).

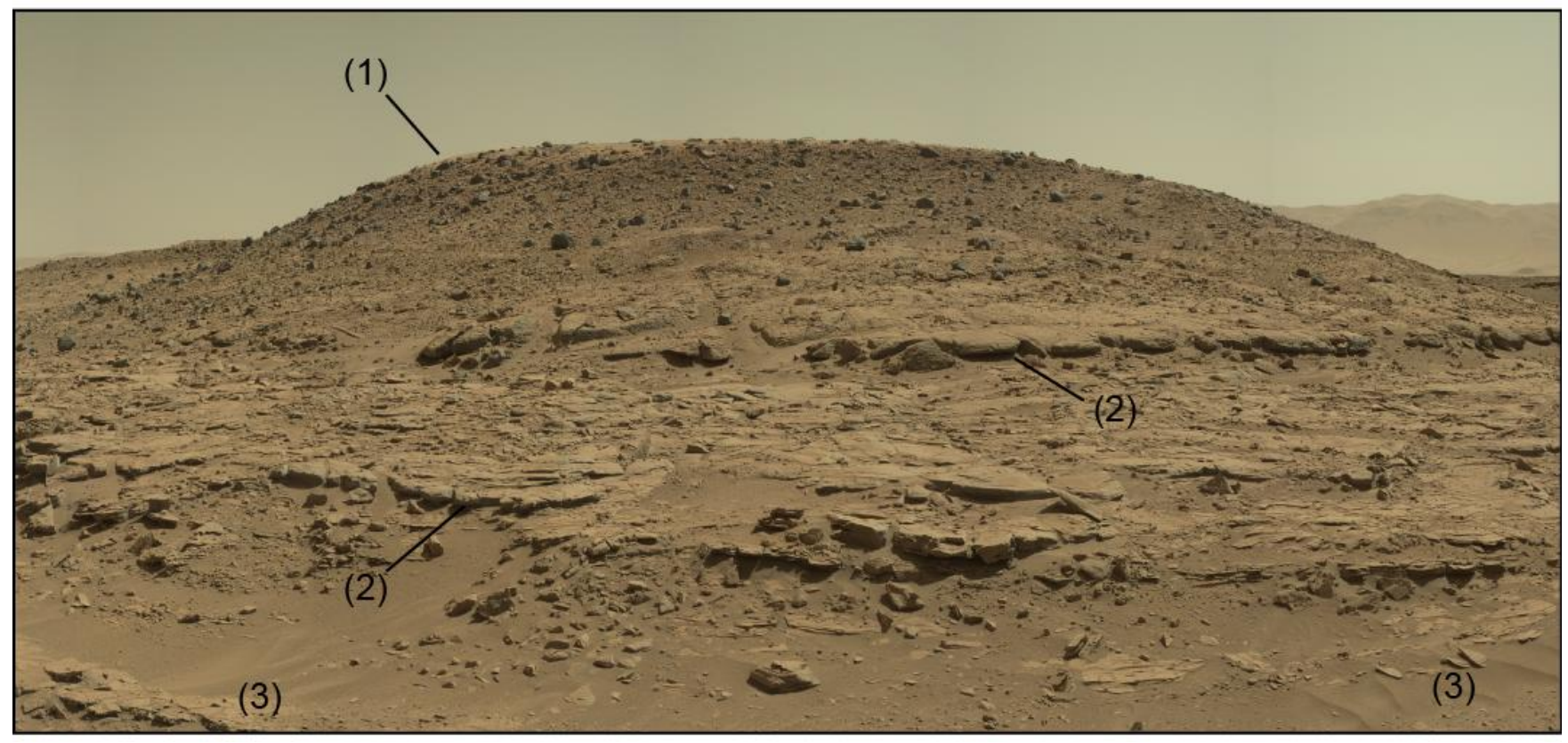

885 Figure 29. Remnant hill observed at the Kimberley. Boulders cover the rounded hillslopes (1),

886 and outcrops of retreating bedrock scarps can be seen in the foreground (2). Relief in exposed

887 bedrock shelters $10-20 \mathrm{~cm}$ sand shadows (3). East-facing image was taken at the location 

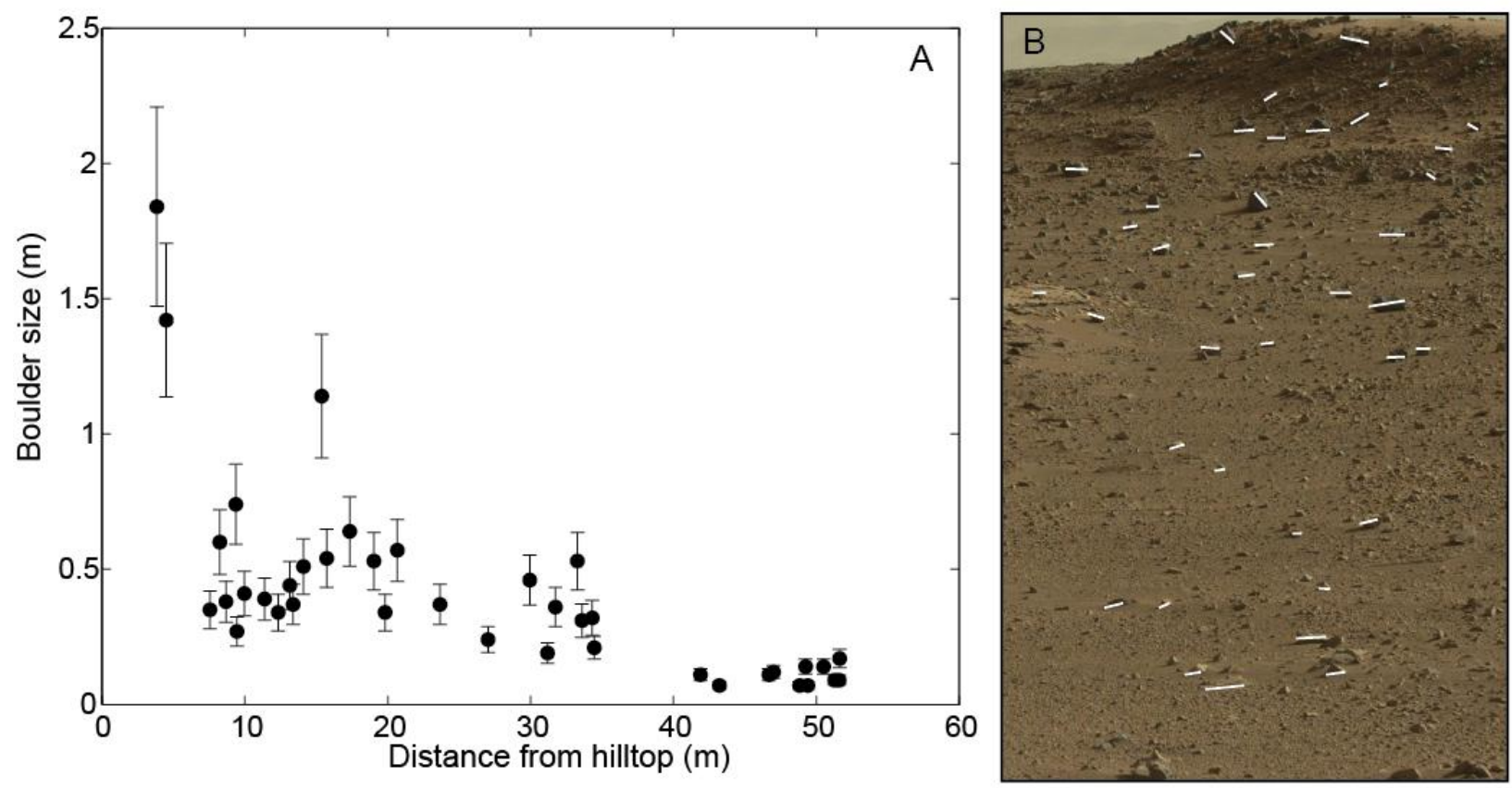

891 Figure 30. Float rock measurements on a remnant hill A. Graph shows decreasing rock size with

892 distance from the hilltop shown in B. Rover-relative distances were calculated and used as a

893 proxy for distance along the transect. The size decrease is interpreted to reflect less first-cycle

894 aeolian erosion on young hilltop rocks and more extensive erosion on older rock further from the

895 degraded scarp. B. Transect and measured float on a remnant hill just beyond Dingo Gap (sol

896538 Mastcam image 0538ML0021250000203544E01_DRCX). White lines indicate the

897 diameters measured on the largest boulders at various elevation levels in the scene.

898

899

\subsection{Landscape evolution by wind and gravity}

The four landscapes observed along the traverse are proposed to represent a spectrum of

901 progressive stages in a cycle of landscape evolution where aeolian erosion and gravity-driven

902 mass wasting, coupled with physical weathering, compete to level the surface. These processes, 
903 operating over the last $3 \mathrm{Ga}$, are taken as necessary and sufficient for the removal of the $\sim 6 \times 10^{4}$

$904 \mathrm{~km}^{3}$ of sediment from Gale Crater needed for the exhumation of Mount Sharp.

905 Physical weathering by impact bombardment and thermal stressing appears to be the

906 main cause of ubiquitous fractures observed along the Curiosity traverse and elsewhere on Mars

907 (e.g., Sullivan et al., 2008; Grotzinger et al., 2005). Gale Crater has been subjected to impact

908 bombardment since its formation at 3.6 Ga (Le Deit et al., 2013; Hartmann and Neukum, 2001).

909 At the surface, small craters in Gale are seen ringed by blocks of fractured rock (Newsom et al.,

910 2015, fig. 8). Millennia of thermal cycling further weathers competent Martian rock as repeated

911 expansion and contraction stresses and fractures the material (Viles et al., 2010). Mars

912 temperature fluctuations occur on a variety of scales, from diurnal to Milankovitch, around a

913 cold mean annual equatorial temperatures of 220 K (Schorghofer, 2008). Bedding planes and

914 polygonal fractures provide additional zones of weakness along which bedrock can fracture.

915 Unlike on Earth, first-cycle aeolian erosion of bedrock is significant on Mars, and occurs

916 because of long exposure of surfaces and the increased energy of grain impacts (Kok, 2010) even

917 with infrequent significant wind events. Aeolian abrasion is evident in Gale Crater from

918 yardangs, ventifacts, fluting and polished surfaces of both bedrock and float, but first-cycle

919 abrasion of rock and continued physical weathering must also account for the diminishing of

920 clast size on the surface with distance from bedrock. In all the traversed landscapes, sand was

921 absent except where it was trapped by local topography, and the volume of sand held in dune

922 fields is a tiny fraction of the amount of sediment created during the exhumation of Mount

923 Sharp. This relative paucity of loose sand on the surface of Gale Crater indicates that potential

924 sand transport from the surface greatly exceeds the production of sand on the surface

925 ("availability-limited" system of Kocurek and Lancaster, 1999). Although rates of erosion have

926 varied greatly in Gale Crater, over geologic time wind transport has been sufficient to exhume

927 nearly all of weathered material from the crater. 
929 Figure 31. Exposed fractured bedrock is subjected to aeolian abrasion and continued physical

930 weathering. Fractures in the outcrop form nucleation points for increased weathering and

931 erosion, funneling local flows that widen and deepen fractures by sand abrasion. Continued

932 breakdown of bedrock and aeolian undercutting cause gravity failure of overhanging scarps.

933 Weathering and abrasion then reduce the size of these fallen clasts. When no longer covered by

934 resistant caprock, underlying less-resistant layers deflate at a much faster rate. Areas initially

935 floored by resistant caprock deflate down as caprock retreats to mesas. When the caprock is

936 completely eroded, remnant hills with a residual cover of disjointed rocks remain. Hill

937 topography is smoothed to flat, and the final surface resulting from this denudation is a desert

938 pavement. On this armored surface, deflation is severely limited, but breaks in the pavement

939 pattern provide holes where erosion is enhanced and the pavement can be eroded from both the

940 surface and sides. Disruptions in the pavement can stem from impacts, fluvial dissection, or the

941 natural uneven distribution of surface clasts. Over geologic time, first cycle erosion by abrasion

942 can also break through the pavement, shrinking cobbles and exposing the surface below.

943 Continued surface deflation by physical weathering and abrasion of surface clasts must

944 ultimately lead to underlying bedrock exposure and a renewal of the cycle.

945 Despite the absence of fluvial or tectonic processes, the proposed landscape evolution

946 model reflects the same patterns of erosion in classical terrestrial landscape evolution models

947 (e.g., Davis, 1899; Gilbert, 1909). Both historical and the proposed aeolian model show the back-

948 stepping that occurs in differentially resistant layers, and the progressive rounding of hillslopes

949 to flat surfaces. The observation of King (1953) that all fluvially-sculpted landscapes share the

950 same morphologies seems to hold true even when the sculpting fluid is air. The major difference

951 is instead interpreted to be the time scale over which these landscapes form. 
A

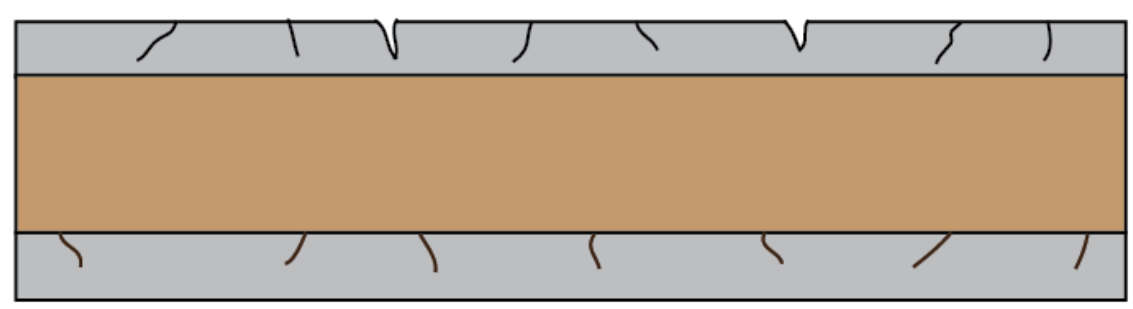

B

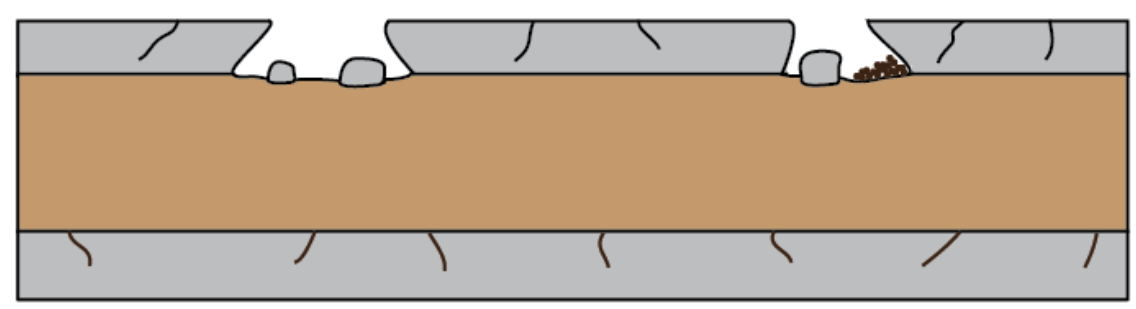

C

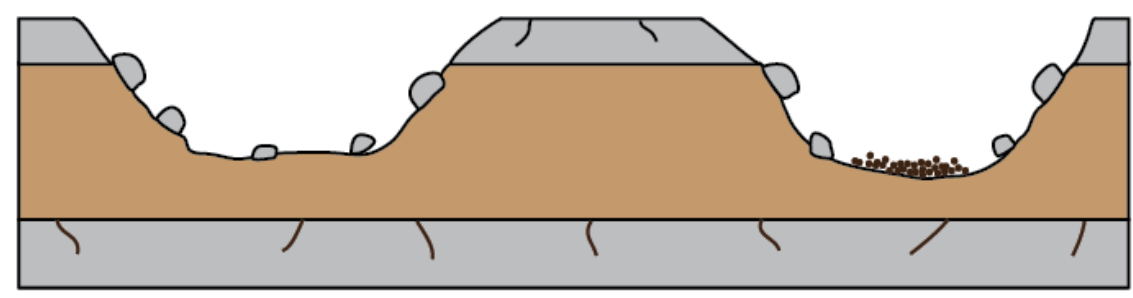

D

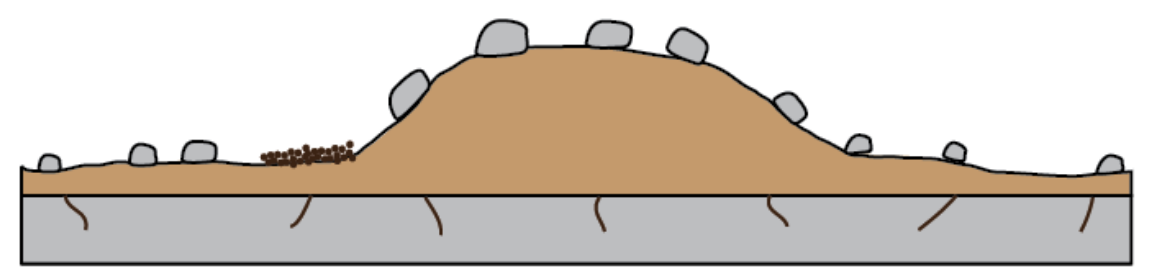

Regolith

Bedrock

Sand

Fractures

$\mathrm{E}$

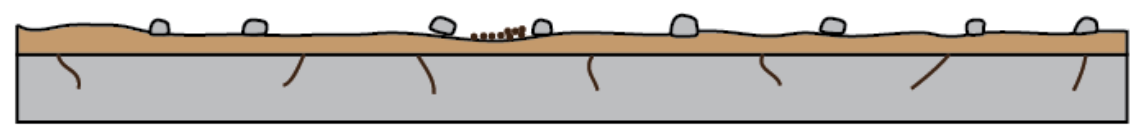

953 Figure 31. Landscape evolution model. A. Bedrock is exposed at the surface and fractures form

954 nucleation points for enhanced erosion. B. Fractures in bedrock widen and cut downward through

955 the competent layer, eventually undercutting the outcrop and pieces of outcrop spall off. Some

956 sand shadows accumulate in the lee of local topography. C. Underlying layers erode faster than

957 bedrock, creating mesas capped by fractured bedrock. Float rock spalled off of the capping unit 
coats the hillslope. In general, rocks further from the hilltop are older, more heavily ventifacted,

959 and smaller. Sand shadows and larger bedforms are sheltered behind meter-scale topography. D.

960 Eventually the capping unit is eroded away, leaving a remnant hill covered by ventifacted

961 fragments of the capping unit. Float rock far from the hilltop has been subjected to more aeolian

962 abrasion than more recently formed float near the hilltop, creating a decrease in rock size down

963 the hill. Sand still accumulates in this meter-scale relief. E. Hill regolith is winnowed away,

964 leaving a heavily ventifacted desert pavement that slowly abrades and deflates until new fractured

965 bedrock is exposed.

966

967 7. Discussion and conclusions

$968 \quad 7.1$ Reconstruction of Gale Crater wind regime over time

969 The range of aeolian features in Gale Crater must have formed over orders of magnitude

970 of time. Although their exact age is unknown, the oldest wind indicators are the exhumation of

971 Mount Sharp, its streamlined morphology, and the position of the Gale Crater wind streak, all of

972 which are consistent with northerly formative winds. These long-term wind indicators require

973 first-cycle erosion of bedrock by the wind, as also directly reflected by the yardangs and

974 ventifacts. Yardangs are overwhelmingly oriented N-S, consistent with northerly winds. At much

975 finer spatial and temporal scales, streamlined nodules carved from bedrock at Yellowknife Bay

976 also indicate a northerly wind. Ventifact measurements, some of which are on bedrock, are less

977 consistent and the interpreted westerly winds are at odds with the other wind indicators. Bridges

978 et al. (2014) suggested that the ventifacts may reflect rare high-speed winds, but given the

979 consistency of the other wind indicators, the ventifacts more likely reflect flow affected by local

980 topography or subsequent clast movement. With the exception of ventifacts, therefore, the long

981 time-scale wind indicators overwhelmingly argue that winds from the north have persisted over

982 the geologic-scale time spans over which Mount Sharp formed (Fig. 32). 


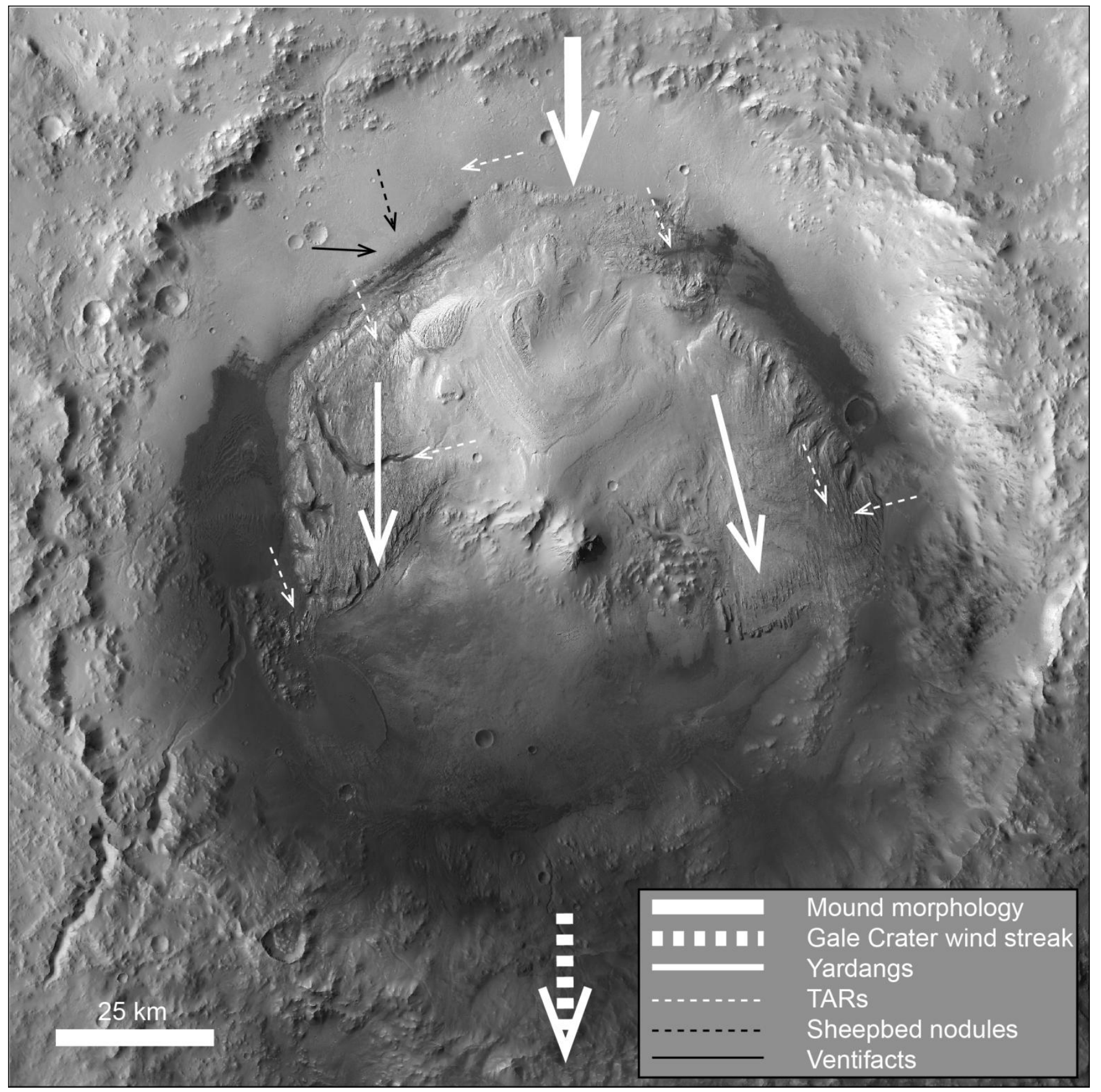

984 Figure 32. Inferred wind directions from aeolian features forming over long time-scales in Gale

985 Crater. Yardang orientation varies slightly $\left(12^{\circ}\right)$ from the east to west of Mount Sharp, and is

986 interpreted to result from flow divergence around the $5 \mathrm{~km}$ high mound. TAR orientations are

987 shown here in representation of the two dominant modes at locations where TARs are most dense.

988 Both TARs and ventifacts cover a wide range of inferred winds and are thought to be poor

989 indicators of regional circulation because of the influence of topography. The Gale Crater wind 

streak extends south of this image (Fig. 3). North-up oriented HRSC background mosaic is also

991 used in all following figures.

992

993

Inferred wind directions from features forming over shorter time-scales reveal a regional

994 north wind that is profoundly modified by crater-scale secondary flow. Crater rim and mound

995 topography delineate the crater moat, and features in the moat are divided between northern and

996 southern halves (Fig. 33). Primary wind from the north is argued by the: (1) deflationary

997 pavements and absence of sand dunes at the sand-starved northern apex of Mount Sharp, (2)

998 orientation of sand shadows, and (3) net southward transport of dunes in the Bagnold and

999 Northeastern dune fields. In the northern half of the crater, secondary flow deflection around the

1000 topography of Mount Sharp is reflected by the: (1) channelization of dune fields along the flanks

1001 of Mount Sharp, (2) SW-facing slipfaces in the Bagnold Dune Field, and (3) SE-facing slipfaces

1002 in the Northeastern Dune Field. A second component of secondary flow is evident by: (1) crater-

1003 rim downward flow evident in all the northern half dune fields, and (2) mound downward flow

1004 evident in the Western Dune Field. The interplay of the primary and secondary winds, plus the

1005 intrusion of southerly winds characteristic of the southern half of the crater moat, appear

1006 responsible for the flow convergence evident in the Western and Northeastern dune fields. In the

1007 southern half of the crater floor, small wind streaks on the crater rim and the dominant

1008 orientation of the Southern Dunes must arise from crater-rim downward flow. The convergence

1009 of northern and southern moat winds regimes is again evident in the northwestern area of the

1010 Southern Dunes. The TARs are not addressed here because their orientations appear strongly

1011 controlled by local topography, thus making them poor general wind indicators. It is nevertheless

1012 notable that TAR orientations, measured largely in the northern half of the crater, are dominated

1013 by two directions $\left(71^{\circ}\right.$ and $\left.337^{\circ}\right)$ interpreted to result from the $\mathrm{NW}$ and $\mathrm{NE}$ winds evident from

1014 the other indicators. 


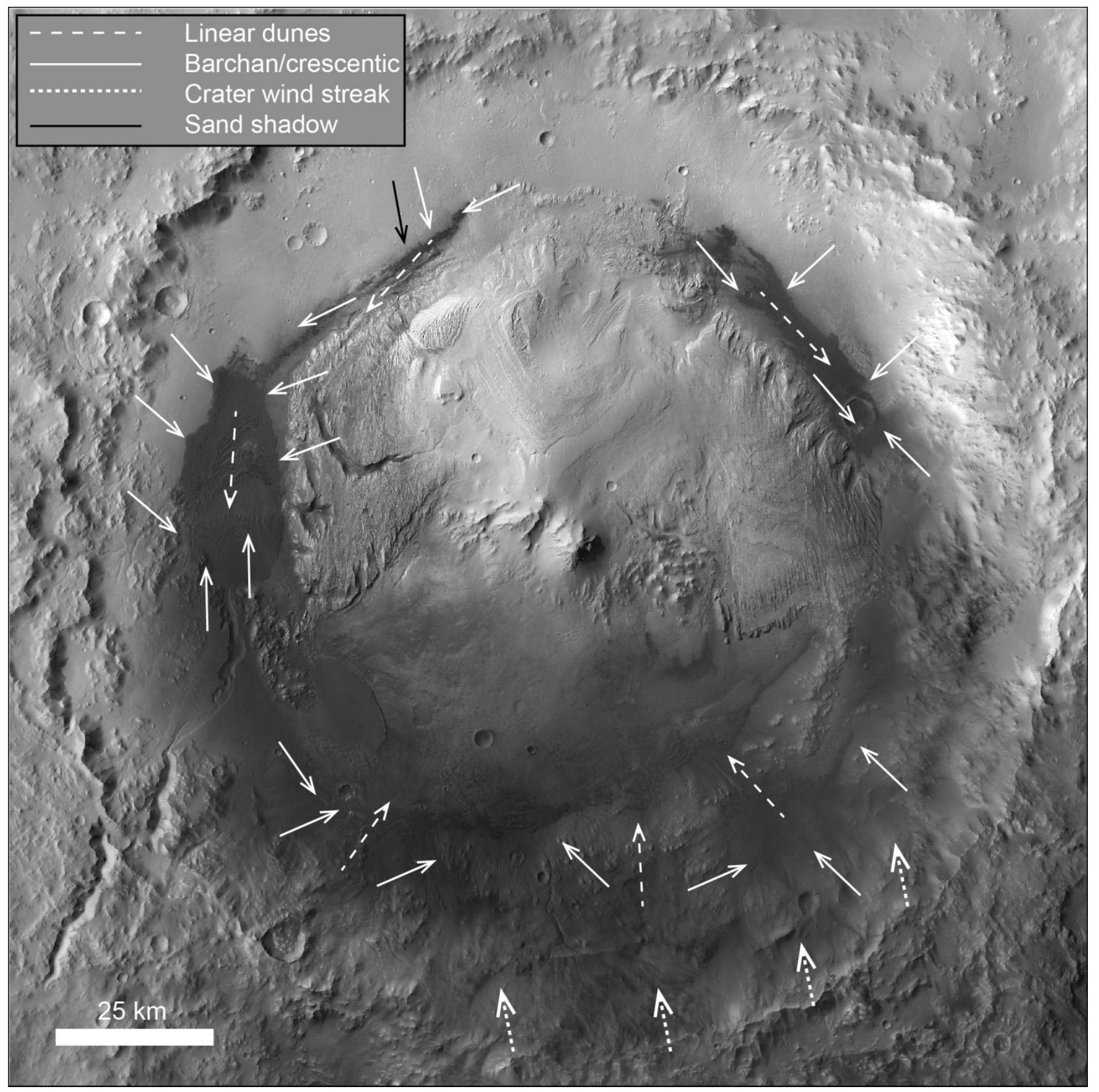

1016 Figure 33. Inferred recent wind directions from aeolian features forming on short time-scales in

1017 Gale Crater. Wind indicators are divided, with interpreted northerly winds dominating the

1018 northern half and southerly winds dominating the southern half. Note the relative association of

1019 wind direction and crater rim orientation in the south, and the apparent divergence of wind

1020 directions around Mount Sharp in the north. 
1023 regional winds, topography-deflected secondary winds, and topography-created katabatic winds

1024 (Fig. 34). The relative impact of each component has evolved with exhumation of the mound

1025 and, potentially, global climate. Regional primary winds from the north must have dominated

1026 during the span of time over which Mount Sharp was exhumed, and emergence of Mount Sharp

1027 by excavation would have greatly altered the wind pattern through time. As the moat was

1028 formed, topography-deflected secondary flows included funneling of the wind along the mound 1029 flanks, and development of a wake in the southern lee of Mount Sharp. Downward flows on the 1030 crater-rim and mound are interpreted as topography-created katabatic winds, which have been 1031 emphasized in circulation models of Gale Crater (Tyler and Barnes, 2013; Hobbs et al., 2010).

1032 Katabatic winds form from atmospheric density gradients caused by fluctuations in temperature, 1033 and can set up in opposition to large-scale regional flows (Rafkin et al., 2001). Such winds 1034 would flow radially into the crater moat from the top of the crater rim, as is evident from the 1035 recently-formed wind indicators, or from the mound, as is evident in the Western Dune Field 1036 (Fig. 33). Katabatic winds would reinforce regional winds in the north, and lee return flows 1037 behind Mount Sharp in the south. Current wind indicators argue for a modern dominance of 1038 crater-rim katabatic winds (Fig. 33), in contrast to the long-time wind indicators that argue for a 1039 dominance of regional northerly winds (Fig. 32). 


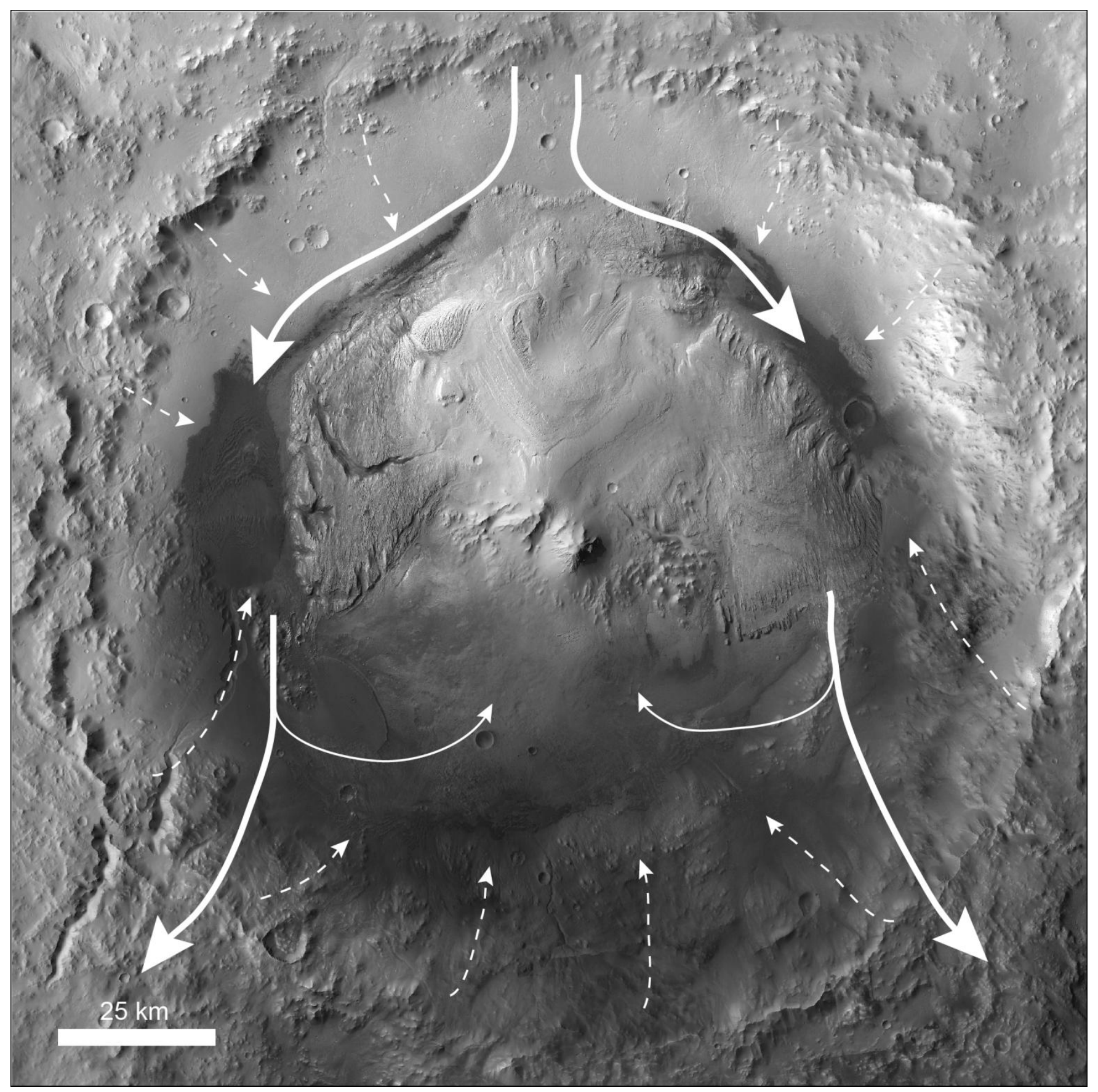

1041 Figure 34. Circulation model for Gale Crater interior. Regional northerly winds (solid lines)

1042 diverge as they encounter Mount Sharp, funneling between mound and rim to the east and west.

1043 Regional flows shed eddies and turbulent vortices in the wake of Mount Sharp. Katabatic slope-

1044 flow winds (dashed lines) flow inward down rim topography, dominating short time-scale

1045 morphologies. Eddies and katabatic flows oppose regional winds and account for convergence in 
1046 the Western and Northeastern Dune Fields. Line thickness and arrow size are schematic

1047 representations of relative wind strength.

1048

1049 The above analysis is based upon the interpretation of geomorphic features that span a

1050 range of spatial and temporal scales. Modeling of wind circulation in Gale Crater is typically

1051 conducted for a particular set of conditions, rather than integrated over geologic spans of time.

1052 Hobbs et al. (2010) modeled circulation in Gale at $\sim 4 \mathrm{~km}$ scale resolution under dust-storm

1053 atmospheric conditions. The model revealed a dominance of regional NNW winds and

1054 topography-driven deflection in agreement with the above results. During the two modeled

1055 Martian sols, both katabatic (downslope) and anabatic (upslope) winds occurred, but these were

1056 weak compared to the regional NNW winds. Tyler and Barnes (2013) modeled the mean diurnal

1057 cycle in Gale Crater over 20 sols and at the same $\sim 4 \mathrm{~km}$ resolution. Their model highlights the

1058 diurnal changes in wind regime, characterized by regional north winds deflected by topography

1059 in the daytime, with strong katabatic winds flowing down Mount Sharp and the crater rim at

1060 night. These models both agree with the conclusions of this study, but further indicate that

1061 variations in the crater wind regime are ongoing, rather than changing gradually with the

1062 exhumation of Mount Sharp. The suggested daily variations in wind regime are perhaps poorly

1063 represented in even the shortest time-scale aeolian features, and as such, our interpretation

1064 represents an integrated view of winds in Gale Crater over geologic time.

10657.2 Aeolian-dominated landscape evolution

1066 At all scales of observation, from orbital images to surface views by Curiosity, the

1067 landscape in Gale Crater is dominated by aeolian features. Evidence for subaqueous processes

1068 occurs only in the stratigraphic record and in relict or exhumed features, whereas no

1069 contemporary features were observed characteristic of landscapes eroded by water (e.g.,

1070 dendritic drainage networks). This supports the representation of the landscape of Gale Crater as 
one fashioned by physical weathering, gravity, and aeolian processes. Most of the landscape

1072 represents a sand-starved, erosional system, but the available sand is organized into aeolian

1073 bedforms comprising a relatively small volume of sediment. This observation is consistent with

1074 the interpretation that the inferred processes (i.e., physical weathering, downslope wasting, and

1075 aeolian abrasion and deflation) are sufficient for moat excavation and Mount Sharp exhumation

1076 from an initially filled crater.

1077 The landscape patterns observed at the surface argue that denudation occurs in

1078 progressive stages from continuous bedrock-capped layers, to separated bedrock-capped mesas,

1079 to remnant hills capped by bedrock clasts, to desert pavements on rocky plains. Processes that

1080 drive the system include bedrock fracturing by impacts and thermal stress, aeolian abrasion that

1081 diminishes bedrock and widens fractures, and aeolian deflation that removes sediment.

1082 Preferential aeolian erosion of less resistant beds creates overhanging scarps that fail due to

1083 gravity. One implication of these processes is that first-cycle erosion of bedrock, directly evident

1084 by yardangs and ventifacts, is otherwise widely present on the Martian surface. A second

1085 implication is that desert pavements, generally considered as stable features on Earth, must

1086 undergo continued aeolian abrasion and deflation, and are ultimately removed on Mars. Given

1087 the documented extremely slow weathering rates on Mars and the apparent infrequency of high-

1088 energy wind events, landscape evolution in Gale Crater must be accredited to either the

1089 geologically long periods over which a surface is exposed, or much higher rates of surface

1090 denudation under a very different climatic regime at the time of initial excavation.

1091 Acknowledgements

1092 This material is partly based upon work supported by the National Aeronautics and Space

1093 Administration, under Contract No. 1450036 issued through the MSLPS Program, and the

1094 National Science Foundation Graduate Research Fellowship under Grant No. DGE-1110007. 
Authors thank the MSL team, Fred Calef for his work on orbital image mosaicking, and

reviewers James Zimbelman and Simone Silvestro for their helpful feedback and suggestions.

\section{References}

1098

1099

1100

1101

1102

1103

1104

1105

1106

1107

1108

1109

1110

1111

1112

1113

1114

1115

1116

1117

1118

1119

1120

1121

1122

1123

1124

1125

1126

1127

1128

1129

1130

1131

1132

1133

1134

1135

1136

1137

1138

1139

1140

Anderson, R., and Bell, J., 2010. Geologic mapping and characterization of Gale Crater and implications for its potential as a Mars Science Laboratory landing site. Mars 5, 76-128.

Arvidson, R., Guinness, E., and Lee, S., 1979. Differential Aeolian Redistribution Rates on Mars. Nature 278, 533-535.

Arvidson, R. E., Guinness, E. A., Moore, H. J., Tillman, J., and Wall, S. D., 1983. Three Mars Years: Viking Lander 1 Imaging Observations. Science 222, 463-468.

Atwood-Stone, C., and McEwen, A., 2013. Avalanche slope angles in low-gravity environments from active Martian sand dunes. Geophys. Res. Lett. 40, doi:10.1002/grl.50586.

Balme, M., Berman, D. C., Bourke, M. C., and Zimbelman, J. R., 2008. Transverse Aeolian Ridges (TARs) on Mars. Geomorphology 101, 703-720.

Bibring, J. P., Langevin, Y., Mustard, J. F., Poulet, F., Arvidson, R., Gendrin, A., Gondet, B., Mangold, N., Pinet, P., and Forget, F., 2006. Global mineralogical and aqueous Mars history derived from OMEGA/Mars Express data. Science 312, 400-404.

Blake, D. F. et al., 2013. Curiosity at Gale Crater, Mars: Characterization and Analysis of the Rocknest Sand Shadow. Science 341, 1239505. doi: 10.1126/science.1239505

Bouchette, F., Schuster, M., Ghienne, J. F., Denamiel, C., Roquin, C., Moussa, A., Marsaleix, P., and Duringer, P., 2010. Hydrodynamics in Holocene Lake Mega-Chad. Quaternary Res. 73, 226-236.

Bourke, M. C., 2010. Barchan dune asymmetry: Observations from Mars and Earth. Icarus 205, 183-197.

Bridges, N. T. et al., 2014. The rock abrasion record at Gale Crater: Mars Science Laboratory results from Bradbury Landing to Rocknest. J. Geophys. Res. Planets 119, 1374-1389.

Bridges, N. T., Spagnuolo, M. G., de Silva, S. L., Zimbelman, J. R., and Neely, E. M., 2015. Formation of gravel-mantled megaripples on Earth and Mars: Insights from the Argentinean Puna and wind tunnel experiments. Aeolian Res. 17, 49-60.

Cooke, R. U., 1970. Stone Pavements in Deserts. Annals of the Association of American Geographers 60, 560-577.

Christensen, P. R., 1986. Regional dust deposits on Mars: Physical properties, age, and history. J. Geophys. Res. 91, 3533-3545.

Davis, W. M., 1899. The geographic cycle. Geography J. 14, 481-504.

de Silva, S. L., Spagnuolo, M. G., Bridges, N. T., and Zimbelman, J. R., 2013. Gravel-mantled megaripples of the Argentinean Puna: A model for their origin and growth with implications for Mars. Geol. Soc. Am. Bull. 125, 1912-1929.

du Pont, S. C., Narteau, C., and Gao, X., 2014. Two modes for dune orientation. Geology 42, 743-746.

Eastwood, E. N., Kocurek, G., Mohrig, D., and Swanson, T., 2012. Methodology for reconstructing wind direction, wind speed and duration of wind events from aeolian cross-strata. J. Geophys. Res. 117, doi:10.1029/2012JF002368.

Edgett, K. S., and Malin, M. C., 2000. New views of Mars eolian activity, materials, and surface properties: Three vignettes from the Mars Global Surveyor Mars Orbiter Camera. J. Geophys. Res.. Planets, 105, 1623-1650.

Edgett, K. S. et al., 2012. Curiosity's Mars Hand Lens Imager (MAHLI) Investigation. Space Sci. Rev. 170, 259-317. 
Farley, K. A. et al., 2014. In situ radiometric and exposure age dating of the Martian surface. Science 343, doi: 10.1126/science.1247166.

Fenton, L. K., Michaels, T. I., and Beyer, R. A., 2014. Inverse maximum gross bedform-normal transport 1: How to determine a dune-constructing wind regime using only imagery. Icarus 230, 5-14.

Geissler, P. E., 2014. The birth and death of transverse aeolian ridges on Mars. J. Geophys. Res.. Planets 119, 2583-2599.

Gilbert, G. K., 1909. The convexity of hillsloped. J. Geology 17, 344-350.

Gillies, J. A., Nickling, W. G., and Tilson, M., 2013. Frequency, magnitude, and characteristics of aeolian sediment transport: McMurdo Dry Valleys, Antarctica. J. Geophys. Res. Earth Surface 118, 461-479.

Golombek, M., Robinson, K., McEwen, A., Bridges, N., Ivanov, B., Tornabene, L., and Sullivan, R., 2010. Constraints on ripple migration at Meridiani Planum from Opportunity and HiRISE observations of fresh craters. J. Geophys. Res. Planets 115, doi:10.1029/2010JE003628.

Grant, J. A., Wilson, S. A., Mangold, N., Calef, F., and Grotzinger, J. P., 2014. The timing of alluvial activity in Gale crater, Mars. Geophys. Res. Lett. 41, 1142-1149.

Greeley, R., Kraft, M., Sullivan, R., Wilson, G., Bridges, N., Herkenhoff, K., Kuzmin, R. O., Malin, M., and Ward, W., 1999. Aeolian features and processes at the Mars Pathfinder landing site. J. Geophys. Res. Planets 104, 8573-8584.

Greeley, R. et al., 2008. Columbia Hills, Mars: Aeolian features seen from the ground and orbit. J. Geophys. Res. Planets 113, doi:10.1029/2007JE002971.

Grotzinger, J. P. et al., 2005. Stratigraphy and sedimentology of a dry to wet eolian depositional system, Burns formation, Meridiani Planum, Mars. Earth and Planetary Sci. Lett. 240, $11-72$.

Grotzinger, J. P., and Milliken, R. E., 2012. The sedimentary rock record of Mars: Distribution, origins, and global stratigraphy. Sed. Geol. of Mars, SEPM no. 102, p. 1-48.

Grotzinger, J. P. et al., 2014. A habitable fluvio-lacustrine environment at Yellowknife Bay, Gale Crater, Mars. Science 343, doi:10.1126/science.1242777.

Grotzinger, J. P. et al., Deposition, Exhumation, and Paleoclimatology of an Ancient Lake Deposit, Gale Crater, Mars. In press: Science.

Haff, P. K., 2001. Desert Pavement: An Environmental Canary? Geology 109, 661-668.

Hartmann, W. K., and Neukum, G., 2001. Cratering chronology and the evolution of Mars. Space Sci. Rev. 96, 165-194.

Hayward, R. K., Fenton, L. K., and Titus, T. N., 2014. Mars Global Digital Dune Database $(\mathrm{MGD}(3))$ : Global dune distribution and wind pattern observations. Icarus 230, 38-46.

Hedin, S. A., 1903. Central Asia and Tibet Towards the Holy City of Lassa, Hurst and Blackett.

Hesp, P. A., 1981. The formation of shadow dunes. J. of Sed. Res. 51, 101-111.

Hobbs, S. W., Paull, D. J., and Bourke, M. C., 2010. Aeolian processes and dune morphology in Gale Crater. Icarus 210, 102-115.

Howard, A., 1977. Effect of slope on the threshols motion and its application to orientation of wind ripples. Geol. Soc. Am. Bull. 88, 853-856.

King, L. C., 1953. Canons of landscape evolution. Geol. Soc. Amer. Bull. 64, 721-752.

Kite, E. S., Lewis, K. W., Lamb, M. P., Newman, C. E., and Richardson, M. I., 2013. Growth and form of the mound in Gale Crater, Mars: Slope wind enhanced erosion and transport. Geology 41, 543-546.

Kocurek, G., and Lancaster, N., 1999. Aeolian system sediment state: theory and Mojave Desert Kelso dune field example. Sedimentology 46, 505-515. 
Kok, J. F., 2010. Analytical calculation of the minimum wind speed required to sustain windblown sand on Earth and Mars. Geophys. Res. Lett. 37, doi:10.1029/2010GL043646.

Laity, J. E., and Bridges, N. T., 2009. Ventifacts on Earth and Mars: Analytical, field, and laboratory studies supporting sand abrasion and windward feature development. Geomorphology 105, 202-217.

Lancaster, N., 1989a. The Namib sand sea : dune forms, processes and sediments, A. A. Balkema, Rotterdam. Brookfield, Vermont.

Lancaster, N., 1989b. Star dunes. Progress in Physical Geography 13, 67-91.

Le Deit, L. L., Hauber, E., Fueten, F., Pondrelli, M., Rossi, A. P., and Jaumann, R., 2013. Sequence of infilling events in Gale Crater, Mars: Results from morphology, stratigraphy, and mineralogy. J. Geophys. Res. Planets 118, 2439-2473.

Lee, P., and Thomas, P. C., 1995. Longitudinal dunes on Mars: Relation to current wind regimes. J. Geophys. Res. Planets 100, 5381-5395.

Malin, M. C., and Edgett, K. S., 2000. Sedimentary rocks of early Mars. Science 290, 19271937.

McFadden, L. D., Wells, S. G., and Jercinovich, M. J., 1987. Influences of eolian and pedogenic processes on the origin and evolution of desert pavements. Geology 15, 504-508.

Minitti, M. E. et al., 2013. MAHLI at the Rocknest sand shadow: Science and science-enabling activities. J. Geophys. Res. Planets 118, 2338-2360.

Newsom, H. E. et al., 2015. Gale crater and impact processes - Curiosity's first 364 Sols on Mars. Icarus 249, 108-128.

Nielson, J., Kocurek, K., 1986. Climbing zibars of the Algodones. Sediment. Geol. 48, 1-15.

Palucis, M. C., Sumner, D. Y., Dietrich, W. E., Hayes, A. G., Williams, R. M. E., Gupta, S., Mangold, N., Newsom, H., Hardgrove, C., and Calef, F., 2014. The origin and evolution of the Peace Vallis fan system that drains to the Curiosity landing area, Gale Crater, Mars. J. Geophys. Res. Planets 119, 705-728.

Parteli, E. J. R., Durán, O., Tsoar, H., Schwämmle, V., Herrmann, H. J., and Stanley, H. E., 2009. Dune Formation under Bimodal Winds. Proceedings of the National Academy of Sciences 106, 22085-22089.

Parteli, E. J. R., Duran, O., Bourke, M. C., Tsoar, H., Poschel, T., and Herrmann, H., 2014. Origins of barchan dune asymmetry: Insights from numerical simulations. Aeolian Res. 12, 121-133.

Rafkin, S. C. R., Haberle, R. M., and Michaels, T. I., 2001. The Mars regional atmospheric modeling system: Model description and selected simulations. Icarus 151, 228-256.

Rubin, D. M., and Hunter, R. E., 1987. Bedform Alignment in Directionally Varying Flows. Science 237, 276-278.

Sagan, C., Smith, B. A., Veverka, J., Fox, P., Dubisch, R., Lederberg, J., Levinthal, E., Quam, L., Tucker, R., and Pollack, J. B., 1972. Variable features on Mars: Preliminary Mariner 9 television results. Icarus 17, 346-372.

Sagan, C., and Bagnold, R. A., 1975. Fluid transport on Earth and aeolian transport on Mars. Icarus 26, 209-218.

Schorghofer, N., 2008. Temperature response of Mars to Milankovitch cycles. Geophys. Res. Lett. 35, doi:10.1029/2008GL034954.

Shockey, K. M., and Zimbelman, J. R., 2013. Analysis of transverse aeolian ridge profiles derived from HiRISE images of Mars. Earth Surface Processes and Landforms 38, 179182.

Silvestro, S., Vaz, D. A., Ewing, R. C., Rossi, A. P., Fenton, L. K., Michaels, T. I., Flahaut, J., and Geissler, P. E., 2013. Pervasive aeolian activity along rover Curiosity's traverse in Gale Crater, Mars. Geology 41, 483-486. 
Stack, K. M. et al., 2014. Diagenetic origin of nodules in the Sheepbed member, Yellowknife Bay formation, Gale crater, Mars. J. Geophys. Res. Planets 119, 1637-1664.

Sullivan, R. et al., 2005. Aeolian processes at the Mars Exploration Rover Meridiani Planum landing site. Nature 436, 58-61.

Sullivan, R. et al., 2008. Wind-driven particle mobility on mars: Insights from Mars Exploration Rover observations at "El Dorado" and surroundings at Gusev Crater. J. Geophys. Res. Planets 113, doi:10.1029/2008JE003101.

Sullivan, R., Bridges, N., Herkenhoff, K., Hamilton, V., and Rubin, D., 2014. Transverse aeolian ridges (TARs) as megaripples: Rover engounters at Meridiani Planum, Gusev, and Gale. Eighth International Conference on Mars, Abstract \#1424.

Thomson, B. J., Bridges, N. T., Milliken, R., Baldridge, A., Hook, S. J., Crowley, J. K., Marion, G. M., de Souza Filho, C. R., Brown, A. J., and Weitz, C. M., 2011. Constraints on the origin and evolution of the layered mound in Gale Crater, Mars using Mars Reconnaissance Orbiter data. Icarus 214, 413-432.

Tirsch, D., Jaumann, R., Pacifici, A., and Poulet, F., 2011. Dark aeolian sediments in Martian craters: Composition and sources. J. Geophys. Res. Planets 116, doi:10.1029/2009JE003562.

Tsoar, H., 1989. Linear dunes - forms and formation. Progress in Physical Geography 13, 507528.

Tsoar, H., Blumberg, D. G., and Stoler, Y., 2004. Elongation and migration of sand dunes. Geomorphology 57, 293-302.

Tyler, D., and Barnes, J. R., 2013. Mesoscale Modeling of the Circulation in the Gale Crater Region: An Investigation into the Complex Forcing of Convective Boundary Layer Depths. Mars 8, 58-77.

Veverka, J., 1975. Variable features on Mars V: Evidence for crater streaks produced by wind erosion. Icarus 25, 595-601.

Viles, H., Ehlmann, B., Wilson, C. F., Cebula, T., Page, M., and Bourke, M., 2010. Simulating weathering of basalt on Mars and Earth by thermal cycling. Geophys. Res. Lett. 37, doi:10.1029/2010GL043522.

Wang , Z. T., Wang, H. T., Niu, Q. H., Dong, Z. B., and Wang, T., 2011. Abrasion of yardangs. Physical Rev. E 84, doi: 10.1103/PhysRevE.84.031304.

Ward, A. W., 1979. Yardangs on Mars - Evidence of recent wind erosion. J. Geophys. Res. 84, 8147-8166.

Warner, N., Gupta, S., Lin, S. Y., Kim, J. R., Muller, J. P., and Morley, J., 2010. Late Noachian to Hesperian climate change on Mars: Evidence of episodic warming from transient crater lakes near Ares Vallis. J. Geophys. Res. Planets 115, doi:10.1029/2009JE003522.

Williams, R. M. E. et al., 2013. Martian Fluvial Conglomerates at Gale Crater. Science 340, 1068-1072.

Wilson, S. A., Zimbelman, J. R., 2004. Latitude-dependent nature and physical characteristics of transverse aeolian ridges on Mars. J. Geophys. Res. 109, doi:10.1029/2004JE002247.

Wray, J. J., 2013. Gale crater: the Mars Science Laboratory/Curiosity Rover Landing Site. Int. J. of Astrobiology 12, 25-38.

Zhang, D. G., Narteau, C., Rozier, O., and du Pont, S. C., 2012. Morphology and dynamics of star dunes from numerical modelling. Nature Geoscience 5, 463-467.

Zimbelman, J. R., 2010. Transverse Aeolian Ridges on Mars: First results from HiRISE images. Geomorphology 121, 22-29.

Zimbelman, J. R., and Scheidt, S. P., 2014. Precision topography of a reversing sand dune at Bruneau Dunes, Idaho, as an analog for Transverse Aeolian Ridges on Mars. Icarus 230, 29-37. 